Aus der Abteilung Kardiologie und Pneumologie

(Prof. Dr. med. G. Hasenfuß)

im Zentrum Innere Medizin

der Medizinischen Fakultät der Universität Göttingen

\title{
Die $\mathrm{Na}^{+} / \mathrm{H}^{+}$-Austauscher-abhängige $\mathrm{pH}$ - \\ Regulation in Vorhof- und Ventrikelmyozyten
}

\author{
INAUGURAL-DISSERTATION \\ zur Erlangung des Doktorgrades \\ der Medizinischen Fakultät \\ der Georg-August-Universität zu Göttingen
}

Vorgelegt von

Hui Yan

Aus Yunnan/China

Göttingen 2011 
Dekan: Prof. Dr. med. C. Frömmel

I. Berichterstatter: Prof. Dr. rer. nat. J. Kockskämper

II. Berichterstatter/in: Prof. Dr. phil. nat. Burckhardt

III. Berichterstatter/in: Prof. Dr. med. Dr. rer. nat. Crozier

Tag der mündlichen Prüfung: 26. Oktober 2011 
1. EINLEITUNG

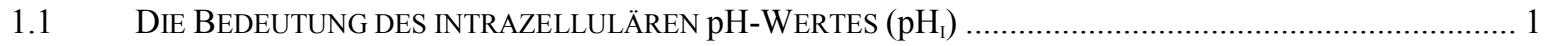

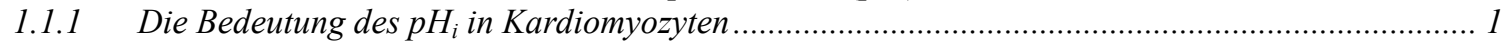

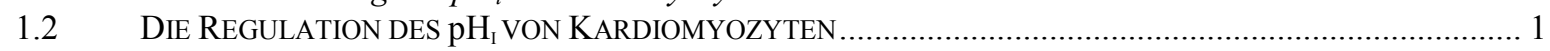

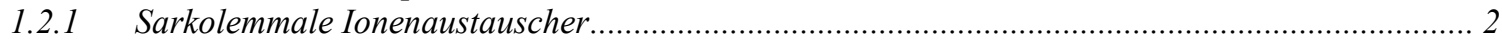

1.2.2 Räumliche Regulation des $\mathrm{pH}_{i}$ im Myokard und in Kardiomyozyten ....................................... 4

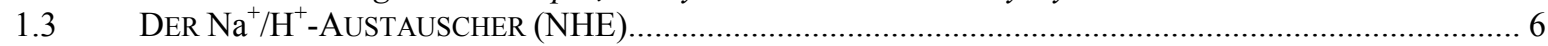

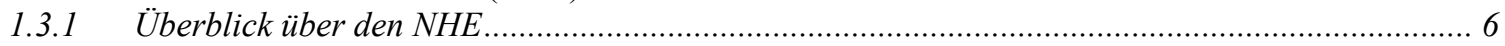

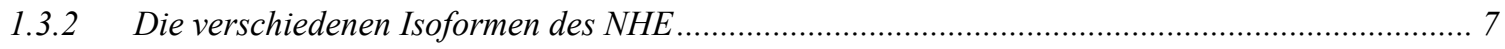

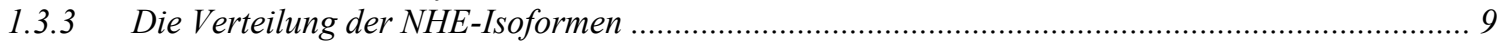

1.3.4 Struktur, Funktion und Lokalisation des NHE-1 ........................................................... 11

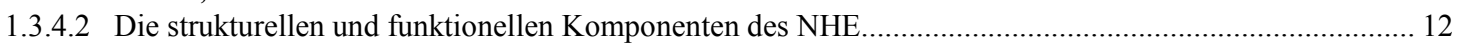

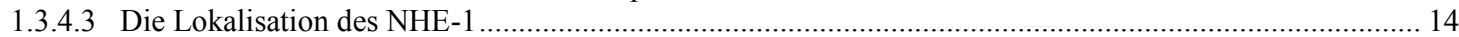

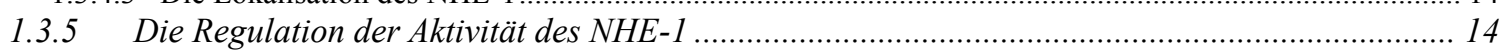

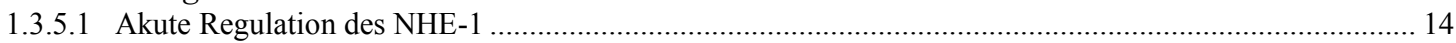

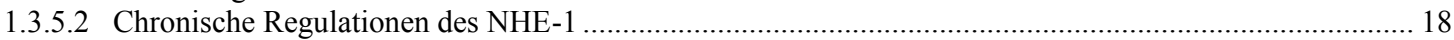

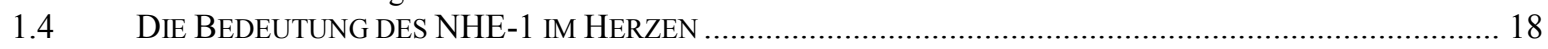

1.4.1 Die physiologische Bedeutung des NHE-1 im Herzen ........................................................ 18

1.4.2 Die pathophysiologische Bedeutung des NHE-1 im Herzen ................................................ 19

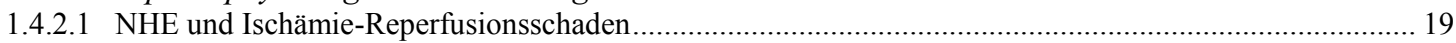

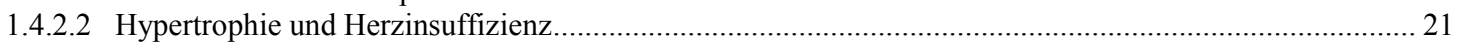

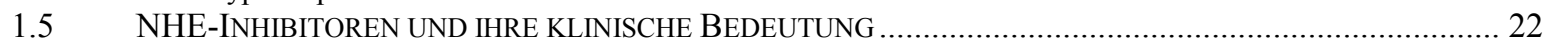

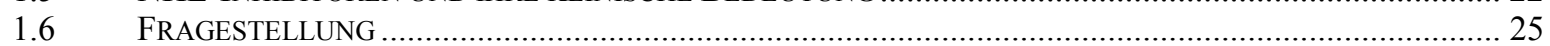

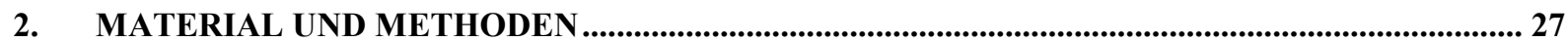

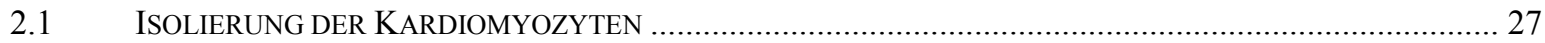

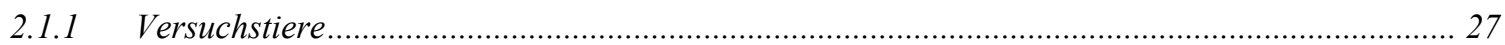

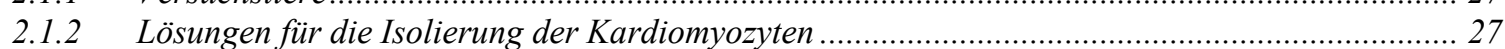

2.1.3 Präparation des Kaninchenherzens und Isolierung der Kardiomyozyten .................................. 28

2.1.3.1 Betäubung der Kaninchen und Entnahme des Herzens................................................................ 28

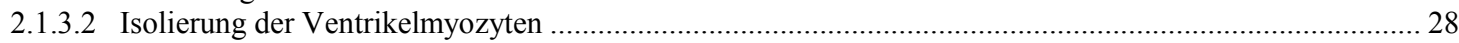

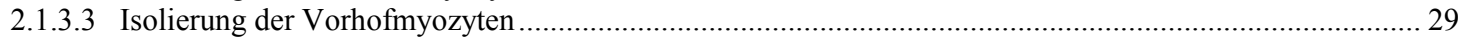

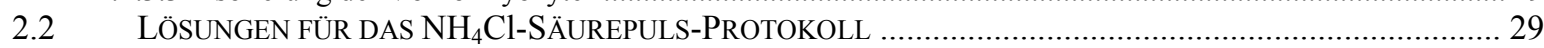

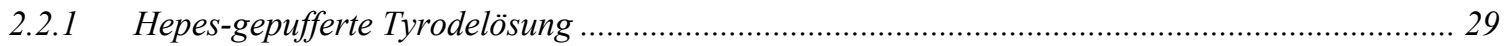

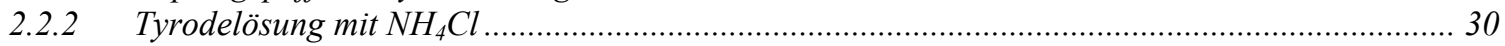

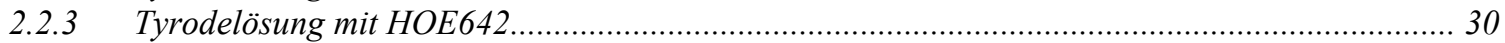

2.3 GERÄTE

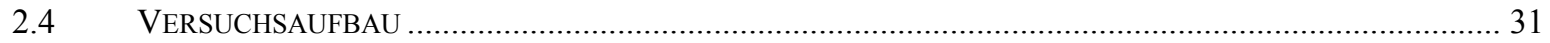

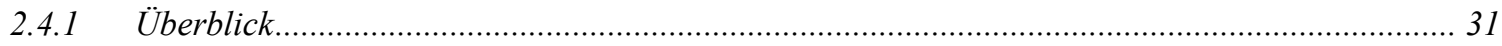

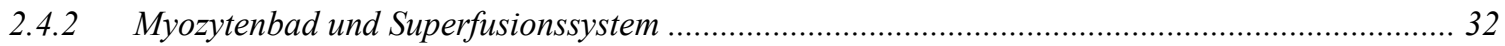

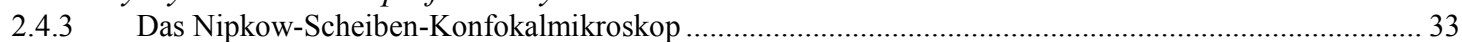

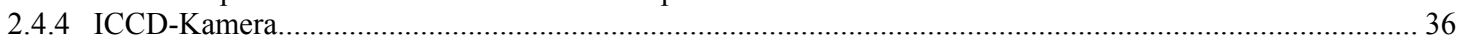

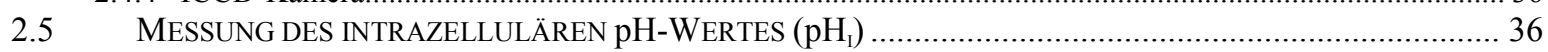

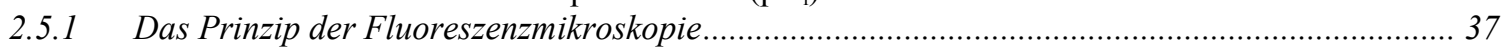

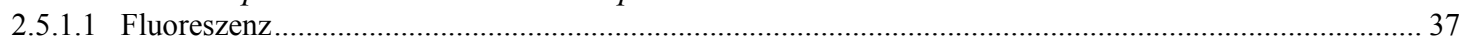

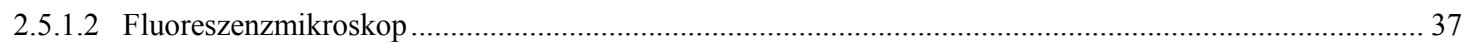

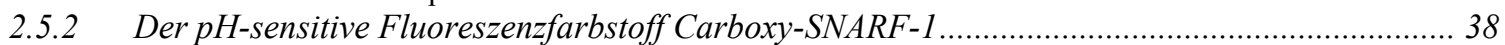

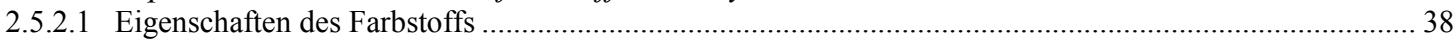

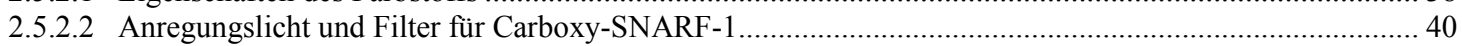

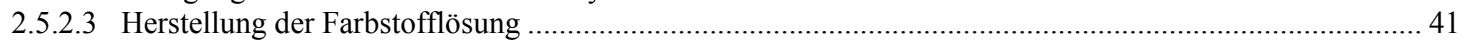

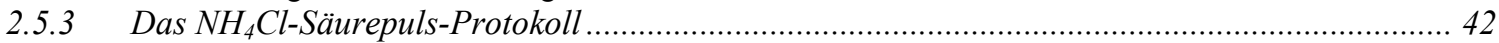

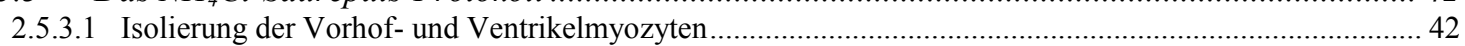

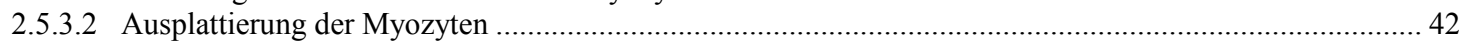

2.5.3.3 Beladung der Zellen mit dem Farbstoff ................................................................................................ 42

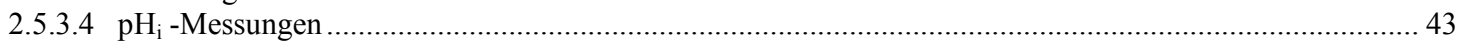

2.5.4 Kalibrierung des Carboxy-SNARF-1-Fluoreszenzsignals ............................................ 45

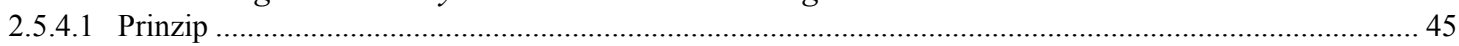

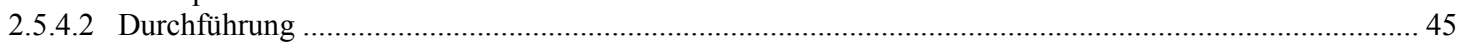




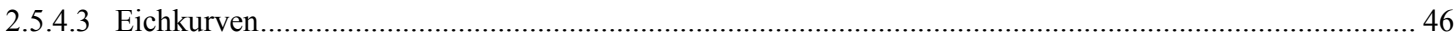

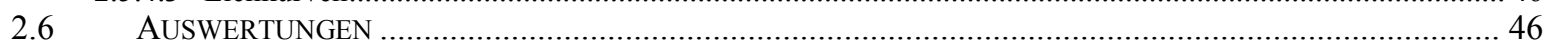

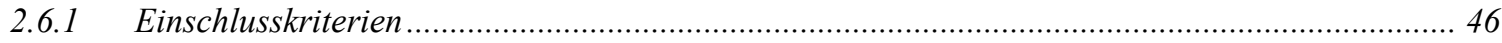

2.6.2 Analyse der pH-Änderungen in verschiedenen subzellulären Regionen der Kardiomyozyten...... 46

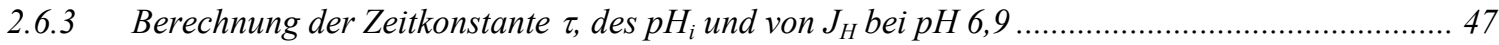

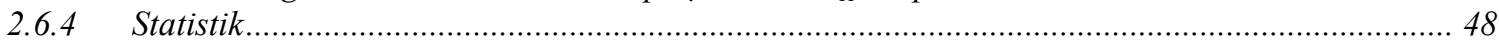

2.7 WESTERN-IMMUNOBLOT-ANALYSE DER NHE1-EXPRESSION .................................................. 49

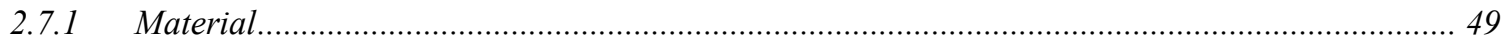

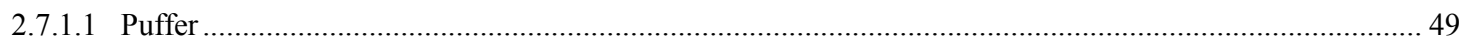

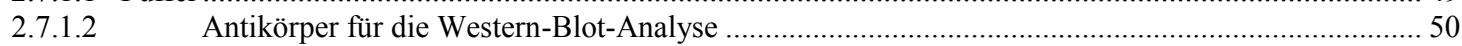

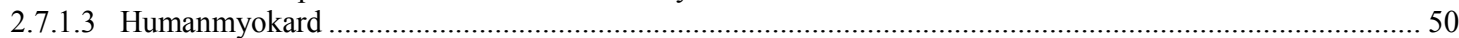

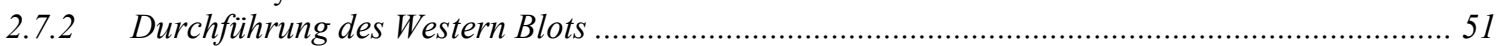

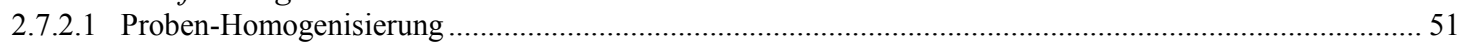

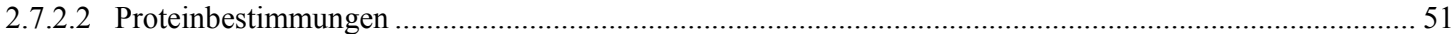

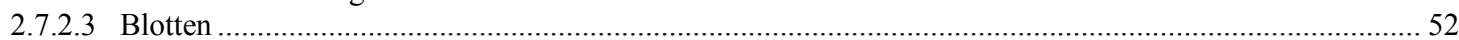

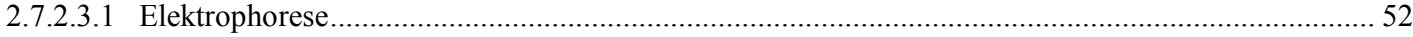

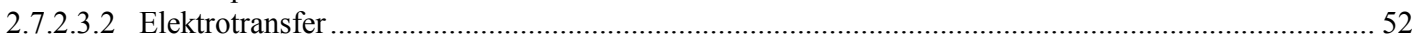

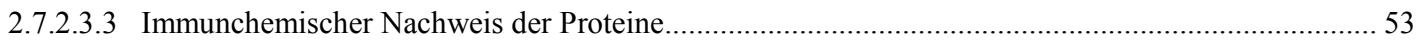

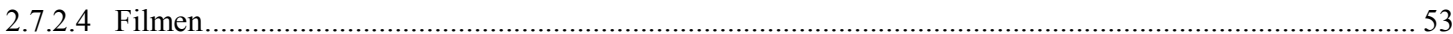

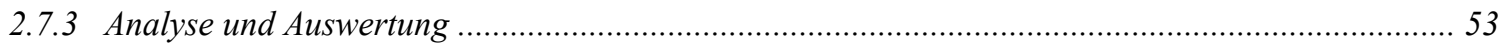

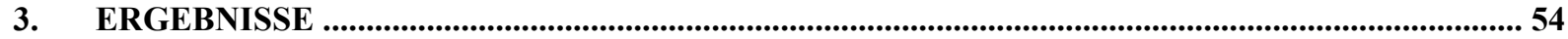

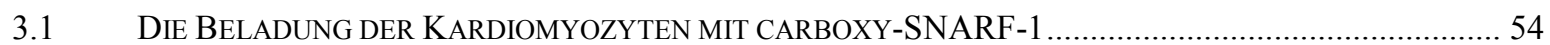

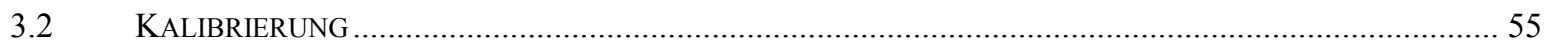

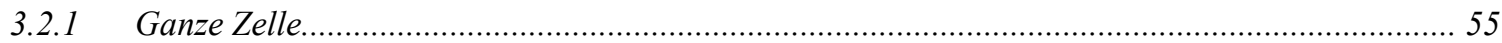

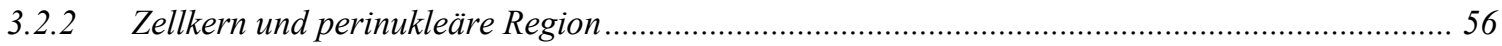

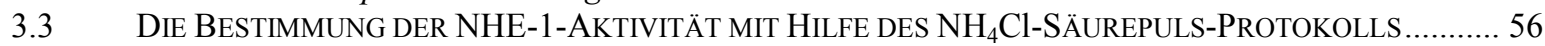

3.3.1 Globale pH-Änderungen eines Kaninchen-Ventrikelmyozyten während eines $\mathrm{NH}_{4} \mathrm{Cl}$-Säurepuls-

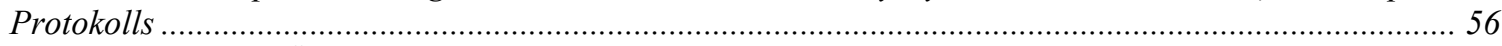

3.3.2 Globale pH-Änderungen eines Kaninchen-Ventrikelmyozyten während eines $\mathrm{NH}_{4} \mathrm{Cl}$-Säurepuls-

Protokolls mit HOE642 ............................................................................................................. 59

3.3.3 Globale pH-Änderungen von Kaninchen-Vorhofmyozyten während eines $\mathrm{NH}_{4} \mathrm{Cl}$-Säurepuls-

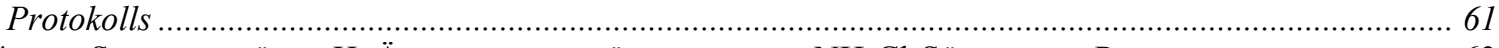

3.4 SUBZELLULÄRE $\mathrm{pH}_{\mathrm{r}}$ - ÄNDERUNGEN WÄHREND EINES $\mathrm{NH}_{4}$ Cl-SÄUREPULS-PROTOKOLLS ..................6.63

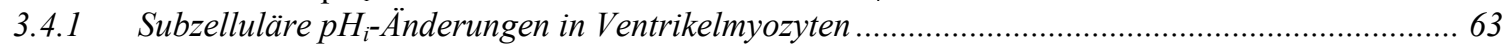

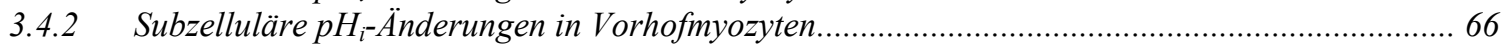

3.4.3 Vergleich der subzellulären $\mathrm{pH}_{i}$ - Änderungen zwischen Vorhof- und Ventrikelmyozyten .............69 69

3.5 DIE EXPRESSION DES NHE-1 IM HUMANEN VORHOF- UND VENTRIKELMYOKARD ............................70

3.5.1. Vergleich der NHE-1-Expression zwischen nicht-insuffizientem menschlichen Vorhof- und

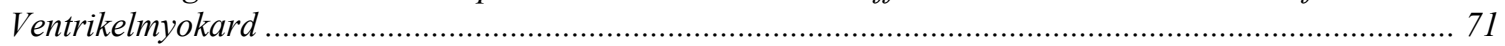

3.5.2 Vergleich der NHE-1-Expression zwischen nicht-insuffizientem und insuffizientem, humanen

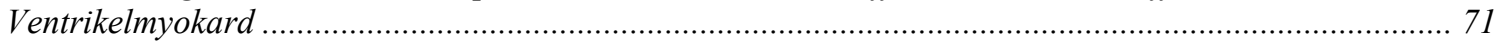

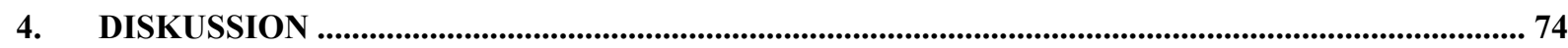

4.1 IDENTIFIZIERUNG UND QUANTIFIZIERUNG DER NHE-1-AKTIVITÄT IN DEN KANINCHEN-

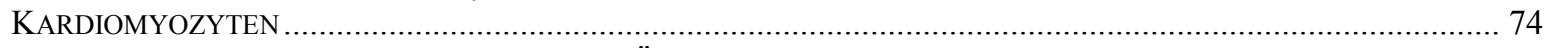

4.2 UNTERSCHIEDE DER GLOBALEN pH-ÄNDERUNGEN UND VON J J ${ }_{\text {PH,9 }}$ ZWISCHEN VORHOF- UND

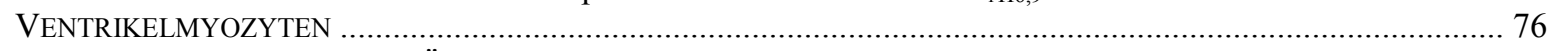

4.3 SUBZELLULÄRE pH-ÄNDERUNGEN IN VORHOF- UND VENTRIKELMYOZYTEN ....................................79

4.3.1 Subzelluläre pH-Änderungen in den Ventrikelmyozyten ........................................................ 79

4.3.2 Subzelluläre pH-Änderungen in den Vorhofmyozyten ............................................................ 79

4.3.3 Unterschiede der subzellulären Regionen zwischen Vorhof und Ventrikel ....................................8 80

$4.4 \quad$ NHE-1-EXPRESSION IN HUMANEM VORHOF- UND VENTRIKELMYOKARD ........................................8 81

4.4.1 NHE-1-Expression in nicht-insuffizientem Vorhof- und Ventrikelmyokard............................... 82

4.4.2 Unterschiede der NHE-1-Expression zwischen insuffizientem und nicht-insuffizientem

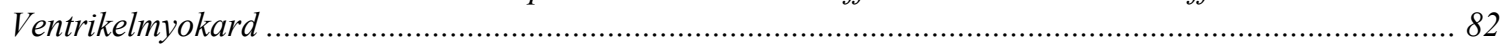

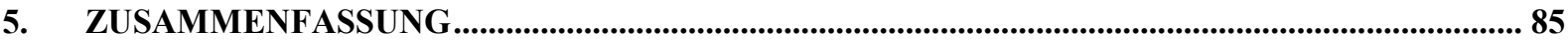

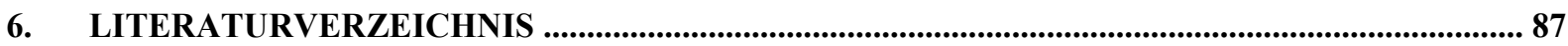




\section{Abkürzungsverzeichnis}

AC Adenylatzyklase

$\mathrm{AE} \quad \mathrm{Cl}^{-}-\mathrm{HCO}_{3}^{-}$-Austauscher (anion exchanger)

BDM 2,3-Butandion-Monoxim

$\beta_{\mathrm{i}} \quad$ die intrazelluläre Puffer-Kapazität

CaM Calmodulin

CaMKII Calmodulin-abhängige Proteinkinase II

$\left[\mathrm{Ca}^{2+}\right]_{\mathrm{i}}$ die intrazelluläre $\mathrm{Ca}^{2+}$-Konzentration

$\mathrm{CBE} \quad \mathrm{Cl}^{-} / \mathrm{HCO}_{3}{ }^{-}$-Austauscher

CHE $\quad \mathrm{Cl}^{-}-\mathrm{OH}^{-}$-Austauscher

CI Cardiac index

$\Delta \mathrm{pH} \quad$ die Differenz zwischen dem maximalen $\mathrm{pH}_{\mathrm{i}}$ und dem minimalen $\mathrm{pH}_{\mathrm{i}}$

DCM dilative Kardiomyopathie

DMA Dimethylamilorid

ECL verstärkte Chemoluminiszenz (enhanced chemoluminescence)

EF Ejektionsfraktion

EIPA Ethylisopropylamilorid

ERK Extracellular signal-regulated kinase

$\mathrm{F}_{0} \quad$ die Fluoreszenz zu Versuchsbeginn

GAPDH Glycerinaldehyd-3-Phosphat-Dehydrogenase

GF Growth factor

$\mathrm{G}_{\mathrm{i}} \quad$ inhibitorisches G-Protein

GPCR G-Protein-gekoppelte(r) Rezeptor(en)

$\mathrm{G}_{\mathrm{q}} \quad$ G-Protein vom $\mathrm{G}_{\mathrm{q}}$-Typ

$\mathrm{G}_{\mathrm{s}} \quad$ stimulatorisches G-Protein 
HEPES 2-(4-(2-Hydroxyethyl)-1-piperazinyl)-ethansulfonsäure

HOE642 4-Isopropyl-3-methylsulphonylbenzoyl-guanidin methanesulphonat

HOE694 3-Methylsulfony-4-piperidinobenzoyl-guanidin

HP Homogenisierungspuffer

HZV Herz-Zeit-Volumen

ICM ischämische Kardiomyopathie

$\mathrm{IP}_{3} \quad$ Inositol-1,4,5-trisphosphat

$\mathrm{J}_{\mathrm{pH} 6.9} \quad$ die Rate des Protonen-Efflux bei $\mathrm{pH}_{\mathrm{i}} 6,9$

MAPK Mitogen-aktivierte Proteinkinase

MCT Monokarboxylat- $\mathrm{H}^{+}$-Kotransporter

MIA(MIBA) Methylisobutyl-Amilorid

MPA 5-N-(methylpropyl)amilorid

$\left[\mathrm{Na}^{+}\right]_{\mathrm{i}} \quad$ die intrazelluläre $\mathrm{Na}^{+}-$Konzentration

$\mathrm{NBC} \quad \mathrm{Na}^{+}-\mathrm{HCO}_{3}{ }^{-}-$Kotransporter

$\mathrm{NCX} \quad \mathrm{Na}^{+} / \mathrm{Ca}^{+}$-Austauscher

NF nicht-insuffizient (non-failing)

NHE $\quad \mathrm{Na}^{+}-\mathrm{H}^{+}$-Austauscher

p90 $0^{\mathrm{RSK}} \quad \mathrm{p} 90$ ribosomale S6-Kinase

PCWP pulmonary capillary wedge pressure

$\mathrm{pH}_{\mathrm{i}} \quad$ der intrazelluläre $\mathrm{pH}-$ Wert

PI Phosphoinositid

$\mathrm{PIP}_{2} \quad$ Phosphatidylinositol-4,5-bisphosphate

PKC Proteinkinase C

$\mathrm{pK}_{\mathrm{s}} \quad$ Säurekonstante

PLC Phospholipase C

PP2Ac katalytische Untereinheit der Proteinphosphatase 2A 
Rezeptor(en)

S.E.M standard error of mean

SS subsarkolemmal

$\tau(\operatorname{tau}) \quad$ die Zeitkonstante für die Erholung des $\mathrm{pH}_{\mathrm{i}}$-Wertes nach dem Säurepuls

TBST Tris-gepufferte Salzlösung

Tris Tris(hydroxymethyl)-Aminomethan

ZVD Zentralvenöser Druck 


\section{Einleitung}

\subsection{Die Bedeutung des intrazellulären $\mathrm{pH}-$ Wertes $\left(\mathrm{pH}_{\mathrm{i}}\right)$}

Für die Lebensfähigkeit einer Zelle ist die Aufrechterhaltung des intrazellulären Milieus von herausragender Bedeutung. Dazu gehört auch die Einhaltung einer konstanten intrazellulären $\mathrm{H}^{+}$-Konzentration $\left(\left[\mathrm{H}^{+}\right]\right)$. Der physiologische intrazelluläre $\mathrm{pH}-\mathrm{Wert}\left(\mathrm{pH}_{\mathrm{i}}\right)(\mathrm{d}$.i der negative dekadische Logarithmus der $\left[\mathrm{H}^{+}\right]$) liegt im Bereich 7,1-7,3 (pH 7,2 entspricht einer $\left[\mathrm{H}^{+}\right]=63$ nM) (Leem et al. 1999; Yamamoto et al. 2005).

Der $\mathrm{pH}_{\mathrm{i}}$ spielt eine kritische Rolle bei der Aufrechterhaltung der physiologischen Funktionen. Nahezu alle Funktionen der Zelle werden durch den $\mathrm{pH}_{\mathrm{i}}$ beeinflusst. Zahlreiche biologische Vorgänge wie Zellwachstum und -differenzierung, biochemische Prozesse und transepithelialer Transport sind nur in einem eng begrenzten pH-Optimum möglich. Ein starker Abfall des $\mathrm{pH}_{\mathrm{i}}$ kann schließlich den Zelltod zur Folge haben (Lidofsky et al. 1993). Kurzum, die Regulationsmechanismen zur Einhaltung eines konstanten intrazellulären pHWertes sind für die Zelle und deren Funktionserhaltung lebensnotwendig. Die Bedeutung des pH-Wertes für die physiologische bzw. pathologische Funktion des Herzens ist der Fokus der vorliegenden Arbeit.

\subsubsection{Die Bedeutung des $\mathrm{pH}_{\mathrm{i}}$ in Kardiomyozyten}

Ein Absinken des $\mathrm{pH}_{\mathrm{i}}$ (z.B. während einer Ischämie) hat eine verminderte Kontraktilität der Herzmuskelfasern zur Folge (Roos und Boron 1981; Orchard und Kentish 1990; Bountra und Vaughan-Jones 1989). Dies beruht auf einer verminderter $\mathrm{Ca}^{2+}$-Sensitivität der Myofilamente (aufgrund der erhöhten $\left[\mathrm{H}^{+}\right]$). Daneben werden Ionenkanäle und -transporter - insbesondere auch $\mathrm{Ca}^{2+}$-Kanäle (L-Typ-Ca ${ }^{2+}$-Kanäle, $\mathrm{Ca}^{2+}$-Freisetzungskanäle) und die SR $\mathrm{Ca}^{2+}$-ATPase -, die Zell-Zell-Kopplung, die $\mathrm{Na}^{+}$-Homöostase und der Metabolismus der Zelle in hohem Maße beeinflusst (Bers 2001).

\subsection{Die Regulation des $\mathrm{pH}_{\mathrm{i}}$ von Kardiomyozyten}

1) der intrazellulären Produktion von Säuren und Basen

2) der intrazellulären intrinsischen Pufferkapazität (intrinsic buffering power) 
3) sowie pH-regulierenden Membrantransportern (Roos und Boron 1981)

Saure und basische Zellprodukte (z.B. Laktat) beeinflussen den pH-Wert. Das intrinsische Puffersystem und die pH-regulierenden Membrantransporter minimieren eine Veränderung des $\mathrm{pH}$-Wertes. Um den physiologischen $\mathrm{pH}_{\mathrm{i}}$ aufrechtzuerhalten, sind diese Mechanismen unerlässlich. Zum intrazellulären Puffersystem gehören der Bikarbonat-Puffer, der Phosphatpuffer, der Ammoniakpuffer, sowie verschiedene Aminosäuren.

\subsubsection{Sarkolemmale Ionenaustauscher}

Bis heute kennt man mindestens 5 sarkolemmale Ionenaustauscher, die an der Regulation des intrazellulären $\mathrm{pH}-$ Wertes beteiligt sind: 1. den $\mathrm{Na}^{+} / \mathrm{H}^{+}$-Austauscher (NHE: $\mathrm{Na}^{+} / \mathrm{H}^{+}$ exchanger), 2. den $\mathrm{Na}^{+}-\mathrm{HCO}_{3}{ }^{-}$-Cotransporter (NBC, $\mathrm{Na}^{+}$-bicarbonate cotransporter), 3. den $\mathrm{Cl}^{-} / \mathrm{HCO}_{3}{ }^{-}$-Austauscher (CBE, chloride-bicarbonate exchanger), 4. den $\mathrm{Cl}^{-} / \mathrm{OH}^{-}$-Austauscher (CHE, chloride-hydroxide exchanger) und 5. den Monocarboxylat- $\mathrm{H}^{+}$-Cotransporter (MCT), der Monocarboxylate wie Laktat oder Pyruvat zusammen mit Protonen transportiert (Vaughan-Jones et al. 2009) (siehe Abbildung 1.1).
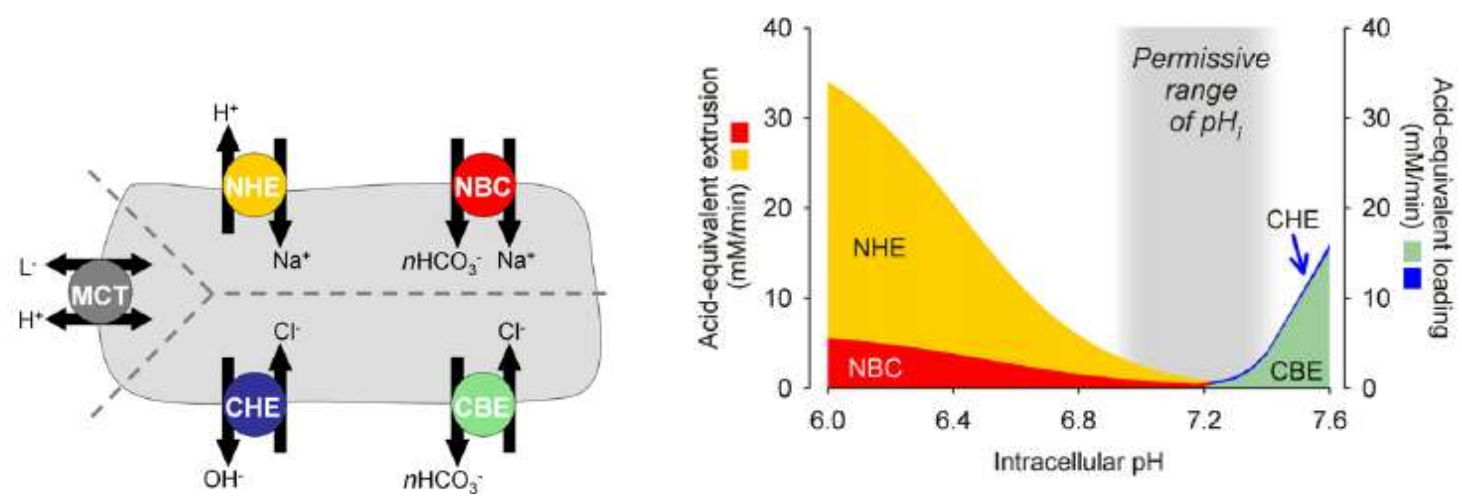

\section{Abbildung 1.1: Sarkolemmale $\mathrm{pH}_{\mathrm{i}}$-Regulationsmechanismen} (Vaughan-Jones et al. 2009, Seite 319) (Erklärung im Text)

Sie regulieren den $\mathrm{pH}_{\mathrm{i}}$ durch die transportierten Ionen $\mathrm{H}^{+}, \mathrm{OH}^{-}$, oder $\mathrm{HCO}_{3}{ }^{-}$. Es wurde gezeigt, dass ein in den intrazellulären Raum transportiertes $\mathrm{HCO}_{3}{ }^{-}$-Anion durch ein intrazelluläres $\mathrm{H}^{+}$-Ion neutralisiert wird (mit der Bildung von $\mathrm{H}_{2} \mathrm{O}$ und $\mathrm{CO}_{2}$ ). Dadurch wird der $\mathrm{pH}_{\mathrm{i}}$, ebenso wie durch den Efflux eines $\mathrm{H}^{+}$-Ions oder wie durch den Influx eines $\mathrm{OH}^{-}$- 
Ions, erhöht. Das heißt, dass die Transporter-Proteine $\mathrm{H}^{+}$-Äquivalente transportieren können. Der NHE und der NBC sind sog. "Säure-Ausschleuser" (acid extruders) (siehe Abbildung 1.1 links). Dabei schleust der NHE die Protonen 1:1 im Austausch gegen $\mathrm{Na}^{+}$in den extrazellulären Raum aus. Der NBC transportiert $\mathrm{HCO}_{3}^{-}-$zusammen mit $\mathrm{Na}^{+}-$in den intrazellulären Raum. Der CHE und der CBE wirken dagegen durch den Efflux von $\mathrm{OH}^{-}$oder $\mathrm{HCO}_{3}{ }^{-}$als "Säure-Belader" (acid loaders).

Bis jetzt wurde nur eine NHE-Isoform (NHE-1) in Kardiomyozyten identifiziert (Sardet et al. 1989; Orlowski und Grinstein 2004). Obwohl es noch eine andere Isoform NHE-6 im Herzen geben könnte, ist die NHE-1 die prädominante Isoform im Herzen (Orlowski et al. 1992; Linz und Busch 2003).

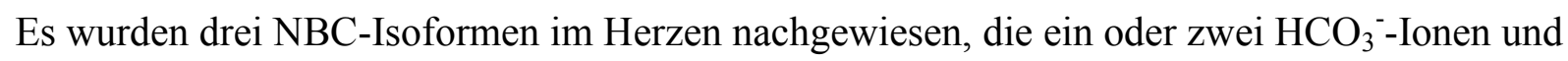
ein $\mathrm{Na}^{+}$-Ion in den intrazellulären Raum kotransportieren (Choi et al. 1999; Virkki et al. 2002; Romero et al. 2004; Yamamoto et al. 2007). Es gibt vier CBE-Isoformen bei den Kardiomyozyten, die den Ausstrom von einem oder zwei $\mathrm{HCO}_{3}{ }^{-}$-Ionen und im Gegenzug den Einstrom eines $\mathrm{Cl}^{-}$-Ions bewerkstelligen (Alper 2006; Richards et al. 1999; Alvarez et al. 2004; Shcheynikov et al. 2006), und eine CHE-Isoform, die beim Einstrom eines $\mathrm{Cl}^{-}$-Ions entweder ein $\mathrm{OH}^{-}$-Ion aus der Zelle oder ein $\mathrm{H}^{+}$-Ion in die Zelle transportiert (Niederer et al. 2008; Alvarez et al. 2004). Ferner gibt es zwei MCT-Isoformen, die für den 1:1 Kotransport von $\mathrm{H}^{-}$und Laktat verantwortlich sind (Halestrap und Meredith 2004).

Sowohl der NHE als auch der NBC werden bei einem niedrigen intrazellulären $\mathrm{pH}-\mathrm{Wert}\left(\mathrm{pH}_{\mathrm{i}}\right.$ < 7.0) aktiviert (Lagadic-Gossmann et al.1992); je geringer der pH-Wert, desto aktiver die Transporter. Sie tragen damit dazu bei, die Zellen vor einer Azidifizierung zu schützen. Dabei ist der NHE hauptsächlich (Vaughan-Jones et al. 2006, 2009) bzw. zu etwa 60\% für den $\mathrm{H}^{+}-$ Ausstrom bei einer intrazellulären Azidose zuständig (Lagadic-Gossmann et al. 1992) (siehe Abbildung 1 rechts). Der NHE-1 erreicht bei einem $\mathrm{pH}_{\mathrm{i}} \leq 6,5$ seine maximale Aktivität, während sie bei $\mathrm{pH}_{\mathrm{i}}>7,2 \mathrm{sehr}$ gering ist (Kaila und Vaughan-Jones 1987).

Der CBE dagegen wird durch einen basischen intrazellulären $\mathrm{pH}-\mathrm{Wert}\left(\mathrm{pH}_{\mathrm{i}}>7,2\right)$ (VaughanJones et al. 2006, 2009) aktiviert und trägt dazu bei, die intrazelluläre $\left[\mathrm{H}^{+}\right]$zu erhöhen (Pucéat und Vassort 1995; Leem et al. 1999). Der CHE bleibt bei pH 7,0-7,5 inaktiv, und auch die anderen drei Transport-Proteine sind bei $\mathrm{pH}_{\mathrm{i}}$ 7,1-7,3 nur wenig aktiv (Vaughan-Jones et al. 2006) (siehe Abbildung 1.1 rechts). Nach Kahn et al. und Fliegel et al. wird dagegen der $\mathrm{pH}_{\mathrm{i}}$ 
unter physiologischen Bedingungen durch den CBE reguliert (Kahn et al. 1991; Fliegel und Fröhlich 1993).

Ein weiterer Mechanismus zur sarkolemmalen $\mathrm{pH}_{\mathrm{i}}$-Regulierung ist der Monocarboxylat- $\mathrm{H}^{+}$Cotransporter (MCT). Dieser Mechanismus fungiert unter physiologischen Bedingungen jedoch im Wesentlichen als Laktat-Transporter. Er ist in der Lage, je nach transmembranärem Gradienten des Laktats, ein Laktat-Molekül zusammen mit einem Proton durch die Membran $\mathrm{zu}$ transportieren. Bei einer Myokardischämie wird das durch die anaerobe Glykolyse produzierte Laktat zusammen mit den dabei entstandenen Protonen über den MCT aus der Zelle transportiert.

\subsubsection{Räumliche Regulation des $\mathrm{pH}_{\mathrm{i}}$ im Myokard und in Kardiomyozyten}

Die Regulation des $\mathrm{pH}_{\mathrm{i}}$ durch die Membrantransporter reguliert den $\mathrm{pH}_{\mathrm{i}}$ im gesamten intrazellulären Raum. Ihre wichtigsten Funktionen zeigen sich hauptsächlich bei deutlichen pH-Abfällen bzw. bei Azidose. Die ersten Mechanismen zur Aufrechthaltung des $\mathrm{pH}_{\mathrm{i}}$ sind jedoch die intrinsischen Puffersysteme wie die intrazellulären $\mathrm{H}^{+}$-Puffer, vor allem HistidinGruppen in Proteinen, und das $\mathrm{CO}_{2} / \mathrm{HCO}_{3}{ }^{-}$-Puffersystem. Sie sind für leichte und lokale $\mathrm{pH}_{\mathrm{i}}{ }^{-}$ Abfälle wichtig. Die beiden Systeme haben eine sehr hohe Pufferkapazität von 1:400.000, d.h. von $400.000 \mathrm{H}^{+}$-Ionen im Zytoplasma würde nur ein $\mathrm{H}^{+}$-Ion nicht abgepuffert werden (Leem et al. 1999). Da die Puffer-Proteine wegen ihres großen Molekulargewichtes nur eingeschränkt mobil sind, werden bei deutlichen $\mathrm{pH}_{\mathrm{i}}$-Abfällen die übrigen nicht gepufferten $\mathrm{H}^{+}$-Ionen durch die Membrantransporter wie z.B. den NHE ausgeschleust. Um die verbleibenden $\mathrm{H}^{+}$-Ionen aus der Tiefe des Zytoplasmas zur Membran zu transportieren, werden sog. intrinsische mobile Puffer verwendet, zu denen Histidyldipeptide wie Acetylcarnosin und Homocarnosin gehören. Diese können als $\mathrm{H}^{+}$-Carrier $\mathrm{H}^{+}$-Ionen zu den Membrantransportern transportieren und damit die $\mathrm{pH}_{\mathrm{i}}$-Differenz in verschiedenen Regionen der Kardiomyozyten ausgleichen (Vaughan-Jones et al. 2002; Zaniboni et al. 2003b; Swietach et al. 2007b). Im Vergleich zu den immobilen Puffern und den Membrantransportern scheint der $\mathrm{H}^{+}$-Transport durch die mobilen Puffer langsam zu sein (Vaughan-Jones et al. 2009). Auf Grund der niedrigen Mobilität des $\mathrm{H}^{+}$und des relativ langsamen $\mathrm{H}^{+}$-Transports durch die mobilen Puffer kann sich unter bestimmten Bedingungen eine $\mathrm{pH}_{\mathrm{i}}$-Differenz in einzelnen Myozyten entwickeln, insbesondere bei intrazellulärer Azidose. Dabei zeigt sich ein $\mathrm{pH}_{\mathrm{i}^{-}}$ Gradient zwischen dem Zentrum der Zelle und der subsarkolemmalen Region, d.h. im 
Zentrum ist der $\mathrm{pH}_{\mathrm{i}}$ kleiner als in der subsarkolemmalen Region, da der NHE-1 schneller Protonen eliminieren kann als die mobilen Puffer Protonen aus dem Zentrum der Zelle zur Membran transportieren können (Swietach und Vanghan-Jones 2005). Zur Minimierung der $\mathrm{pH}_{\mathrm{i}}$-Differenz tragen auch die Connexin-Kanäle in den gap junctions und die Carboanhydrase bei (Zaniboni et al. 2003a; Swietach et al. 2007a).

Die intrazellulären $\mathrm{H}^{+}$-Ionen können durch eine reversible Carboanhydrase-katalysierte Reaktion mit $\mathrm{HCO}_{3}{ }^{-}$-Anionen $\mathrm{zu} \mathrm{H}_{2} \mathrm{O}$ und $\mathrm{CO}_{2}$ umgewandelt werden. Da $\mathrm{CO}_{2}$ sehr schnell diffundiert und membrandurchgängig ist, können die intrazellulären $\mathrm{pH}$-Änderungen dadurch minimiert werden. Das durch die Membran in den extrazellulären Raum gelangte $\mathrm{CO}_{2}$ kann entweder weiter direkt in Blutkapillaren diffundieren oder durch extrazelluläre Carboanhydrase wieder $\mathrm{zu} \mathrm{H}^{+}$und $\mathrm{HCO}_{3}{ }^{-}$umgewandelt werden. Die hier hergestellten $\mathrm{H}^{+}$Ionen können mit dem verbliebenen $\mathrm{CO}_{2}$ zusammen in die Blutkapillaren diffundieren. Dadurch wird die intrazelluläre Azidose minimiert. Die $\mathrm{HCO}_{3}{ }^{-}$-Ionen werden dann wieder durch den Membrantransporter NBC in den intrazellulären Raum transportiert und durchlaufen denselben Kreislauf erneut (Vaughan-Jones et al. 2009).

Die Connexin-Kanäle befinden sich zwischen benachbarten Myozyten (Saffitz et al. 1994). In Ventrikelmyozyten von Säugetieren ist Cx43 das häufigste Connexin (Yeager 1998). Wenn es einen $\mathrm{H}^{+}$-Gradienten zwischen benachbarten Zellen gibt, werden die $\mathrm{H}^{+}$-Ionen entsprechend ihrem Gradienten durch die Connexin-Kanäle der gap junctions passiv transportiert (Zaniboni et al. 2003a; Swietach et al. 2007a). Der Transport der $\mathrm{H}^{+}$-Ionen durch die Kanäle zwischen den Myozyten wirkt hauptsächlich bei einem physiologischen $\mathrm{pH}_{\mathrm{i}}$ von 7,2 bis 6,9. Solch eine $\mathrm{H}^{+}$-Kommunikation bietet die Möglichkeit, die lokalen Unterschiede des $\mathrm{pH}_{\mathrm{i}}$ zwischen Myozyten auszugleichen und dadurch einen einheitlichen $\mathrm{pH}_{\mathrm{i}}$ innerhalb des Myokards aufrechtzuerhalten (Vaughan-Jones et al. 2009). Während einer schweren Azidose ist die $\mathrm{H}^{+}$Permeabilität der Connexin-Kanäle jedoch stark reduziert. Dies scheint ein Schutzmechanismus zu sein, um die lokale Störung der Myozyte zu isolieren und so eine Schädigung der benachbarten Myozyten zu vermeiden. Im Vergleich dazu sind die Membrantransporter NHE und NBC hauptsächlich bei Azidose wirksam (siehe Abbildung 2). 


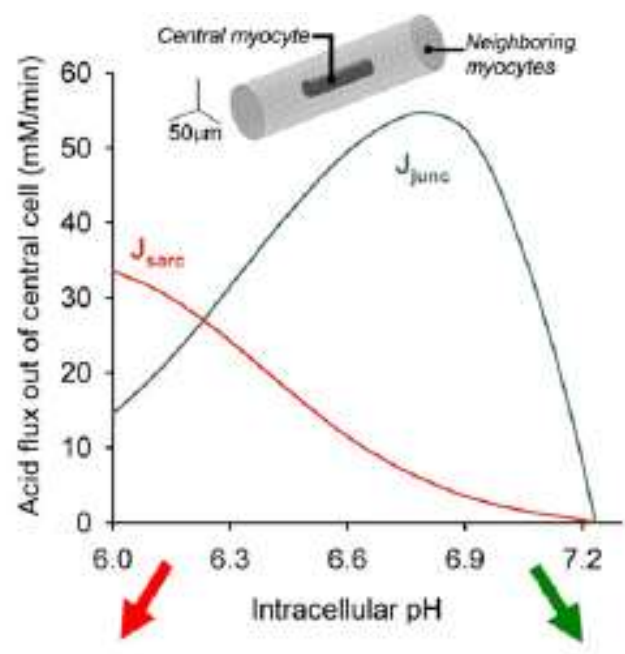

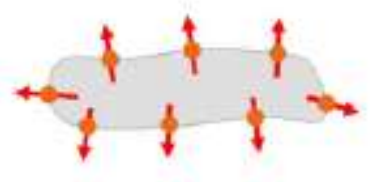

ACTIVE

(Sarcolemmal)

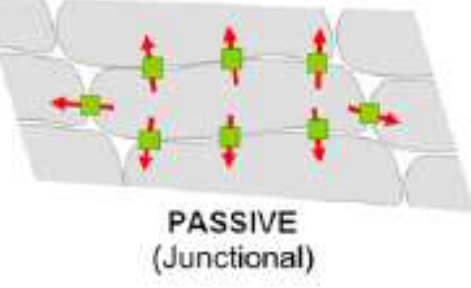

PASSIVE

Abbildung 1.2: Vergleich des $\mathrm{H}^{+}$-Efflux über sarkolemmale Transporter und gap junctions bei $\mathrm{pH}_{\mathrm{i}}$ - ̈̈nderungen

(Vanghan-Jones et al. 2009, Seite 324) (Erklärung im Text)

\subsection{Der $\mathrm{Na}^{+} / \mathrm{H}^{+}$-Austauscher (NHE)}

\subsection{1 Überblick über den NHE}

Beim $\mathrm{Na}^{+} / \mathrm{H}^{+}$-Austauscher (NHE) handelt es sich um ein Glykoprotein, das sich in Membranen befindet. Es schleust Protonen 1:1 im Austausch gegen extrazelluläres $\mathrm{Na}^{+}$aus der Zelle heraus.

Bereits 1961 wurde die Existenz des NHE und der $\mathrm{Na}^{+} / \mathrm{K}^{+}$-ATPase sowie deren Bedeutung für die Zellfunktionen zum ersten Mal von P. Mitchell im Kontext des chemiosmotischen Modells herausgestellt (Mitchell 1961). Im Jahre 1967 wurde der NHE erstmals in Mitochondrien aus Mäuseleberzellen experimentell nachgewiesen (Mitchell und Moyle 1967). Im Jahre 1976 folgte die Darstellung des NHE in intestinalen und renalen Bürstensaum-Membranvesikeln (Murer et al. 1976). Rund zehn Jahre später folgten die zwei anderen wichtigen Meilensteine der NHE-Forschung: 1987 die Klonierung des ersten NHEkodierenden Gens (heute bezeichnet als NHE-1) in prokaryoten Zellen von E. coli (Goldberg et al. 1987) und 1989 dann in eukaryoten Zellen des Menschen (Sardet et al. 1989). Seitdem 
haben die Kenntnisse über dieses Protein stark zugenommen. Weitere Isoformen in Säugern wurden identifiziert und kloniert und deren Gene isoliert. Bei der Erforschung ihrer molekularen Strukturen, deren Lokalisation und der Regulation ihrer Aktivitäten und mRNAExpression wurden große Fortschritte gemacht. Insbesondere wurde ihre wichtige Bedeutung für die physiologische und pathophysiologische Funktion des Herzens durch die Entwicklung von Antagonisten in vielen experimentellen Studien nachgewiesen. Aus diesem Grunde wird der NHE als wichtiger Ansatzpunkt bei der Behandlung Ischämie-bedingter Schädigungen der Herzfunktion angesehen.

\subsubsection{Die verschiedenen Isoformen des NHE}

Die als erste identifizierte Form eines klonierten Säuger-Gens ist die NHE-1-Isoform, welche zugleich auch die am besten untersuchte Isoform des NHE ist. Bis heute sind neun verschiedene Isoformen identifiziert worden (Xu et al. 2005). Die verschiedenen Isoformen sind strukturell und funktionell miteinander verwandt, unterscheiden sich aber hinsichtlich ihres Vorkommens im Gewebe, ihrer Lokalisation und Regulation in der Zelle und ihrer pharmakologischen Charakteristika. Allen gemeinsam sind folgende Eigenschaften: a) die pH-Sensitivität; b) die Beeinflussung der Aktivität durch die extrazelluläre $\mathrm{Na}^{+}$-Konzentration $\left(\left[\mathrm{Na}^{+}\right]\right)$(Boyarsky et al. 1988; Benos 1982; Yun et al. 1995); c) die Sensitivität gegenüber Amilorid und dessen Analoga; und d) die Verminderung der Aktivität bei ATP-Mangel (Wakabayashi et al. 1997; Goss et al. 1994)

Die pH-Sensitivität wurde bereits im Zusammenhang mit der $\mathrm{pH}_{\mathrm{i}}$-Regulation erwähnt. Die weiteren funktionellen Eigenschaften des NHE sind:

\section{1) Beeinflussung der Aktivität durch die extrazelluläre $\left[\mathrm{Na}^{+}\right]$}

Die treibende Kraft für den Transportmechanismus des NHE ist der chemische Gradient für $\mathrm{H}^{+}$und $\mathrm{Na}^{+}$. Letzterer wird durch die $\mathrm{Na}^{+} / \mathrm{K}^{+}$-ATPase aufrechterhalten. Wegen des äquivalenten Austausches von $\mathrm{H}^{+}$und $\mathrm{Na}^{+}$in einem elektroneutralen Verhältnis von 1:1 kann der NHE das Membranpotenzial nicht beeinflussen (Murer et al. 1976).

In einem natürlichen System ist die Aktivität des NHE von der extrazellulären $\mathrm{Na}^{+}-$ Konzentration abhängig. In einem experimentellen System kann der NHE durch eine Umkehrung des $\left[\mathrm{Na}^{+}\right]$-Gradienten seine Transportrichtung verändern. Die Wechselwirkung zwischen extrazellulärer $\left[\mathrm{Na}^{+}\right]$und dem Transporter wird durch die Michaelis-MentenKinetik beschrieben. Allerdings unterscheidet sich das genaue Verhältnis zwischen der 
Aktivität des NHE und der extrazellulären $\left[\mathrm{Na}^{+}\right]$je nach Isoform. So ist dieses Verhältnis beispielsweise bei NHE-1, -2 und -3 hyperbol, bei NHE-4 hingegen sigmoidal. Die Affinität der NHE-Isoformen zu Na ${ }^{+}$liegt zwischen 5 und $50 \mathrm{mM}\left(\mathrm{K}_{\mathrm{d}}\right)$ (Orlowski und Grinstein 1997). Die $\mathrm{Na}^{+}$-Affinität des NHE-3 ist höher als die des NHE-1 und NHE-2. Das spricht dafür, dass der NHE-3 $\mathrm{Na}^{+}$bei niedriger extrazellulärer $\left[\mathrm{Na}^{+}\right]$besser aus dem Medium aufnehmen kann als NHE-1 und NHE-2, was mit seiner Rolle bei der Absorption des $\mathrm{Na}^{+}$aus dem Lumen des proximalen renalen Tubulus und des Darms zu erklären ist.

Im Gegensatz zur extrazellulären $\left[\mathrm{Na}^{+}\right]$wird das Verhältnis zwischen der Aktivität des NHE und $\mathrm{pH}_{\mathrm{i}}$ nicht durch eine einfache Michaelis-Menten-Kinetik beschrieben. Ein Anstieg des $\mathrm{pH}_{\mathrm{i}}$ kann die Aktivität des NHE stark stimulieren. Dabei zeigt sich ein Hill Koeffizient von ca. 3, was dafür spricht, dass außer einer Transporter-Bindungsstelle für $\mathrm{H}^{+}$auch andere Bindungsstellen für $\mathrm{H}^{+}$existieren. Erstmals wurde 1982 die Existenz eines sog. $\mathrm{H}^{+}$-Sensors als zweite Bindungsstelle des $\mathrm{H}^{+}$von Aronson et al. postuliert, die sich in der N-terminalen Transmembran-Region befindet und den Transporter allosterisch aktiviert (Aronson et al. 1982; Fliegel 1999). Damit ist die intrazelluläre pH-Sensitivität des NHE zu erklären.

Die Beziehung zwischen dem $\mathrm{pH}_{\mathrm{i}}$ und der Aktivität des NHE wird hauptsächlich vom $\mathrm{H}^{+}$Sensor kontrolliert. Wenn der $\mathrm{pH}_{\mathrm{i}}$ sinkt, stimuliert die zytoplasmatische $\left[\mathrm{H}^{+}\right]$den NHE durch Bindung an den $\mathrm{H}^{+}$-Sensor, und es kommt zu einer Steigerung des Ausstroms von $\mathrm{H}^{+}$. Der sog. Set-Point für diese Regulation liegt im Bereich des normalen physiologischen Ruhe-pHWertes. So wird bei einem pH-Wert kleiner als 7,2 die Aktivität des NHE durch die einsetzende Protonierung des $\mathrm{H}^{+}$-Sensors erhöht, um das Zytosol vor einer Azidifizierung zu schützen. Der NHE-1 erreicht bei einem $\mathrm{pH}_{\mathrm{i}} \leq 6,5$ seine maximale Aktivität. Bei einem $\mathrm{pH}-$ Wert $>$ 7,2 dagegen wird der Transporter abgeschaltet, um die Zellen vor einer zu starken Alkalisierung des Zytosols zu schützen (Kaila und Vaughan-Jones 1987). Die unterschiedlichen Isoformen des NHE weisen auch eine unterschiedliche Affinität zu zytoplasmatischem $\mathrm{H}^{+}$auf.

\section{2) Antagonisten: Amilorid und seine Derivate}

Eine weitere wichtige Eigenschaft des NHE besteht darin, dass er durch Amilorid und seine 5'-Amino-substituierten Derivate inhibiert wird, welche seit 1971 als unspezifische, potente Hemmer des NHE im distalen Tubulus der Niere bekannt sind und auch als Kalium-sparende Diuretika eingesetzt werden (Kleyman und Cragoe 1988; Murphy et al. 1991). Weil Amilorid nur eine relativ geringe Effektivität und Selektivität aufweist, wurden neuere NHEInhibitoren aus der Gruppe der Benzoylguanidinderivate, wie z.B. HOE-694, (Counillon et al. 
1993a; Orlowski und Kandasamy 1996) entwickelt, die spezifisch gegen den NHE gerichtet sind. Bei pharmakologischen und kinetischen Studien wurden die verschiedenen Isoformen des NHE aufgrund ihrer unterschiedlichen Eigenschaften entdeckt. Die unterschiedlichen Affinitäten der plasmalemmalen Isoformen zu Amilorid weisen folgenden Rangfolge auf: NHE-1 > NHE-2 >> NHE-3 > NHE-4 (Orlowski 1993; Bookstein et al. 1996; Counillon et al. 1993b; Orlowski und Kandasamy 1996). Die NHE-Isoformen in Mitochondrien (NHE-6) werden nicht selektiv durch Amilorid, aber effektiv durch Benzoylguanidinderivate wie HOE694 inhibiert.

Außer den Amilorid-Analoga und den Benzoylguanidinderivaten gibt es noch andere Medikamente, die den NHE hemmen können. Dazu gehören Cimetidin (ein $\mathrm{H}_{2}$-RezeptorAntagonist), Clonidin (ein $\alpha_{2}$-adrenerger Rezeptor-Agonist), Harmalin (ein Medikament gegen Halluzinationen), Loperamid (ein Opiat-Rezeptor-Agonist) und weitere. Cimetidin und Harmalin hemmen den NHE mit ähnlicher Rangfolge wie Amilorid und seine Analoga: NHE$1>$ NHE-2 > NHE-3 (Orlowski 1993; Yu et al. 1993), während Clonidin selektiver für den NHE-2 ist.

\section{3) Regulation durch ATP}

Obwohl der chemische Gradient für $\mathrm{H}^{+}$und $\mathrm{Na}^{+}$als die treibende Kraft für den NHE dient und für den Transport von $\mathrm{H}^{+}$und $\mathrm{Na}^{+}$keine direkte metabolische Energie verbraucht wird, wird ATP für die Funktion des NHE benötigt. Bei niedriger interzellulärer [ATP] ist der NHE in starkem Maße inhibiert. Ein ATP-Mangel scheint die Aktivität des NHE zu hemmen, und zwar durch eine Reduzierung der Affinität $\mathrm{zu} \mathrm{H}^{+}{ }_{\mathrm{i}}$. Das kann mit einer verminderten Phosphorylierung im zytoplasmatischen Teil des NHE erklärt werden (siehe 1.3.5.1) (Wakabayashi et al. 1997). Andererseits wurde jedoch in einigen Studien gezeigt, dass die Änderung der Aktivität des NHE in einer metabolisch insuffizienten Zelle nicht mit der Aktivitätsänderung vergleichbar ist, die bei einer Phosphorylierung des NHE zu beobachten ist (Goss et al. 1994). In einigen Versuchen mit dem NHE-3 wurde dagegen beobachtet, dass auch nach Eliminierung eines großen Teils des C-Terminus die ATP-Sensitivität des NHE-3 bestehen bleibt (Cabado et al. 1996). Bis heute ist der genaue Zusammenhang zwischen der Regulation der Aktivität des NHE und der [ATP $]_{i}$ nicht abschließend geklärt.

\subsubsection{Die Verteilung der NHE-Isoformen}


Außer in den pharmakologischen und kinetischen Eigenschaften unterscheiden sich die NHEIsoformen vor allem bzgl. ihres Verteilungsmusters. Außer dem NHE-6 und dem NHE-7, deren Lokalisation intrazellulär ist, befinden sich die Isoformen NHE-1 bis -5 in der Plasmamembran (Mahnensmith und Aronson 1985; Szabó et al. 2005). Der NHE-1 kommt ubiquitär in der Zellmembran aller Säugetierzellen vor (Counillon und Pouysségur 1995; Fliegel und Fröhlich 1993). NHE-2, -3, -4 und -5 zeigen eine eingeschränkte, gewebespezifische Verteilung (Orlowski et al. 1992).

Der NHE-2 und der NHE-4 werden hauptsächlich in den Nieren und im gastrointestinalen Epithel exprimiert und tragen zur $\mathrm{Na}^{+}$-Resorption (Tse et al. 1993) und zur osmotischen Regulation der medullären Nierenzellen bei (Bookstein et al. 1997). Der NHE-3 befindet sich vor allem in der Nierenrinde und im gastrointestinalen Epithel (Tse et al. 1993), aber in geringerem Maße auch im Hoden, den Ovarien, der Prostata und weiteren Geweben (Brant et al. 1995). In der apikalen Membran des renalen proximalen Tubulusepithels ist der NHE-3 für die Resorption von $\mathrm{Na}^{+}$und $\mathrm{HCO}_{3}{ }^{-}$zuständig (Biemesderfer et al. 1993). In der Membran des intestinalen Epithels ist der NHE-3 ebenfalls zuständig für die $\mathrm{Na}^{+}$-Resorption (Hoogerwerf et al. 1996; Moe 1999). Der NHE-5 wird außer in der Milz, der Skelettmuskulatur und dem Hoden vor allem im Gehirn exprimiert, wo er den $\mathrm{pH}_{\mathrm{i}}$ in Neuronen reguliert (Raley-Susmann et al. 1991). Der NHE-6 befindet sich nicht in der Plasmamembran, sondern in der inneren Membran von Mitochondrien (Garlid 1988). Nach Brett et al. hingegen ist der NHE-6 nicht in den Mitochondrien, sondern in den Endosomen lokalisiert (Brett et al. 2002). Auch der NHE7 wird ubiquitär exprimiert, hauptsächlich aber im Golgi-Apparat, wo ihm eine wichtige Rolle bei der Aufrechterhaltung der Homöostase von Kationen zukommt (Numata und Orlowski 2001). Der NHE-8 wird ebenfalls ubiquitär exprimiert, vor allem aber in den Nieren, im Hoden und der Skelettmuskulatur sowie in der Leber. In der apikalen Membran des renalen proximalen Tubulusepithels trägt der NHE-8 darüberhinaus zum Ionen-Transport bei (Goyal et al. 2003). NHE-9 wird auch wie NHE-6 in den Endosomen nachgewiesen (Nakamura et al. 2005)

Alle NHE-Isoformen weisen ein bestimmtes Maß an Homologie auf, sowohl Speziesübergreifend innerhalb einer Isoform als auch Isoform-übergreifend innerhalb derselben Spezies. Zum Beispiel stimmt die Aminosäuresequenz des NHE-1 des Schweins zu 96\% mit dem menschlichen NHE-1 überein, zu 93\% mit dem NHE-1 der Maus und zu 92\% mit dem NHE-1 des Hamsters. In menschlichen Zellen weist der NHE-3 eine 39\%-ige Übereinstimmung mit dem NHE-1 auf, der NHE-5 ist zu 53\% mit NHE-1 identisch (Fliegel 
1996), während der NHE-6 nur zu 20\% mit anderen Isoformen identisch ist. Der NHE-8 ist ebenfalls nur zu 23-27\% mit den anderen NHE-Isofomen identisch. Der NHE-9 zeigt eine 57\%ige Übereinstimmung mit dem NHE-7 (Nakamura et al. 2005).

\subsubsection{Struktur, Funktion und Lokalisation des NHE-1}

\subsubsection{Die molekulare Struktur des NHE-1}

Der NHE-1 ist ein Glykoprotein mit einem Molekulargewicht von etwa 110 kDa (Karmazyn et al. 1999). Er besteht aus einer hydrophoben, Membran-assoziierten, amphipathischen Nterminalen Domäne aus 500 Aminosäuren und einer stark hydrophilen C-terminalen Domäne aus 315 Aminosäuren (siehe Abbildung 1.3).

Die Membran-assoziierte N-terminale Domäne besteht aus 12 transmembranären Segmenten. Die hydrophile C-terminale Domäne befindet sich im Zytoplasma, wo viele Proteine wie beispielsweise Proteinkinasen oder Calmodulin gebunden werden können (Wakabayashi et al. 2000). Sie weist mehrere potentielle Phosphorylierungsstellen auf. Beide Domänen unterscheiden sich auch funktionell voneinander. Während die N- terminale Domäne verantwortlich für den Transport der Ionen ist, vermittelt die zytoplasmatische Domäne die Regulation und Aktivierung des Transporters.

Die zytoplasmatische Domäne des NHE-1 kann weiter in vier Subdomänen unterteilt werden. Die erste Subdomäne ist der Bereich, der die Aktivität des NHE-1 durch ATP bzw. durch Phosphatidylinositol-4,5-bisphosphat reguliert (Aharonovitz et al. 2000). Die zweite Subdomäne enthält eine Bindungsstelle für ein Inhibitor-Protein, das als Calcineurinhomologes Protein bekannt ist (Lin und Barber 1996). Die dritte Subdomäne besteht aus zwei Bindungsstellen für Calmodulin (CaM-A und -B). CaM-A liegt im Bereich der Aminosäuren 636-656 und weist eine hohe Affinität zu Calmodulin auf, während CaM-B im Bereich der Aminosäuren 667-684 liegt und eine niedrigere Calmodulin-Affinität besitzt (Wakabayashi et

al. 1997). Die letzte Subdomäne dient als Phosphorylierungsregion des NHE-1, wo Proteinkinasen und -phosphatasen die Aktivität des NHE-1 durch Phosphorylierung bzw. Dephosphorylierung regulieren können (Moor und Fliegel 1999).

Alle bekannten Isoformen stimmen in hohem Maße in den transmembranären Segmenten M3M10 überein. Davon sind M6 und M7 in allen NHE-Isoformen nahezu identisch (ca. 95\% Übereinstimmung). Im Vergleich dazu erweisen sich die hydrophilen C-terminalen Domänen 
in allen Isoformen nur als zu 24-56\% identisch. Dies spricht dafür, dass die transmembranären Segmente für die Basis-Funktion des NHE (Transport von $\mathrm{H}^{+}$und $\mathrm{Na}^{+}$) zuständig sind, die prinzipiell in allen Isoformen identisch ist, und die C-terminale Domäne im Zytoplasma unterschiedlich ist und daher eine unterschiedliche Regulation des NHE ermöglicht (Wakabayashi et al. 1997; Orlowski und Grinstein 1997).

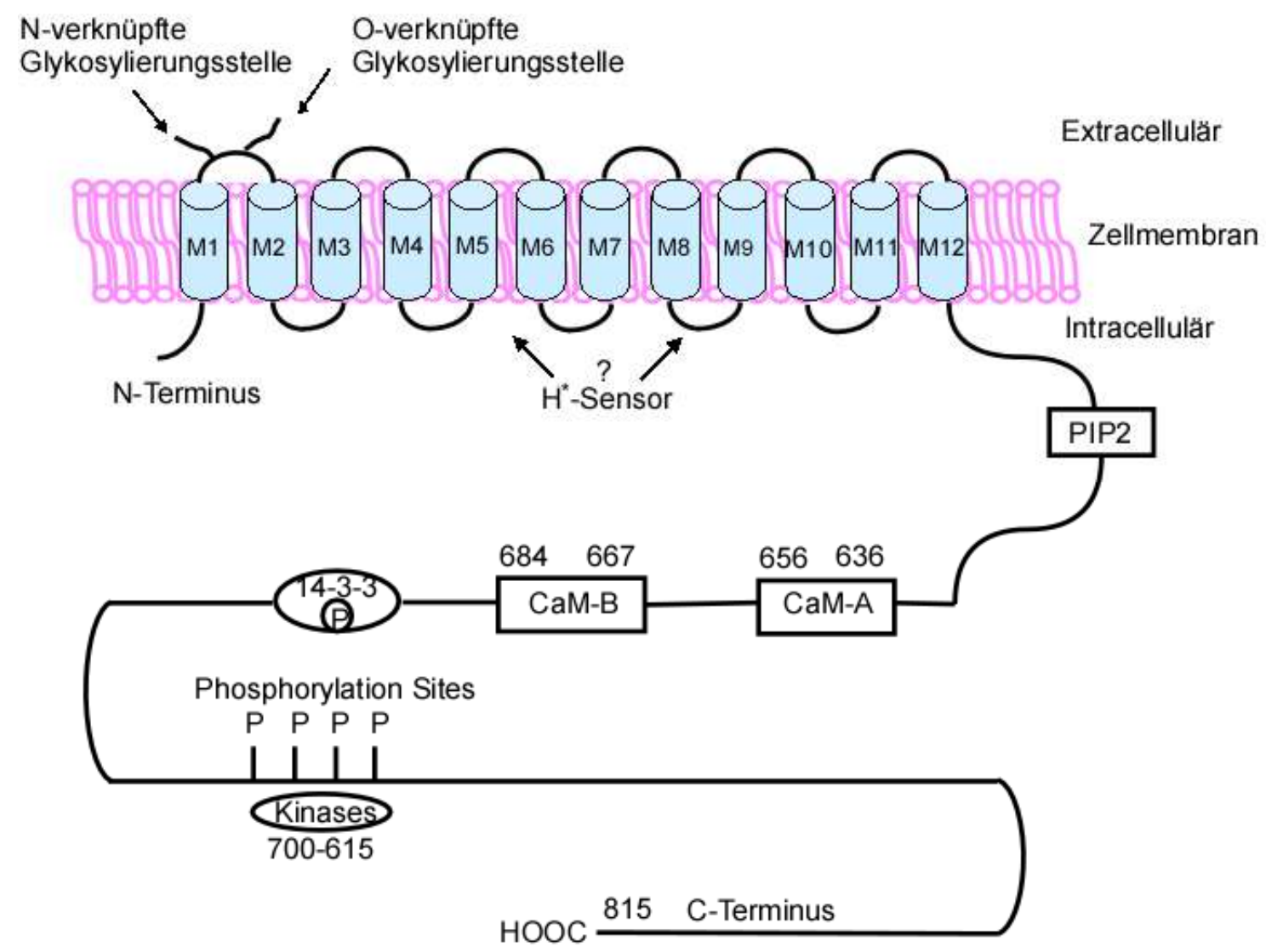

Abbildung 1.3: Die molekulare Struktur des NHE-1

(modifiziert nach Karmazyn et al. 1999, Seite 778) (Erklärung im Text)

\subsubsection{Die strukturellen und funktionellen Komponenten des NHE}

Einige diskrete strukturelle Komponenten des NHE, welche auch seine Funktion beeinflussen können, wurden durch biochemische und pharmakologische Studien identifiziert. Dazu gehören die Glykosylierungsstellen, die Bindungsstelle für Amilorid, der $\mathrm{H}^{+}$-Sensor, die Regulationsstelle für ATP, sowie verschiedene Phosphorylierungsstellen.

\section{a. Glykosylierung}

Der NHE-1 ist ein glykosyliertes Protein mit zwei Glykosylierungsstellen: eine N- und eine O-verknüpfte Glykosylierungsstelle. Sie befinden sich auf der ersten extrazellulären Schleife 
des Proteins (siehe Abbildung 1.3) (Wakabayashi et al. 1997). Sie dienen als Zelloberflächenantigen und Adhäsionsstelle und sind für die Faltung und den Schutz vor Proteolyse wichtig (Counillon et al. 1994; Counillon und Pouysségur 1995). Die genaue Bedeutung ist allerdings noch unbekannt. Bei einer Mutation des Asn $^{75}$ wird das Verschwinden der N-verknüpften Glykosylierungsstelle des NHE-1 bei Mensch und Kaninchen beobachtet. Bei einem Mangel der N-verknüpften Glykosylierungsstelle ist die Aktivität des NHE in der renalen Bürstensaum-Membran von Kaninchen vermindert (Yusufi et al. 1988).

\section{b. Die Bindungsstelle von Amilorid}

Amilorid und seine Analoga sind kompetitive Inhibitoren des externen $\mathrm{Na}^{+}$-Transports durch den NHE. Es ist jedoch nachgewiesen, dass die Bindungsstelle von Amilorid nicht mit der Bindungsstelle von externem $\mathrm{Na}^{+}$identisch ist. Die vierte Transmembranregion (Counillon et al. 1993b) und die neunte Transmembranregion (Wang D et al. 1995) tragen zur AmiloridSensitivität bei.

\section{c. Der $\mathbf{H}^{+}$-Sensor}

Die Beziehung zwischen dem $\mathrm{pH}_{\mathrm{i}}$ und der Aktivität des NHE wird hauptsächlich vom $\mathrm{H}^{+}$Sensor kontrolliert. Die Versuche von Gerchman et al. weisen darauf hin, dass der $\mathrm{H}^{+}$-Sensor in Escherichia coli sich an der intrazellulären Schleife zwischen dem Transmembransegment 7 und 8 befindet (Fliegel et al. 1993). Aber der bakterielle Transporter scheint in dieser Hinsicht nur wenig mit den eukaryotischen Transportern übereinzustimmen. Es wird angenommen, dass der $\mathrm{H}^{+}$-Sensor des NHE der Säugetiere sich an den intrazellulären Schleifen zwischen den Transmembransegment M4 und M5 und zwischen M6 und M7 befindet (Karmazyn et al. 1999).

\section{d. Die Quartärstruktur des NHE}

Über die Tertiär- und Quartärstruktur des NHE-1 ist nur wenig bekannt (Orlowski und Grinstein 1997). Allerdings wurde in biochemischen und immunologischen Studien nachgewiesen, dass weder das NHE-1- noch das NHE-3-Protein als Mono-, sondern vielmehr als Homodimer in der Zellmembran vorliegt, um seine volle Funktion zu entfalten (Fafournoux et al. 1994; Counillon und Pouysségur 1995; Wakabayashi et al. 1997). Über die extrazellulären Schleifen 5 und 6 kommt es wohl zu einer Verbindung zweier NHE-1Monomere zu einem Homodimer (Shrode et al. 1998). 


\subsubsection{Die Lokalisation des NHE-1}

Der NHE-1 kommt ubiquitär in der Zellmembran aller Säugetierzellen vor (Counillon und Pouysségur 1995; Fliegel und Fröhlich 1993). Wie vorher erwähnt, wurde bis jetzt nur eine NHE-Isoform (NHE-1) in Kardiomyozyten identifiziert (Sardet et al. 1989; Orlowski und Grinstein 2004).

Es wird angenommen, dass sich der NHE-1 primär in den Glanzstreifen (in der Nähe von Connexin 43) von Vorhof- und Ventrikelmyozyten befindet. In den Ventrikelmyozyten befindet sich der NHE-1 nicht in der lateralen Membran, sondern entlang des transversalen tubulären Systems (Petrecca et al. 1999). Es ist nicht bekannt, ob sich die physiologische Lokalisation des NHE-1 unter pathologischem Einfluss wie einer Ischämie verändert (Karmazyn et al. 1999).

\subsubsection{Die Regulation der Aktivität des NHE-1}

Wie in 1.3.2 erwähnt, ist die treibende Kraft für den Ionen-Transport durch den NHE der chemische Gradient für $\mathrm{H}^{+}$und $\mathrm{Na}^{+}$. Die Gemeinsamkeiten aller Isoformen sind die $\mathrm{pH}_{\mathrm{i}^{-}}$ Sensitivität, die Beeinflussung der Aktivität durch die extrazelluläre $\left[\mathrm{Na}^{+}\right]$, die AmiloridSensitivität und eine Verminderung der Aktivität bei ATP-Mangel. Der ubiquitär verbreitete NHE-1 wird auch von diesen Faktoren reguliert. Außerdem wird der NHE-1, die in Kardiomyozyten dominante Isoform, durch weitere physiologisch und pathophysiologisch relevante Faktoren akut (innerhalb von Sekunden bis Minuten) und chronisch (innerhalb von Tagen) reguliert.

\subsubsection{Akute Regulation des NHE-1}

Die Hauptfunktion des NHE ist die $\mathrm{pH}_{\mathrm{i}}$-Regulation, und der NHE wiederum wird vom $\mathrm{pH}_{\mathrm{i}}$ reguliert bzw. stimuliert. Außer einer Transportbindungsstelle für $\mathrm{H}^{+}$gibt es noch eine andere $\mathrm{H}^{+}$-Bindungsstelle, den $\mathrm{H}^{+}$-Sensor. Der $\mathrm{H}^{+}$-Sensor kontrolliert die Transportbindungsstelle für $\mathrm{H}^{+}$bzw. die Aktivität des NHE. Die beiden $\mathrm{H}^{+}$-Bindungsstellen befinden sich zusammen in der Transmembranregion der N-terminalen Domäne. Die Affinität von $\mathrm{H}^{+}$zu dem $\mathrm{H}^{+}$-Sensor ist ein Indikator für die $\mathrm{pH}_{\mathrm{i}}$-Sensibilität, die von der zytoplasmatischen Domäne hauptsächlich durch Phosphorylierung und durch Calmodulin (CaM) reguliert wird. Die Phosphorylierung des NHE am C-Terminus lässt sich durch chemische Stimuli wie Hormone, parakrine oder autokrine Regulatoren sowie durch mechanische Stimuli regulieren. Die chemischen Stimuli 
werden nach intrazellulären und extrazellulären Faktoren unterschieden. Zu den intrazellulären Faktoren gehören $\mathrm{H}^{+}$, ATP und $\mathrm{Ca}^{2+}$. Die extrazellulären Faktoren sind u.a. $\alpha_{1^{-}}$ adrenerge Agonisten (Vu et al. 1991; Connolly et al. 1996; Ishihara et al. 1997), Endothelin (Gunasegaram et al. 1999; Krämer et al. 1991; Wu und Tseng 1993; Fareh et al. 1996), Angiotensin II (Brunner und Opie 1998; Coughlin 1994), Thrombin (Yasutake et al. 1996; Sabri et al. 2000) und Wachstumsfaktoren (Grace et al. 1996; Howard et al. 2001). Sie spielen eine wichtige Rolle für die Regulation des NHE-1 in Kardiomyozyten.

Zusammenfassend wird die Aktivität des NHE-1 primär durch den $\mathrm{pH}_{\mathrm{i}}$ und sekundär über die Phosphorylierung am C-Terminus und durch Calmodulin reguliert.

\section{a. G-Protein-gekoppelte Rezeptoren (GPCRs) und Phosphorylierung des NHE-1}

Die Regulation der Aktivität des NHE-1 wird zumeist durch die Phosphorylierung erklärt (Karmazyn et al. 1999). 1990 wurde erstmals von Sardet und Counillon darauf hingewiesen, dass der Wachstumsfaktor eine Phosphorylierung des Proteins hervorrufen kann (Sardet et al. 1990). Die vermehrte Phosphorylierung des Proteins kann z.B. über Mitogen-aktivierte Proteinkinasen (MAPK) erfolgen (Takewaki et al. 1995; Sabri et al. 1998; Wang H et al. 1997). In der Skelett-Muskulatur findet die Phosphorylierung des NHE-1 innerhalb der ersten 178 Aminosäuren des C- Terminus statt (Wang H et al. 1997).

Viele wichtige Hormonstimuli wie $\alpha_{1}$-adrenerge Agonisten (Yokoyama et al. 1998), Endothelin-1 (Khandoudi et al. 1994a), Angiotensin II (Gunasegaram et al. 1999), Thrombin (Glembotski et al. 1993) und Wachstumsfaktoren (Karmazyn et al. 1999) können nach der Bindung an ihre Rezeptoren $(\mathrm{R})$ in der Zellmembran und erfolgter Signaltransduktion (zumeist über $\mathrm{G}_{\mathrm{q}}$-Proteine) die Aktivität des NHE steigern, was zumeist durch eine Phosphorylierung des NHE ausgelöst wird. Neben den NHE-stimulierenden Rezeptoren gibt es auch NHE-hemmende Rezeptoren wie z.B. Adenosin-, $\alpha_{1^{-}}, \beta_{1^{-}}$, und $\mathrm{AT}_{2}$-Rezeptoren. Sie inhibieren die Aktivität des NHE über $\mathrm{G}_{\mathrm{s}^{-}}$oder $\mathrm{G}_{\mathrm{i}}$-Proteine (Avkiran und Haworth 2003; Vaughan-Jones et al. 2009) (siehe Abbildung 1.4). 


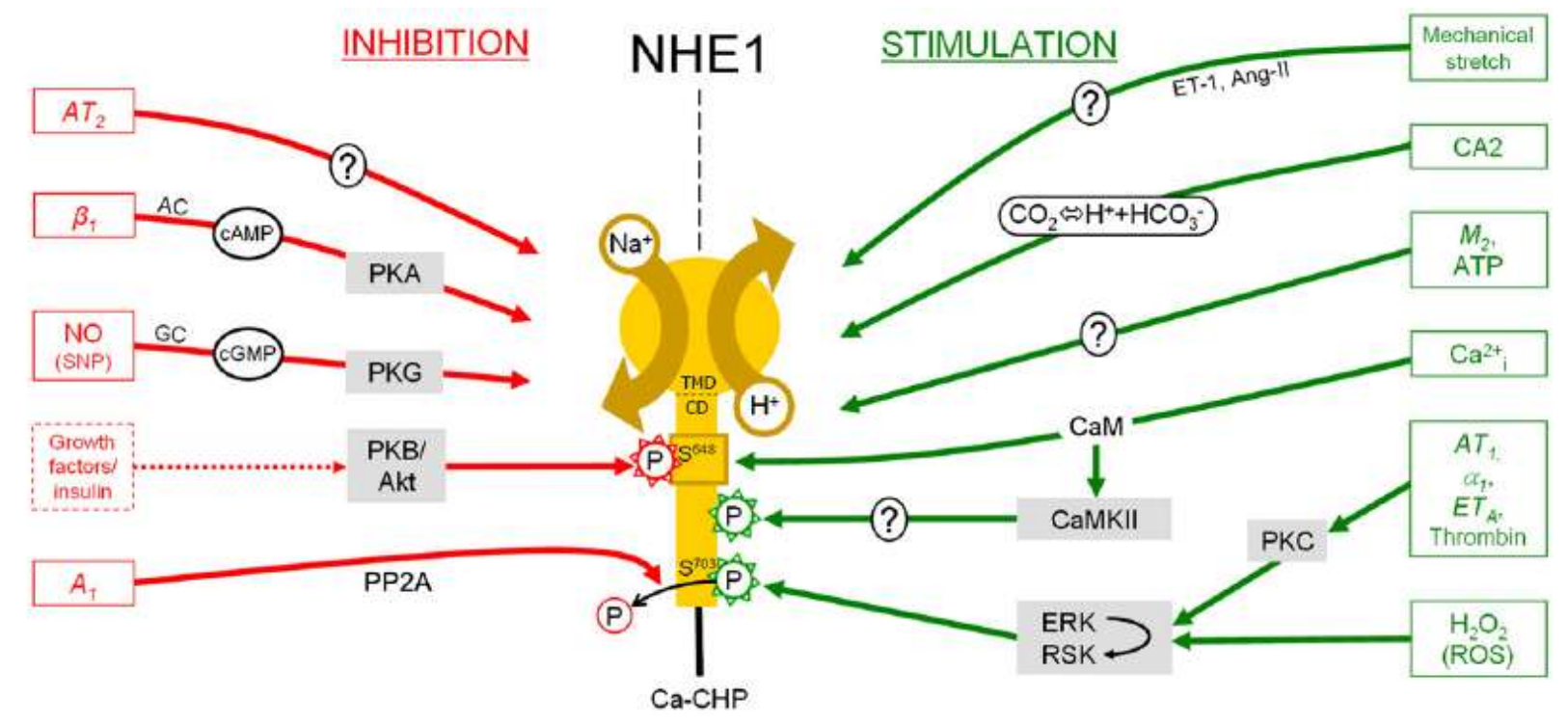

Abbildung 1.4: GPCR-vermittelte Stimulation und Hemmung der sarkolemmalen NHE-1-Aktivität (Vaughan-Jones et al. 2009, Seite 321) (Erklärung im Text)

$\mathrm{Zu}$ den distalen Mechanismen der Signalwege wurden in den letzen Jahren viele Versuche durchgeführt. Wie in Abbildung 4 dargestellt ist ihr genauer Mechanismus häufig noch nicht bekannt. Von Moor und Fliegel (1999) wurde aber darauf hingewiesen, dass in Ventrikelmyozyten von Mäusen $\mathrm{G}_{\mathrm{q}}$-Protein-gekoppelte Rezeptoren eine Steigerung der Aktivität des NHE durch die extrazelluläre Signal-regulierte Kinase (ERK) und die ribosomale p90 S6 Kinase (p90 $\left.{ }^{\mathrm{RSK}}, \mathrm{RSK}\right)$ hervorrufen. Die $\mathrm{p} 90^{\mathrm{RSK}}$ kann den NHE direkt phosphorylieren (Takahashi et al. 1999). In einigen Versuchen wurde jedoch gezeigt, dass ERK und $\mathrm{p} 90^{\mathrm{RSK}}$ nicht unbedingt für diese Stimulation notwendig sind (Snabaitis et al. 2000). Deswegen vermutet man, dass neben dem ERK-p90 ${ }^{\text {RSK }}{ }_{-}$Signalweg noch ein weiterer Signalweg existiert, der über die Phospholipase (PLC) und Proteinkinase C (PKC) verläuft. Obwohl die PKC die Aktivität des NHE stimulieren kann, ist der NHE kein Substrat der PKC. Es wird daher vermutet, dass die PKC über ERK wirkt und den NHE dann ebenfalls durch den ERK-p90 ${ }^{\mathrm{RSK}}$-Signalweg aktivieren kann (Avkiran und Haworth 2003).

$\beta_{1}$-Adrenozeptoren können $\mathrm{G}_{\mathrm{s}}$-vermittelt den NHE über eine Aktivierung der Adenylatcyclase (AC) hemmen, aber der genaue Mechanismus ist noch unbekannt. Die anderen NHEhemmenden $\mathrm{G}_{\mathrm{i}}$-gekoppelten Rezeptoren, wie z.B. der Adenosin- $\mathrm{A}_{1}-\mathrm{R}$, hemmen die Aktivität des NHE nicht direkt, sondern durch Inhibierung der durch die $\mathrm{G}_{\mathrm{q}}$-gekoppelten Rezeptoren verursachten Stimulierung des NHE (Avkiran und Yokoyama 2000). Der zugrunde liegende Mechanismus wurde von der Arbeitsgruppe von Metin Avkiran aufgeklärt (Snabaitis et al. 
2006). Die Protein-Phosphatase 2A (PP2A) spielt dabei eine kritische Rolle. Die PP2A transloziert nach Aktivierung des Rezeptors zunächst zu den Glanzstreifen, wo der NHE lokalisiert ist. Dort erfolgt eine Dephosphorylierung des NHE genau an dem Punkt, an dem der NHE zuvor über Aktivierung von $\mathrm{G}_{\mathrm{q}}$-gekoppelten Rezeptoren durch ERK-p90 ${ }^{\text {RSK }}$ phosphoryliert wurde (Snabaitis et al. 2006) (siehe Abbildung 1.5).

\section{Regulation von NHE}

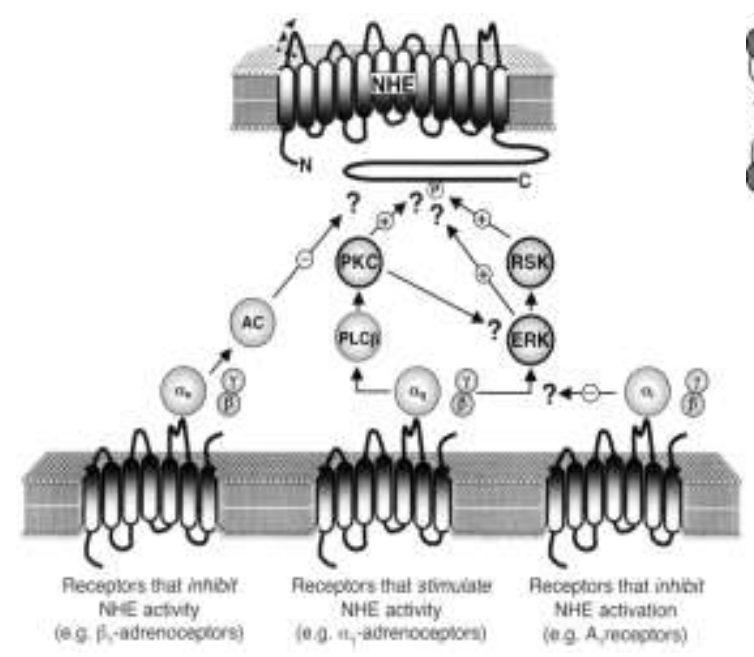

2003

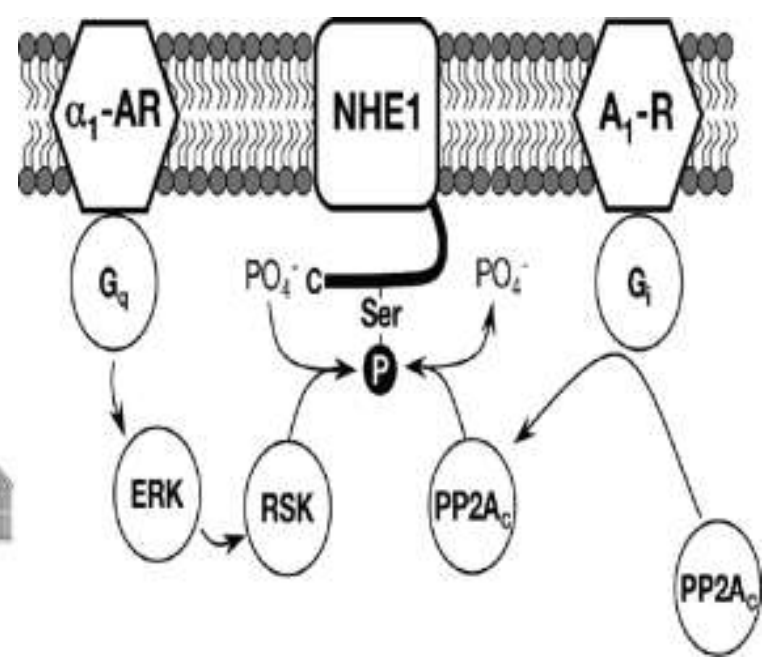

2006

Abbildung 1.5: GPCR-vermittelte Regulation der NHE-1-Aktivität

(Avkiran und Haworth 2003, Seite 946; Snabaitis et al. 2006, Seite 20262) (Erklärung im Text)

Bei ATP-Mangel ist die Aktivität des NHE vermindert, was u.a. auf eine durch Phosphatidylinositol-4,5-bisphosphat-induzierte Dephosphorylierung zurückzuführen ist (Aharonovitz et al. 2000). Neben der Phosphorylierung gibt es noch andere von der Phosphorylierung unabhängige Aktivierungsmechanismen des NHE, wie z.B. die Calmodulin-Regulation.

\section{b. Calmodulin}

Calmodulin hat zwei Bindungsstellen am NHE: die Calmodulin-Bindungsstelle A (CaM-A) und die Calmodulin-Bindungsstelle B (CaM-B) (s.o.). Die Calmodulin-Bindung an die beiden Bindungsstellen hat ähnliche Konsequenzen für die Regulation des NHE-1, aber dabei spielt die CaM-A die Hauptrolle (Orlowski und Grinstein 1997). $\mathrm{Ca}^{2+}$ und Calmodulin verbinden sich bei der Erhöhung der $\left[\mathrm{Ca}^{2+}\right]_{\mathrm{i}} \mathrm{zu}$ einem $\mathrm{Ca}^{2+} / \mathrm{Calmodulin-Komplex,} \mathrm{der} \mathrm{sich} \mathrm{aus} \mathrm{einem}$ 
Molekül Calmodulin und $4 \mathrm{Ca}^{2+}$-Ionen zusammensetzt und die Aktivität des NHE stimuliert (Counillon und Pouysségur, 1995). Nach Entfernung der beiden CaM-Bindungsstellen steigt die Aktivität des NHE kontinuierlich an ähnlich wie bei der Erhöhung der $\left[\mathrm{Ca}^{2+}\right]_{\mathrm{i}}$. Es wird daher vermutet, dass bei normaler $\left[\mathrm{Ca}^{2+}\right]_{\mathrm{i}}$ die unbesetzte CaM-A als ein Autoinhibitor des NHE dient.

\subsubsection{Chronische Regulationen des NHE-1}

Neben der akuten Regulation der Aktivität des NHE durch zahlreiche Stimuli, lässt sich der NHE auch durch eine veränderte Expression langfristig beeinflussen. So kann ein $\mathrm{pH}_{\mathrm{i}}-\mathrm{Abfall}$ bei Ischämie eine vermehrte Expression des NHE-1 hervorrufen (Yang et al. 1996; Fliegel und Fröhlich 1993). Sandmann et al. (Sandmann et al. 2001) und Yang et al. (Yang et al. 1996) konnten diesen Effekt im Rattenmyokard nachweisen, in welchem eine vermehrte Aktivität des NHE-1 und eine Erhöhung der Proteinkonzentration gezeigt werden konnte. Die chronische metabolische Azidose verursacht in renalen epithelialen Zellen einen Anstieg der mRNA-Expression des NHE-1 (Moe et al. 1991; Igarashi et al. 1992). Auch $\alpha_{1}$-adrenerge Stimulation, Endothelin und Thrombin können die Expression des NHE-1-Proteins stimulieren (Fliegel und Wang 1997). Darüber hinaus wurde beobachtet, dass eine dauerhafte Behandlung mit Glukokortikoiden zu einer Steigerung der Expression des NHE-1 und des NHE-3 in Kaninchen-Kardiomyozyten führt (Yamaji et al. 1992).

\subsection{Die Bedeutung des NHE-1 im Herzen}

\subsubsection{Die physiologische Bedeutung des NHE-1 im Herzen}

Da der NHE-1 in Säugetierzellen ubiquitär exprimiert wird, wird er auch als die „Housekeeping“-Isoform bezeichnet (Orlowski und Grinstein 1997; Counillon and Pouysséqur 2000). Er ist an vielen verschiedenen, physiologisch wichtigen Funktionen beteiligt, wie
a) an der Regulation des $\mathrm{pH}_{\mathrm{i}}$
b) an der Regulation der $\left[\mathrm{Na}^{+}\right]_{\mathrm{i}}$
c) an der Regulation des Zellvolumens
d) an der Regulation des Zellwachstums. 
In Herzmuskelzellen wird vermutlich ausschließlich der NHE-1 exprimiert (Sardet et al. 1989; Orlowski und Grinstein 2004). Er wird bei intrazellulärer Azidose aktiviert und schützt die Zelle so vor Azidose. Andererseits kann der NHE-1 aber auch zu pathologischen Veränderungen des Herzens beitragen.

\subsubsection{Die pathophysiologische Bedeutung des NHE-1 im Herzen}

Eine gesteigerte Aktivität des NHE-1 kann auch pathophysiologische Folgen haben. Sie spielt eine kritische Rolle bei Herzkrankheiten, insbesondere beim Ischämie-Reperfusionsschaden, sowie bei Hypertrophie und Herzinsuffizienz.

\subsubsection{NHE und Ischämie-Reperfusionsschaden}

Das Herz braucht mehr Sauerstoff als die meisten anderen Organe, und Kardiomyozyten reagieren auf Sauerstoffmangel ausgesprochen empfindlich. Während der Ischämie fällt der pH-Wert als Folge des anaeroben Metabolismus und des ATP-Katabolismus sowohl intra- als auch extrazellulär ab. Die dadurch hervorgerufene intrazelluläre Azidose führt zu einer schnellen Aktivierung des NHE-1, der $\mathrm{H}^{+}$aus der Zelle heraus- und dafür $\mathrm{Na}^{+}$in die Zelle hineinschleust. Dies führt $\mathrm{zu}$ einer Akkumulation von intrazellulärem $\mathrm{Na}^{+}$. Der Energiemangel und die zusätzliche extrazelluläre Akkumulation von $\mathrm{H}^{+}$führen zu einer Hemmung der $\mathrm{Na}^{+} / \mathrm{K}^{+}$-ATPase (Karmazyn et al. 2001), die das intrazelluläre $\mathrm{Na}^{+}$gegen das extrazelluläre $\mathrm{K}^{+}$austauschen könnte; somit wird weniger $\mathrm{Na}^{+}$eliminiert und die Akkumulation von intrazellulärem $\mathrm{Na}^{+}$weiter begünstigt. Die erhöhte $\left[\mathrm{Na}^{+}\right]_{\mathrm{i}}$ führt zu einer Modulation der Aktivität des $\mathrm{Na}^{+} / \mathrm{Ca}^{2+}$-Austauschers (NCX), der aufgrund des verringerten $\mathrm{Na}^{+}$-Gradienten weniger $\mathrm{Ca}^{2+}$ aus der Zelle entfernt bzw. $\mathrm{Ca}^{2+}$ sogar aktiv in die Zelle transportieren kann im sog. "reverse mode". Daraus resultiert eine Akkumulation von $\mathrm{Ca}^{2+} \mathrm{im}$ Zellinnern, welches über die SR-Ca ${ }^{2+}$-ATPase ins SR aufgenommen wird. Durch die Erhöhung der Konzentration von Calcium im intrazellulären Raum ([Ca $\left.\left.{ }^{2+}\right]_{\mathrm{i}}\right)$ kommt es zu sowohl einem positiv inotropen Effekt als auch zu Zellschäden. Diese Veränderungen, die in Verbindung zur myokardialen Ischämie stehen, treten vor allem in der Reperfusionsphase auf, da der NHE bei der Ischämie durch die extrazelluläre Azidose gehemmt wird. Während der Reperfusion werden die extrazellulär akkumulierten $\mathrm{H}^{+}$-Ionen und Metaboliten schnell ausgewaschen und damit die Hemmung des NHE aufgehoben. Die Zellschäden beruhen auf einer $\mathrm{Ca}^{2+}$-Überladung der Zelle (Tani und Neely 1989; Pierce und Meng 1992) (siehe Abbildung 1.6). Bei einer $\mathrm{Ca}^{2+}$-Überladung wird $\mathrm{Ca}^{2+}$ spontan aus dem SR freigesetzt. So 
kommt es zu unkontrollierten Kontraktionen und $\mathrm{Ca}^{2+}$-getriggerten Arrhythmien. Eine $\mathrm{Ca}^{2+}$ Akkumulation in den Mitochondrien kann die mitochondriale Funktion stören (Karmayn et al. 1999). Alle diese Vorgänge können zur Zellschädigung nach Reperfusion und damit zum sog. Ischämie-Reperfusionsschaden führen.

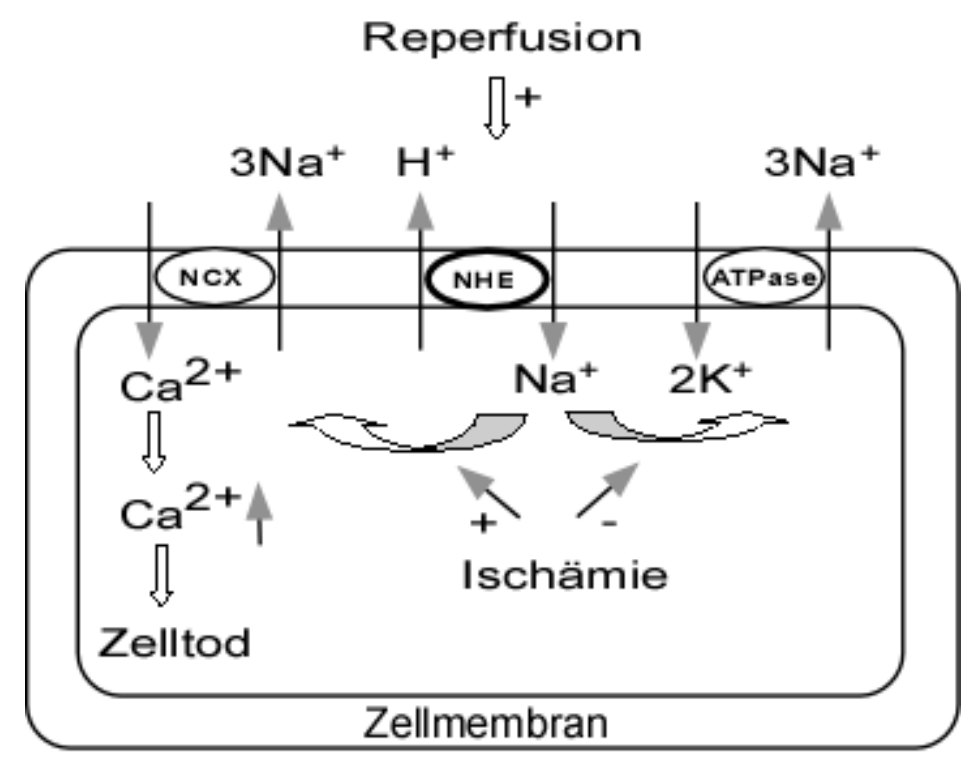

\section{Abbildung 1.6: $\mathrm{Ca}^{2+}$-Überladung der Zelle nach Ischämie und Reperfusion führt zum Zelltod.}

(modifiziert nach Karmazyn et al. 1999, Seite 780) (Erklärung im Text)

Als Ursache für die Zellschäden gibt es neben der $\mathrm{Ca}^{2+}$-Überladung der Zelle noch eine andere Hypothese: das sog. pH-Paradoxon. Hierbei wird Folgendes angenommen: Während einer Ischämie kommt es als Folge des intrazellulären ATP-Mangels zu einer Aktivierung von Phospholipasen und Proteasen, die die Zellmembran schädigen können. Die Aktivität dieser Enzyme wird durch die Azidose jedoch herabgesetzt. Nach der schnellen Normalisierung des $\mathrm{pH}_{\mathrm{i}}$ während der Reperfusion wird genau diese Aktivitäts-Einschränkung wieder aufgehoben. Die Phospholipasen und Proteasen werden rasch reaktiviert und dies führt zum Zelltod (Karmazyn et al. 1999).

Die Aktivierung des NHE-1 bei Ischämie-Reperfusion ist nicht nur auf die Senkung des $\mathrm{pH}_{\mathrm{i}}$ zurückzuführen, sondern auch auf die Stimulierung von GPCR. Während einer Ischämie kommt es zur Aktivierung des sympathischen Nervensystems und zur Freisetzung von Noradrenalin in der ischämischen Region (Schomig und Richardt 1990). $\alpha_{1}$-Adrenerge Agonisten (wie das Noradrenalin) können in isolierten Kardiomyozyten während einer 
Ischämie den NHE-1 stimulieren (Pucéat et al. 1993). Zudem wurde gezeigt, dass in isolierten Kardiomyozyten von Mäusen die Stimulation von $\alpha_{1}$-adrenergen Rezeptoren die postischämische kontraktile Dysfunktion noch verschlimmern kann (Khandoudi et al. 1994b). Darüber hinaus wurde beobachtet, dass die $\alpha_{1}$-adrenerge Stimulation die durch die Reperfusion hervorgerufenen Arrhythmien in der Ischämieregion verstärkt. Dieser Effekt kann nicht nur von $\alpha_{1}$-adrenergen Antagonisten, sondern auch von NHE-1-Inhibitoren aufgehoben werden (Avikran und Haworth 2003). Dies spricht dafür, dass $\alpha_{1}$-adrenerge Agonisten eine wichtige Rolle bei der Stimulierung des NHE-1 während einer Ischämie spielen können. Thrombin (Yokoyama und Avkiran 1997) und Endothelin können ähnlich wirken (Brunner und Opie 1998; Khandoudi et al. 1994a).

\subsubsection{Hypertrophie und Herzinsuffizienz}

Obwohl in den letzten Jahren große Fortschritte bei der Diagnose und Behandlung kardiovaskulärer Erkrankungen gemacht wurden, sind diese noch immer die häufigste Todesursache in westlichen Industrienationen. In Europa beträgt die Inzidenz der Herzinsuffizienz 1,3/1000. Dabei ist die ischämische Schädigung des Myokards die häufigste Ursache (36\%), gefolgt von Kardiomyopathien unbekannten Ursprungs (34\%), Hypertension (14\%) und Vitien (7\%) (Cowie et al. 1999). Die 5-Jahres-Mortalität der Patienten mit Herzinsuffizienz liegt bei 59\% (Mosterd et al. 2001). Der Erforschung der pathophysiologischen Prozesse auf zellulärer und molekularer Ebene kommt daher eine wichtige Bedeutung zu.

Viele Studien zeigen, dass der NHE-1 in die Entwicklung der kardialen Hypertrophie und der Herzinsuffizienz involviert ist (Karmazyn 2001; Yoshida und Karmazyn 2000; Camilión de Hurtado et al. 2002; Jandeleit-Dahm et al. 2000). Die oben bereits erwähnten Hormonstimuli ( $\alpha_{1}$-adrenerge Agonisten, Endothelin-1, Angiotensin II und Thrombin) sind zugleich auch Hypertrophie-Stimuli, die u. a. durch erhöhte mechanische Belastung des Myokards aktiviert werden. Sie fördern das Zellwachstum u. a. dadurch, dass sie den NHE-1 stimulieren. Die Stimulierung des NHE-1 hat verschiedene intrazelluläre Veränderungen zur Folge, die zu Hypertrophie und Herzinsuffizienz führen können.

Die Erhöhung der $\left[\mathrm{Na}^{+}\right]_{\mathrm{i}}$, die nach der Stimulierung des NHE-1 erfolgt, kann die Proteinsynthese verstärken und damit zum Hypertrophieprozess beitragen ( $\mathrm{Gu}$ et al. 1998). Die $\left[\mathrm{Na}^{+}\right]_{\mathrm{i}}$-Erhöhung führt über eine Modulation des NCX auch zu einer $\left[\mathrm{Ca}^{2+}\right]_{\mathrm{i}}$-Erhöhung. $\mathrm{Ca}^{2+}$ aktiviert verschiedene $\mathrm{Ca}^{2+}$-abhängige Proteine und Signalwege (z.B. Calcineurin-NFAT 
oder die nukleäre CaMKII), die die Transkription erhöhen und Hypertrophie hervorrufen können. Außerdem kann eine erhöhte Transkription durch die vom NHE-1 hervorgerufene intrazelluläre Alkalose unterstützt werden (Karmazyn et al. 1999). Eine Erhöhung des $\mathrm{pH}_{\mathrm{i}^{-}}$ Wertes um 0,1 Einheiten kann die Proteinsynthese um bis zu 40\% steigern (Fuller et al. 1990). Als Folge der Hypertrophie kommt es zu einer Herzinsuffizienz.

Aufgrund solcher Studien-Ergebnisse wird der NHE als ein potentielles Behandlungsziel zum Schutz vor Reperfusionsschäden als auch Hypertrophie und Herzinsuffizienz angesehen. In verschiedenen tierexperimentellen Studien zeigte sich eine eindeutige Reduktion der kardialen Hypertrophie (Schlüter et al. 1998; Engelhardt et al. 2002) und Herzinsuffizienz nach NHE-1Inhibition (Kusumoto et al. 2001; Spitznagel et al. 2000; Yoshida und Karmazyn 2000).

\subsection{NHE-Inhibitoren und ihre klinische Bedeutung}

Die erste Klasse von NHE-Inhibitoren bildet Amilorid und seine 5'-Amino-substituierten Derivate, die 1971 entdeckt wurden. $\mathrm{Zu}$ dieser Klasse gehören beispielsweise Ethylisopropylamilorid (EIPA), Dimethylamilorid (DMA), 5-N-(methylpropyl)amiloride (MPA) und Methylisobutyl-Amiloride (MIA oder MIBA) (Counillon et al. 1993). Amilorid und seine Derivate können den NHE kompetitiv hemmen, indem sie mit $\mathrm{Na}^{+}$um dessen Bindungsstelle an der äußeren Membran konkurrieren. Sie sind jedoch in nur relativ geringem Maße effektiv und selektiv für den NHE. Daher wurden neue NHE-Inhibitoren aus der Gruppe der Benzoylguanidinderivate wie 3-Methylsulfonyl-4-piperidinobenzoyl-guanidin (HOE694) (Counillon et al. 1993; Orlowski und Kandasamy 1996) und HOE642 (Cariporid) (Scholz et al. 1995) entwickelt. Sie sind spezifisch gegen den NHE gerichtet, zeigen keine Inhibition anderer Ionentransportsysteme und erweisen sich durch die höhere Effektivität und Selektivität als dem Amilorid überlegen. Der NHE-1 ist empfindlicher gegenüber den Amiloriden und den Benzoylguanidinderivaten als der NHE-2, -3 und -4 (Orlowski 1993; Bookstein et al. 1996; Counillon et al. 1993; Orlowski und Kandasamy 1996).

Der erste NHE-1-Inhibitor aus der Gruppe der Benzoylguanidinderivate war HOE694. Das später entwickelte HOE642 (Cariporid) (siehe Abbildung 1.7) erwies sich als dem HOE694 überlegen. Es ist stärker und spezifischer gegen den NHE-1 wirksam als HOE694 (Scholz et al. 1993; Counillon et al. 1993). HOE642 ist etwa 60-mal stärker gegen den NHE-1 wirksam als gegen den NHE-2 (Scholz et al. 1995). Aus diesem Grunde wird HOE642 für die potentielle Behandlung NHE-induzierter Ischämie- und Reperfusionsschäden eingesetzt. Der 
Interaktionsmechanismus zwischen dem NHE-1 und seinen Inhibitoren ist nicht genau bekannt. Nach Karmazyn et al. kommt es dabei zu einer Bindung des Inhibitors an lipophile transmembranäre Einheiten des Transporters (Karmazyn et al. 2001).

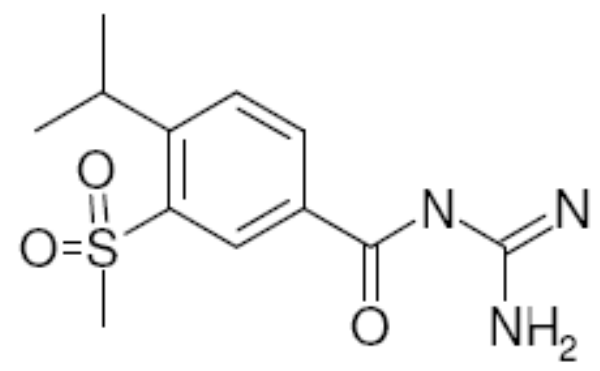

Cariporide (HOE642, $379.5 \mathrm{~g} / \mathrm{mol}$ )

\section{Abbildung 1.7: Strukturformel vom HOE642 (Cariporid)}

(Klämbt 2005)

Neben HOE642 (Cariporid) werden auch andere Benzoylguanidinderivate wie das Aminoguanidinderivat T-162559 (Kusumoto et al 2002), Zoniporid (Tracy et al. 2003), KBR9032 (Wang et al. 2000), Sabiporid (Touret et al. 2003) und Eniporid (Kovar et al. 2001) in der präklinischen und klinischen Forschung als NHE-1-Inhibitoren eingesetzt.

In zahlreichen Studien wurde eine Reihe von kardioprotektiven Effekten durch den Einsatz von NHE-1-Inhibitoren im ischämischen Myokard von Tieren und Menschen beobachtet (siehe Tabelle 1.1)

1. Verbesserung der Funktionserholung des linken Ventrikels nach Reperfusion

2. Reduzierung der Infarktgröße und Nekrose

3. Reduzierung der von Ischämie und Reperfusion abhängigen unkontrollierten Kontraktionen

4. Verminderung der Dyshomöostase von Ionen während Ischämie und Reperfusion

5. Reduzierung der Apoptose

6. Reduzierung der durch Ischämie und Reperfusion hervorgerufenen Arrhythmie

7. Reduzierung der Postinfarktsmortalität

8. Reduzierung der Mortalität und Inzidenz von Myokardinfarkten nach kononarer Bypass-Op.

19. Steigerung der linksventrikulären Funktion nach Ballon-Angioplastie*

Tabelle 1.1: Kardioprotektive Effekte von NHE-Inhibitoren im ischämischen Myokard in experimentellen und klinischen Studien

(Kamazyn et al. 1999) * klinische Studie 
Es konnte nachgewiesen werden, dass die wichtigsten kardioprotektiven Effekte der NHE-1Inhibitoren mit einem verminderten Anstieg der $\left[\mathrm{Na}^{+}\right]_{\mathrm{i}}$ und der $\left[\mathrm{Ca}^{2+}\right]_{\mathrm{i}}$ einhergehen (Scholz und Albus 1995).

Toxische Effekte der NHE-1-Inhibitoren fallen mit hoher Wahrscheinlichkeit sehr gering aus. Der Grund hierfür liegt zum einen darin, dass der NHE-1 unter physiologischen Bedingungen eine niedrige Aktivität aufweist, und zum anderen darin, dass Nebenwirkungen der NHE-1Inhibitoren durch die hohe Selektivität für den NHE-1 minimiert werden konnten.

Obwohl die Ergebnisse zahlreicher experimenteller Untersuchungen zu NHE-1-Inhibitoren vielversprechend hinsichtlich der kardioprotektiven Effekte in IschämieReperfusionssituationen erschienen, verliefen die großen klinischen Studien von Cariporid enttäuschend. Am GUARDIAN-Trial (Guard during ischemia against necrosis) von Cariporid nahmen über 11590 Hochrisikopatienten für einen Myokardinfarkt mit instabiler Angina pectoris oder NSTEMI teil, die zur Revaskularisierung interventionell oder bypasschirurgisch behandelt wurden. Im Ergebnis zeigte sich jedoch kein Vorteil für die Cariporid-Gruppe hinsichtlich des Studienendpunkts Myokardinfarkt. Allerdings konnte durch Subgruppenanalyse eine kleine Gruppe von bypasschirurgisch behandelten Patienten identifiziert werden, die von Cariporid bei der höchsten Dosierung mit einer 25\%igen Risikoreduktion profitierte (Théroux et al. 2000). Bei klinischen Studien zum NHE-1Inhibitor Zoniporid kam es ebenfalls zu enttäuschenden Ergebnissen (Fleischer et al. 2005).

Die enttäuschenden Ergebnisse der klinischen Studien wurden nach Murphy und Avkiran et al. (Murphy und Allen 2009; Avkiran et al. 2008) damit erklärt, dass die NHE-1-Inhibitoren wie Cariporid nicht während sondern nach der Ischämie-Phase verabreicht wurden. In einigen Experimenten hatte man die Gabe von NHE-1-Inhibitoren während der Ischämie mit der Gabe von NHE-1-Inhibitoren zu Beginn der Reperfusion verglichen. Es wurde gezeigt, dass es bei der Gabe von NHE-1-Inhibitoren während der Ischämie zu einer Verbesserung der Ventrikelfunktion im Myokard kommen kann. Diese Verbesserung kann dagegen nicht beobachtet werden, wenn der NHE-1-Inhibitor erst während der Reperfusion verabreicht wird (Myers et al. 1995). Auch wenn der NHE-1-Inhibitor sofort zu Beginn der Reperfusionsphase gegeben wird, braucht es eine bestimmte Zeit, bis der Inhibitor die betroffenen Myozyten erreichen kann. Dadurch wird die Wirkung des NHE-1-Inhibitors unter diesen Bedingungen reduziert (Murphy und Allen 2009). Deshalb sollten, um die maximale kardiale Protektion von NHE-1-Inhibitoren zu erhalten, diese sowohl während der Ischämie als auch der 
Reperfusion gegeben werden (was in der klinischen Praxis in den allermeisten Fällen nicht möglich ist). Im Gegensatz dazu zeigten Meng und Pierce, dass am rechten Ventrikel des Rattenmyokards ein kardioprotektiver Effekt von NHE-1-Inhibitoren nur während der Reperfusion zu beobachten war (Meng und Pierce 1990). In einem anderen Versuch zeigte sicht, dass ein antiarrhythmischer Effekt von HOE694 und Ethylisobutylamilorid auch nur bei der Gabe des NHE-1-Inhibitors während der Reperfusion vorhanden war (Yasutake et al. 1994).

David Allen ist zudem der Meinung, dass die Erhöhung der intrazellulären $\mathrm{Na}^{+}$-Konzentration während der Ischämie nicht durch den NHE-1 (allein) verursacht wird, sondern (zusätzlich) von persistierenden $\mathrm{Na}^{+}$-Kanälen (Murphy und Allen 2009). Viele NHE-1-Inhibitoren können nicht nur den NHE-1 sondern auch die persistierenden $\mathrm{Na}^{+}-\mathrm{Kanäle}$ hemmen. Er hat deshalb empfohlen, dass eine optimale Therapie daraus bestünde, während der Ischämie einen NHE1-Inhibitor plus einen Blocker der persistierenden $\mathrm{Na}^{+}$-Kanäle zu verabreichen und während der Reperfusion einen selektiven NHE-1-Inhibitor zu verabreichen (Murphy und Allen 2009). Es wurde auch vermutet, dass der Puffer für die beobachteten Unterschiede eine wichtige Rolle spielt. Avkiren et al. haben beobachtet, dass eine kardioprotektive Wirkung von NHEInhibitoren bei Verwendung einer Bikarbonat-freien Lösung innerhalb eines größeren zeitlichen Rahmens erzielt werden kann als bei Verwendung einer Bikarbonat-haltigen Lösung (Shimada et al. 1996).

Zusammengefasst gibt es viele mögliche Gründe für das Scheitern der klinischen Studien. Der Widerspruch zwischen den ausgeprägten kardioprotektiven Effekten von NHE-1-Inhibitoren in zahlreichen Tierexperimenten und den eher schwachen Resultaten klinischen Studien bleibt bisher nur unzureichend verstanden und erfordert weitere Forschungen.

\subsection{Fragestellung}

Die meisten Untersuchungen zur Funktion des kardialen NHE-1 wurden in Ventrikelmyozyten durchgeführt. Zur Funktion und Aktivität des NHE-1 in Vorhofmyozyten ist dagegen bisher kaum etwas bekannt. Das ist insofern von besonderer physiologischer und pathophysiologischer Relevanz, als eine gestörte NHE-Funktion auch zu Erkrankungen des Vorhofmyokards beitragen kann. 
Jüngste Untersuchungen haben zudem gezeigt, dass es subzelluläre Unterschiede in der Regulation von intrazellulären Botenstoffen und Ionen geben kann. Die subzellulären Unterschiede können funktionelle Konsequenzen für die Herzmuskelzellen mit sich bringen. Dies gilt auch für die kardiale $\mathrm{H}^{+}$- und $\mathrm{Na}^{+}$-Homöostase. Da Vorhof- und Ventrikelmyozyten sich hinsichtlich ihrer Größe und des Vorhandenseins eines T-tubulären Membransystems unterschieden, gibt es möglicherweise auch Unterschiede zwischen diesen beiden Zelltypen bezüglich der subzellulären $\mathrm{H}^{+}$-Homöostase.

Auch wenn bereits viele Kenntnisse über den NHE-1 vorhanden sind, so basieren diese doch weitgehend auf Experimenten mit myokardialen Geweben und Zellen von Tieren. Diese Ergebnisse können nicht immer direkt auf den Menschen übertragen werden. Es gibt zu wenige Kenntnisse über die Aktivität und Expression des NHE-1 im humanen Myokard. Insofern sind Versuche an humanem Myokard von besonderer Relevanz.

In der vorliegenden Arbeit wurden Experimente zur NHE-1-abhängigen, globalen und lokalen $\mathrm{pH}_{\mathrm{i}}$-Regulation in Vorhof- und Ventrikelmyozyten aus Kaninchenherzen und, zu einem kleinen Teil, aus humanen Herzen durchgeführt. Außerdem wurde die NHE-Expression in humanem Vorhof- und Ventrikelgewebe bei verschiedenen Herzerkrankungen analysiert, um die folgenden Fragen zu beantworten:

1. Gibt es Unterschiede in der NHE-1-abhängigen, globalen $\mathrm{pH}_{\mathrm{i}}$-Regulation zwischen Vorhof- und Ventrikelmyozyten?

2. Gibt es NHE-1-abhängige subzelluläre $\mathrm{pH}_{\mathrm{i}}$-Unterschiede in Vorhof- und Ventrikelmyozyten?

3. Gibt es Unterschiede in der NHE-Expression zwischen humanem Vorhof- und Ventrikelgewebe und bei verschiedenen Herzerkrankungen? 


\section{Material und Methoden}

\subsection{Isolierung der Kardiomyozyten}

\subsubsection{Versuchstiere}

Für die Experimente wurden nur weibliche Kaninchen (Chinchilla-Bastard-Kaninchen) mit einem Körpergewicht von 1,5-2 kg verwendet. Sie wurden unter standardisierten Bedingungen gehalten (Futter und Wasser ad libitum, normaler Tag- und Nachtrhythmus). Die Verwendung dieser Versuchstiere zu wissenschaftlichen Zwecken wurde gemäß $§ 4$ Abs. 3 TierSchG unter Aktenzeichen T 8.02 der Bezirksregierung Braunschweig angezeigt.

\subsubsection{Lösungen für die Isolierung der Kardiomyozyten}

1).

\begin{tabular}{|c|c|c|c|c|}
\hline & Stoff & Konzentration & Firma & \\
\hline $\begin{array}{l}\mathrm{Ca}^{2+} \text { freie } \\
\text { Tyrode- } \\
\text { Losung }\end{array}$ & $\begin{array}{l}\mathrm{NaCl} \\
\mathrm{KCl} \\
\mathrm{MgSO}_{4} \\
\mathrm{Na}_{2} \mathrm{HPO}_{4}\left(\mathrm{H}_{2} \mathrm{O}\right) \\
\mathrm{HEPES} \\
\text { Glucose } \\
\text { Penicillin G/Streptomycin }\end{array}$ & $\begin{array}{l}137 \mathrm{mM} \\
5,4 \mathrm{mM} \\
1,2 \mathrm{mM} \\
1,2 \mathrm{mM} \\
20 \mathrm{mM} \\
15 \mathrm{mM} \\
100 \mathrm{U} / \mathrm{ml}\end{array}$ & $\begin{array}{l}\text { Merck } \\
\text { Merck } \\
\text { Merck } \\
\text { Merck } \\
\text { Sigma (\#H3375) } \\
\text { Merck } \\
\text { Sigma (\#P4333) }\end{array}$ & $\begin{array}{l}\text { Gelost in dd } \mathrm{H}_{2} \mathrm{O} \\
\mathrm{pH} 7,54 \text { bei RT }\end{array}$ \\
\hline $\begin{array}{l}\mathrm{Ca}^{2+} \text { haltige } \\
\text { Tyrode-Losung }\end{array}$ & $\begin{array}{l}\mathrm{Ca}^{2+} \text { freie Tyrode-Lösung } \\
\mathrm{CaCl}_{2}\end{array}$ & $1 \mathrm{mmol} / 1$ & Fluka & $\begin{array}{l}\text { Gelost in } \mathrm{Ca}^{2+} \text { - freier } \\
\text { Tyrodelosung } \\
\text { pH } 7,54 \text { bei RT }\end{array}$ \\
\hline Enzymlosung & $\begin{array}{l}\text { Ca2+freie Tyrode-Löung } \\
\text { Taurine } \\
\text { DL-Glutamin săure } \\
\text { DL-Carnitin } \\
\text { Collagenase } 2 \\
\text { Protease XIV } \\
1 \mathrm{M} \mathrm{CaCl}\end{array}$ & $\begin{array}{l}60 \mathrm{mM} \\
8 \mathrm{mM} \\
2 \mathrm{mM} \\
100 \mathrm{mg} / \mathrm{dl} \\
2,1 \mathrm{mg} / \mathrm{dl} \\
0,025 \mathrm{mM}\end{array}$ & $\begin{array}{l}\text { Sigma (\#T9931) } \\
\text { Sigma (\#G1126) } \\
\text { Sigma (\#C9500) } \\
\text { Worthington Lot } \\
\text { (\#MOK4224) } \\
\text { Sigma (\#P5147) } \\
\text { Fluka }\end{array}$ & $\begin{array}{l}\text { Gelost in } \mathrm{Ca}^{2+} \text { - freier } \\
\text { Tyrodelosung } \\
\text { pH } 7,54 \text { bei RT }\end{array}$ \\
\hline $\begin{array}{l}\text { Stopp-Losung } \\
\text { plus } 2 \% \text { Albumin }\end{array}$ & $\begin{array}{l}\text { IM CaCl} \\
\text { Albumin in Fraktion V } \\
\text { BDM }\end{array}$ & $\begin{array}{l}0,05 \mathrm{mM} \\
2000 \mathrm{mg} / \mathrm{dl} \\
20 \mathrm{mM}\end{array}$ & $\begin{array}{l}\text { Fluka } \\
\text { Sigma (\#A2153) } \\
\text { Sigma (\#B0753) }\end{array}$ & $\begin{array}{l}\text { Gelost in } \mathrm{Ca}^{2+} \text { - freier } \\
\text { Tyrodelosung } \\
\text { pH } 7,54 \text { bei RT }\end{array}$ \\
\hline $\begin{array}{l}\text { Modifiziertes } \\
\text { M199 }\end{array}$ & $\begin{array}{l}\text { Taurine } \\
\text { D, L-Carnitine } \\
\text { D, L-Creatine } \\
\text { Penicillin G } \\
\text { Streptomycin } \\
\text { 100Fach L-glutamine }\end{array}$ & $\begin{array}{l}5 \mathrm{mM} \\
5 \mathrm{mM} \\
5 \mathrm{mM} \\
100 \mathrm{U} / \mathrm{ml} \\
0,02 \mathrm{mM} \\
2 \mathrm{mM}\end{array}$ & $\begin{array}{l}\text { Sigma (\#T9931) } \\
\text { Sigma (\#C9500) } \\
\text { Sigma (\#C0780) } \\
\text { Sigma (\#P4333) } \\
\text { Sigma (\#P4333) } \\
\text { PAA (\#M1 1-004) }\end{array}$ & $\begin{array}{l}\text { Gelost in M199 } \\
\text { (Sigma \#M7528) } \\
\text { pH 7,54 bei RT }\end{array}$ \\
\hline
\end{tabular}

Tabelle 2.1: Lösungen für die Isolierung der Kardiomyozyten 
2). Waschlösungen: Tyrodelösung mit verschiedenen $\mathrm{Ca}^{+}-$Konzentrationen

\begin{tabular}{|l|c|c|c|}
\hline Waschlösung & $\begin{array}{l}\mathrm{Ca}^{2+} \text {-freie Tyrode - } \\
\text { Lösung }\end{array}$ & $1 \mathrm{M} \mathrm{CaCl}_{2}$ & $\mathrm{Ca}^{2+}$-Konzentration \\
\hline Nr.1*,2,3 & $40 \mathrm{ml}$ & $2 \mu \mathrm{l}$ & $50 \mu \mathrm{M}$ \\
\hline Nr. 4 & $25 \mathrm{ml}$ & $3,12 \mu \mathrm{l}$ & $124 \mu \mathrm{M}$ \\
\hline Nr. 5 & $25 \mathrm{ml}$ & $6,25 \mu \mathrm{l}$ & $250 \mu \mathrm{M}$ \\
\hline Nr.6 & $25 \mathrm{ml}$ & $12,5 \mu \mathrm{l}$ & $500 \mu \mathrm{M}$ \\
\hline Nr. 7 & $25 \mathrm{ml}$ & $25 \mu \mathrm{l}$ & $1000 \mu \mathrm{M}$ \\
\hline
\end{tabular}

Tabelle 2.2: Zusammensetzung der Waschlösung: Tyrodelösung mit verschiedenen $\mathrm{Ca2}^{+}$-Konzentrationen

*Dem Behälter mit der Waschlösung Nr. 1wurde BDM (Konzentration $30 \mathrm{mM}$ ) zugegeben.

Nach sterilem Filtern wurden alle Lösungen bei Raumtemperatur auf einen pH-Wert von 7,54 eingestellt, bei $4^{\circ} \mathrm{C}$ gelagert und bei Gebrauch auf $37^{\circ} \mathrm{C}$ erwärmt. Das M199-Medium plus 6\% Albumin wurde bei $-20^{\circ} \mathrm{C}$ gelagert.

\subsubsection{Präparation des Kaninchenherzens und Isolierung der Kardiomyozyten}

\subsubsection{Betäubung der Kaninchen und Entnahme des Herzens}

Nach der Desinfizierung und dem Punktieren der Ohrvene mit einer Butterflykanüle wurden zur Antikoagulation 25-40 I.U. Heparin gespritzt. Anschließend wurde zur Betäubung der Kaninchen 0,1 g/2,5 ml Trapanal (Thiopental-Natrium), das in $10 \mathrm{ml} \mathrm{0,9 \%} \mathrm{NaCl}$ gelöst wurde, injiziert, bis die Corneal- und Schmerzreflexe aufgehoben waren. Es folgte die transdiaphragmale Eröffnung der Brusthöhle und die medioklavikulare Durchtrennung der Brustwand an beiden Seiten durch einen Zugang am Rippenbogen. Nach der Befreiung des Herzens vom Perikard und der Ablösung der Gefäße vom Bindegewebe sowie der vorsichtigen Durchtrennung der Aorta am Ende der Aorta ascendens wurde das Kaninchenherz aus dem Thorax entnommen. Das Herz wurde sofort mit kalter $\mathrm{Ca}^{2+}$-haltiger Tyrodelösung (Temperatur ca. $4^{\circ} \mathrm{C}$, siehe Tabelle 2.1 ) gespült.

\subsubsection{Isolierung der Ventrikelmyozyten}

Die Isolierung der Kaninchen-Kardiomyozyten basiert auf der enzymatischen Verdauungstechnik mit Collagenase, die sich als eine Standardmethode zur Isolierung von Kardiomyozyten etabliert hat (Tytgat 1994; Yasutake et al. 1996). Nach der Entnahme aus dem Thorax wurde das Herz sofort mit kalter $\mathrm{Ca}^{2+}$-haltiger Tyrodelösung gespült. 
Anschließend wurde es an eine Langendorff-Apparatur angeschlossen und durch die Aorta retrograd mit $37^{\circ} \mathrm{C}$ warmer, mit Sauerstoff begaster, $\mathrm{Ca}^{2+}$-haltiger Tyrodelösung für 5 Minuten perfundiert (Diiring 1996). Es folgte eine weitere 5-minütige Perfusion mit $\mathrm{Ca}^{2+}$ freier Tyrodelösung, um die $\mathrm{Ca}^{2+}$-abhängige interzelluläre Matrix aufzuweichen. Zur Verdauung des Myokards erfolgte anschließend eine 10-minütige Perfusion mit Collagenasehaltiger Enzymlösung. Die Myokardverdauung wurde mittels einer albuminhaltigen Stopplösung beendet. In Anwesenheit des Zytoprotektivums 2,3-Butandionmonoxim (BDM) (Mulieri et al. 1989) in der Stopplösung wurde das Herz unter sterilen Bedingungen an der Grenze von Vorhof und Ventrikel in ein ventrikuläres und ein atriales Myokard geteilt. Das verdaute Ventrikelmyokard wurde in einem mit Waschlösung Nr. 1 (siehe Tabelle 2.2) gefüllten Becherglas zerschnitten, und der Überstand wurde filtriert. In einem mit Waschlösung Nr. 2 gefüllten Becherglas wurde das Schneiden und Filtern wiederholt. Nach einer 6-10-minütigen Sedimentation wurde die gefilterte Suspension durch eine Reihe von Waschlösungen (Nr. 3 bis 7) mit steigenden $\mathrm{Ca}^{2+}$-Konzentrationen (von $50 \mu \mathrm{M}$ bis $1000 \mu \mathrm{M}$ ) wiederholt gewaschen und für 6-10 Minuten sedimentiert. Für den letzten Waschgang wurde modifiziertes M199 plus 6\% Albumin (500 ml modifiziertes M199 + Albumin Fraktion V 30 g) verwendet. Zum Schluss wurde nach einer langen Sedimentierung (10-20 Minuten) die letzte Suspension in M199-Medium bei $37^{\circ} \mathrm{C}$ bis zur Verwendung aufbewahrt.

\subsubsection{Isolierung der Vorhofmyozyten}

Das verdaute Vorhofgewebe wurde mit einer Schere zerschnitten und in der Vertiefung einer Zellkulturschale gesammelt. Alle 10 Minuten wurden mit einer Einmalpipette je 2-3 Tropfen der normalen Tyrodelösung zugegeben. Nach ca. 2-3 Stunden (je nach Größe der Gewebe) wurden die Gewebereste entfernt, dann wurden weitere 2-3-mal im Abstand von 10 Minuten je 3-4 Tropfen der normalen Tyrodelösung zugegeben. Auf diese Weise wurde die $\mathrm{Ca}^{2+}$ Konzentration der Zellsuspension schrittweise auf $2 \mathrm{mM}$ erhöht.

\subsection{Lösungen für das $\mathrm{NH}_{4} \mathrm{Cl}-\mathrm{Säurepuls-Protokoll}$}

\subsubsection{Hepes-gepufferte Tyrodelösung}

Für die $\mathrm{NH}_{4} \mathrm{Cl}$-Säurepuls-Versuche wurde Hepes-gepufferte Tyrodelösung als Basislösung verwendet. Sie hatte folgende Zusammensetzung: 


\begin{tabular}{lll} 
Stoff & Konzentration & Firma \\
\hline $\mathrm{NaCl}$ & $140 \mathrm{mM}$ & Merck \\
$\mathrm{KCl}$ & $5 \mathrm{mM}$ & Merck \\
$\mathrm{CaCl}$ & $2 \mathrm{mM}$ & Fluka \\
$\mathrm{MgCl}_{2}$ & $1 \mathrm{mM}$ & Merck \\
$\mathrm{HEPES}$ & $10 \mathrm{mM}$ & Sigma (\#H3375) \\
Glukose & $10 \mathrm{mM}$ & Merck
\end{tabular}

Tabelle 2.3: Zusammensetzung der Hepes-gepufferten Tyrodelösung für das Säurepuls- Protokoll

HEPES (2-(4-(2-Hydroxyethyl)-1-piperazinyl)-ethansulfonsäure) ist eine ProtonenPuffersubstanz. Die Summenformel ist $\mathrm{C}_{8} \mathrm{H}_{18} \mathrm{~N}_{2} \mathrm{O}_{4} \mathrm{~S}$ mit einem Molekulargewicht von 238.30 Dalton. Bei einer Säurekonstante von $\mathrm{pK}_{\mathrm{s}}=7,55$ (bei $25^{\circ} \mathrm{C}$ ) besitzt Hepes eine gute Pufferkapazität zwischen pH 6,8 - 8,2, d.h. im physiologischen pH-Bereich.

\subsubsection{Tyrodelösung mit $\mathrm{NH}_{4} \mathrm{Cl}$}

Tyrodelösung mit $\mathrm{NH}_{4} \mathrm{Cl}$ enthielt Hepes-gepufferte Tyrodelösung (siehe Tabelle 2.3) und zusätzlich $20 \mathrm{mM} \mathrm{NH}_{4} \mathrm{Cl}$.

\subsubsection{Tyrodelösung mit HOE642}

Tyrodelösung mit HOE642 (4-Isopropyl-3-methylsulphonylbenzoyl-guanidinmethansulphonat, Cariporide) enthielt Hepes-gepufferte Tyrodelösung (siehe Tabelle 2.3) und zusätzlich $6 \mu \mathrm{M}$ HOE642. HOE642 (Cariporide) ist ein selektiver Hemmstoff des NHE1 (Scholz et al. 1995; Strömer et al. 2000). Es wurde als wässrige Stammlösung mit einer Konzentration von $10^{-2} \mathrm{M}$ zubereitet.

\subsection{Geräte}

\begin{tabular}{|l|l|l|}
\hline \multicolumn{1}{|c|}{ Gerät } & \multicolumn{1}{c|}{ Firma } & Typ \\
\hline Argon- Ionen- Laser & VisiTech international (Sunderland UK) & 150m (50 mW ) \\
$\begin{array}{l}\text { Computer } \\
\begin{array}{l}\text { Aufnahme und } \\
\text { Analyseprogramm }\end{array}\end{array}$ & Gacintosh & G4-Prozessor, Betriebssystem Mac OS 9.0 \\
Filter & VisiTech international & QED Camera standalone, Version 1.6a58 \\
\hline
\end{tabular}




\begin{tabular}{|lll|}
\hline ICCD-Kamera & VisiTech international (Sunderland UK) & XR MEGA-10 \\
Konfokale Einheit & VisiTech international (Sunderland UK) & QLC 100 \\
Mikroskop & Nikon GmbH (Düsseldorf D) & Nikon Eclipse TE 2000U \\
Objektiv & Nikon GmbH (Düsseldorf D) & Nikon CFI S-Fluor 40x / 1.30 Oil \\
Rollenpumpe & Schütt Labortechnik (Göttingen D) & MC 360 \\
Mikromanipulator & Burleigh (Ontario Canada) & EXFO PCS 5000 \\
Stimulationseinheit & $\begin{array}{l}\text { SI Heidelberg (Heidelberg D) } \\
\text { Hugo Sachs Elektronic (March- }\end{array}$ & STIM6 \\
Superfusionseinheit & $\begin{array}{l}\text { Hugstetten D) } \\
\text { Technical Manufacturin }\end{array}$ & SH27B \\
Druckluftgefederter Tisch & Corporation(Peabody USA) & Micro-g 63-560 \\
\hline
\end{tabular}

Tabelle 2.4: Liste der verwendeten Geräte

\subsection{Versuchsaufbau}

\subsection{1 Überblick}

Der Versuchsaufbau ist in der Abbildung 2.1 schematisch dargestellt. Die Abbildung 2.2 zeigt ein Foto vom Hauptteil des Versuchsaufbaus: das Konfokalmikroskop und die Superfusionsapparatur mit den Vorratsgefäßen.

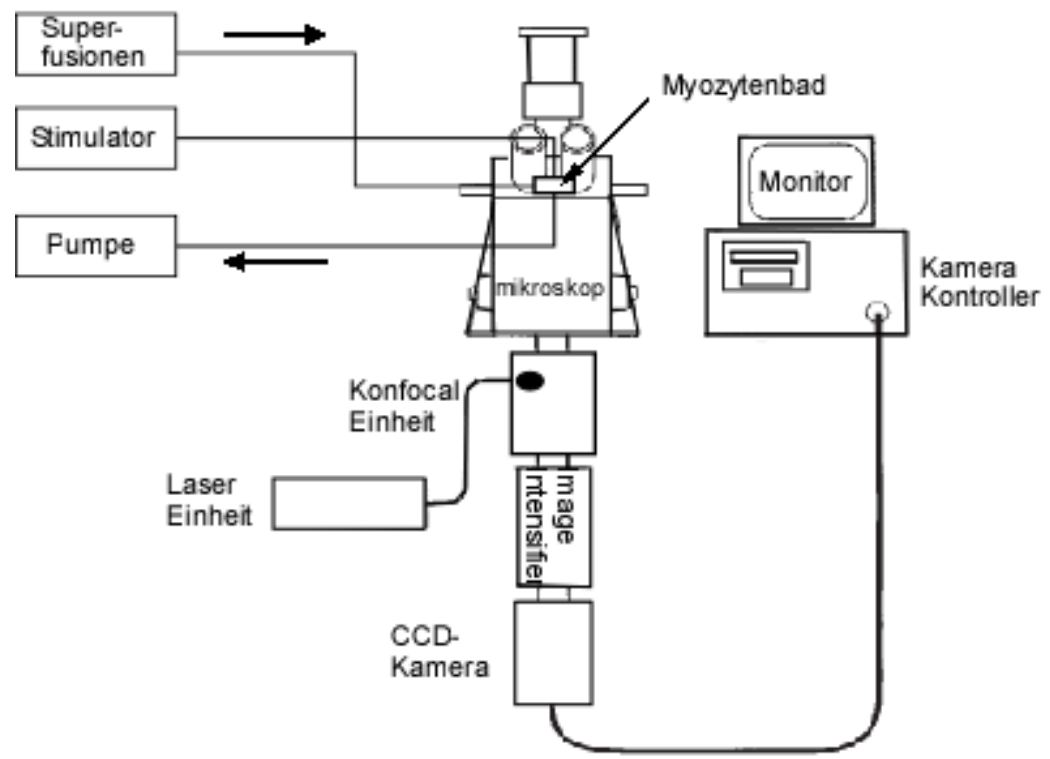

Abbildung 2.1: Versuchsaufbau (modifiziert nach Genka et al. 1999, Seite 201) 


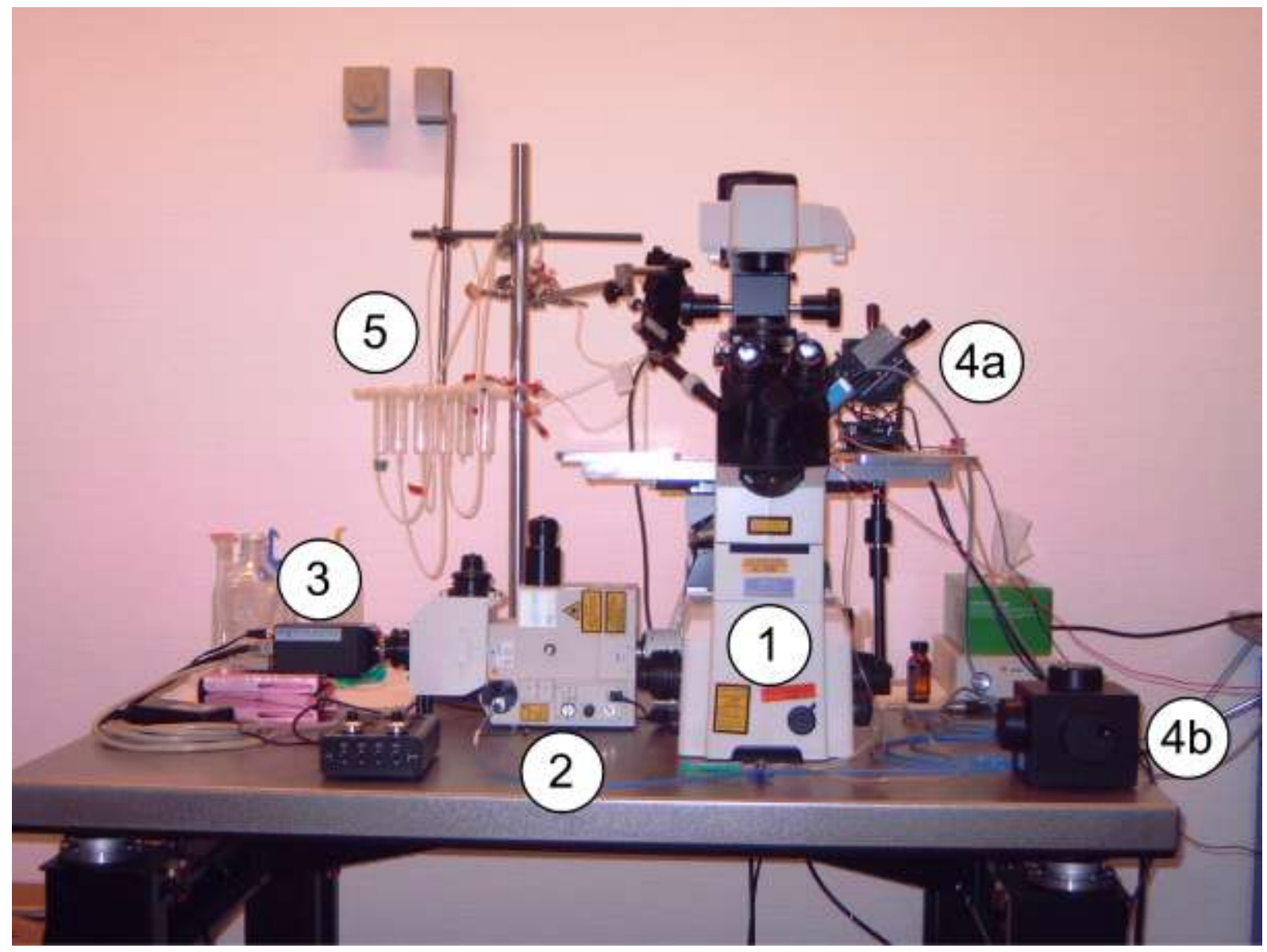

Abbildung 2.2: Das Nipkow-Scheiben-Konfokalmikroskop besteht aus folgenden Komponenten:

(1) Umkehrmikroskop; (2) konfokale Einheit (Nipkow-Scheibe); (3) ICCD-Kamera; (4) Mikromanipulator; (5) Superfusionsapparatur mit Vorratsgefäßen.

\subsubsection{Myozytenbad und Superfusionssystem}

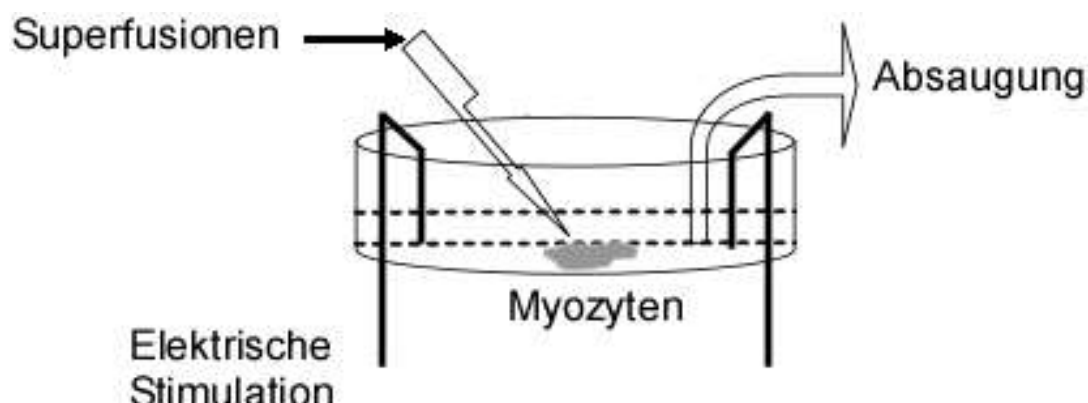

Abbildung 2.3: Myozytenbad 
Als Myozytenbad diente ein rundes Kulturschälchen (Durchmesser: 35 mm, Firma: WillCo Wells BV, Amsterdam, NL., Bestellnummer: HBSt-3522) mit einem Glasboden (Durchmesser: $22 \mathrm{~mm}$ ) (siehe Abbildung 2.3). Der Glasboden wurde laminiert, damit die Myozyten besser anheften und während der Messung ihre Position nicht verändern können. Dazu wurden $20 \mu \mathrm{l}$ Laminin (Maus-Laminin, 2,5 mg/ml, Firma: Tebu-Bio, Offenbach, Deutschland, Bestellnummer: 0172005) in $1 \mathrm{ml}$ Tyrodelösung verdünnt. Ein Tropfen dieser Lösung wurde auf den Boden des Schälchens aufgebracht und nach einer Stunde gegen die Zellsuspension ausgetauscht. Den Zellen wurde 30 Minuten Zeit zum Anheften gegeben. Anschließend wurde die Tyrodelösung abgesaugt und gegen Tyrodelösung mit dem $\mathrm{pH}-$ sensitiven Fluoreszenzfarbstoff Carboxy-SNARF-1 ausgetauscht.

Während der Messung wurden die Zellen kontinuierlich mit Tyrodelösung überspült. Die Superfusionsapparatur bestand aus 6 Vorratsgefäßen (handelsübliche $20 \mathrm{ml}$ Injektionsspritzen), Verbindungsschläuchen, Dreiwegehähnen und einem Auslass. Die Dreiwegehähne dienten als Ein- und Ausschalter der Superfusionslösungen. Die Versuchslösungen wurden getrennt in die entsprechenden Vorratsgefäße gefüllt, die an einem Stativ befestigt waren. Der Auslass der Superfusionsapparatur wurde ohne direkten Kontakt aber in unmittelbarer Nähe des untersuchten Kardiomyozyten positioniert, damit der Myozyt zum einen ständig mit frischer Lösung überspült wurde, und zum anderen ein schneller Lösungswechsel möglich war. Die Geschwindigkeit bzw. der Fluss, mit dem die Zellen überspült wurden, wurde anhand der Höhendifferenz zwischen den Vorratsgefäßen und dem Auslass der Superfusionsapparatur reguliert. Der Lösungsfluss betrug 2-3 ml/min. Damit war ein schneller Lösungswechsel innerhalb von etwa 1 Sekunde gewährleistet. Mit Hilfe einer Rollenpumpe und einem dünnen Schlauch wurde die Badlösung aus der Kulturschale abgesaugt.

\subsubsection{Das Nipkow-Scheiben-Konfokalmikroskop}

Seit den 1990er Jahren werden Laser-Scanning-Konfokalmikroskope mit einem Argon-IonenLaser mit 488 nm Lichtemission für die Anregung von Fluorescein-Derivaten verwendet.

\section{1)Prinzipien des Konfokalmikroskops}

Beim konventionellen Mikroskop kann alles Licht, sowohl das aus der Brennebene des Objektivs als auch das aus den optischen Ebenen darüber und darunter, auf den Detektor oder die menschlichen Augen gelangen. Es kommt zu Überlappensbildern der Brennebene und den Ebenen darüber und darunter. Die räumliche Auflösung ist daher eingeschränkt. 
Beim konfokalen Mikroskop wird Licht, das nicht aus der Brennebene des Objektivs stammt, durch eine Lochblende (sog. pinhole) im Emissionsstrahlengang ausgeblendet, so dass nur das Licht aus der Fokusebene den Detektor oder die Kamera erreicht. Dadurch wird die räumliche Auflösung deutlich erhöht, subzelluläre Details werden besser sichtbar. Die Schichtdicke der optischen Ebene wird durch den Durchmesser der Lochblende bestimmt. Je größer der Durchmesser, desto größer ist die Schichtdicke der optischen Ebene. Üblicherweise beträgt diese Schichtdicke etwa 0,5-1,0 $\mu \mathrm{m}$. Werden nacheinander mehrere Schichten in verschiedenen Fokusebenen des Objekts abgetastet und abgebildet, kann daraus eine dreidimensionale Rekonstruktion des Objektes durch den Computer erstellt werden.

2) Das Prinzip des Nipkow-Scheiben-Konfokalmikroskops

Da die konfokale Optik dafür sorgt, dass nur Licht aus der Brennebene des Objektivs zum Detektor gelangt, und das Sichtfeld durch die Lochblende auf einen Punkt beschränkt wird, erzeugt ein herkömmliches Konfokalmikroskop zunächst nur einen Bildpunkt. Um ein komplettes Bild des Objekts zu erhalten, muss das Objekt durch Lichtstrahlen Punkt für Punkt gerastert werden und dann am Computer zu einem dreidimensionalen Bild zusammengesetzt werden. Damit die Änderungen der verschiedenen Regionen des Objekts möglichst gleichzeitig aufgenommen werden, ist eine Abtastrate mit einer hohen Geschwindigkeit (mehrere Tausend Punkte pro Sekunde) mit Hilfe einer entsprechenden Kamera erforderlich.

Dazu ist die Abtastrate herkömmlicher Laser-Scanning-Konfokalmikroskope jedoch nicht ausreichend, und deshalb wurde das Nipkow-Scheiben-Konfokalmikroskop entwickelt. Basierend auf dem Prinzip des Konfokalmikroskops dient hier eine sog. Nipkow-Scheibe mit 20.000 Lochblenden dazu, konfokale Bilder zu generieren. Der Aufbau eines solchen Nipkow-Scheiben-Konfokalmikroskops ist in Abbildung 2.4 dargestellt. 


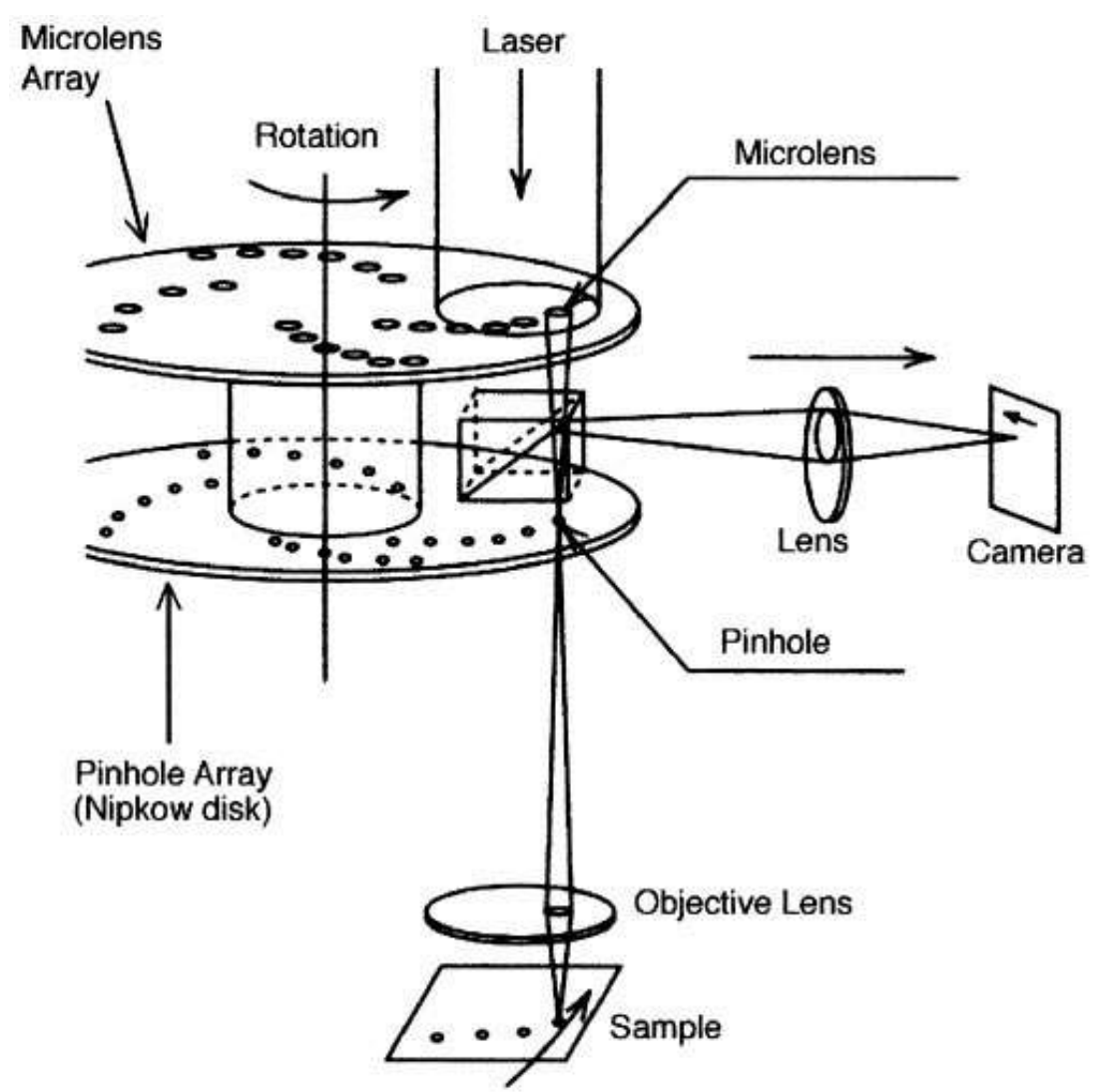

Abbildung 2.4: Schematisches Diagramm des Nipkow-Scheiben-Konfokalmikroskops (Ishida et al. 1999, Seite 2115) (Erklärung im Text)

Über der eigentlichen Nipkow-Scheibe befindet sich eine zweite Scheibe mit 20,000 Mikrolinsen (ca. $20 \mu \mathrm{m}$ Durchmesser) mit identischem Muster. Die Mikrolinsen dienen dazu, die Lichtausbeute zu erhöhen. Ohne die Scheibe mit den Mikrolinsen erreichen nur ca. 2\% des Laserlichts durch die Lochblenden das Objekt. Das ist zu wenig, um den FluoreszenzFarbstoff anzuregen. Durch die Mikrolinsen wird das Laserlicht genau durch die darunter liegenden Lochblenden fokussiert und die Transmission des Laserlichts wird von 2\% auf 40\% gesteigert. Dies ermöglicht die ausreichende Anregung des Fluoreszenz-Farbstoffs (Genka et al. 1999).

Wegen der auf den Nipkow-Scheiben liegenden mehreren Tausend Lochblenden sorgt ein Nipkow-Scheiben-Konfokalmikroskop für eine wesentlich schnellere Abtastrate. Erstens kann das darauf zurückgeführt werden, dass das Objekt gleichzeitig von tausenden Laserstrahlen gleichzeitig angeregt wird. Zweitens werden die Nipkow-Scheibe und die darüber liegende Scheibe mit den Mikrolinsen durch einen Motor mit 1,800 U/min gedreht (Siehe Abbildung 2.5). Eine $30^{\circ}$ Rotation ist ausreichend für eine komplette Abtastung einer Ebene (Genka et al. 1999). Dadurch entstehen zweidimensionale, konfokale Bilder in so schneller Folge, dass die Einzelbilder im Auge zu einem stehenden Bild des Objekts verschmelzen können. 


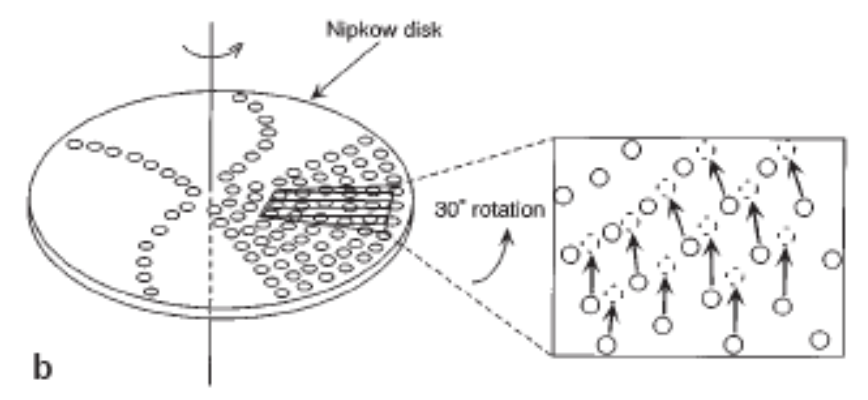

Abbildung 2.5: Schematische Darstellung des Nipkow-Prinzips

(Genka et al. 1999, Seite 201)

\subsubsection{ICCD-Kamera}

Für eine schnelle Aufnahme von zweidimensionalen, konfokalen Fluoreszenzbildern mit dem Nipkow-Scheiben-Konfokalmikroskop ist eine hochempfindliche und schnelle Kamera die wichtigste Voraussetzung. In dieser Arbeit wurde eine sog. Intensified Charge-Coupled Device (ICCD)-Kamera der Firma Stanford Photonics verwendet (Modell: XR-MEGA 10). Diese Kamera ermöglichte die Aufnahme von Bildern mit einer Frequenz von bis zu $120 \mathrm{~Hz}$. ICCD ist ein CCD-Bildsensor, der mit einem sog. Image Intensifier zur Erhöhung der Empfindlichkeit und einer schnellen elektronischen Steuerung der Belichtungszeit ausgestattet ist. Der Image Intensifier besteht aus 3 Funktionseinheiten: einer Photokathode, durch die die eintreffenden Photonen in Photo-Elektronen umgewandelt werden; einer Mikrokanalplatte, die die von der Photokathode kommenden Photo-Elektronen vermehrt, und einem Phosphorschirm, auf dem die verstärkten Photo-Elektronen wieder in Photonen zurückverwandelt werden. Durch diesen Prozess ist die Empfindlichkeit gegenüber einer herkömmlichen CCD-Kamera wesentlich erhöht. (http://www.iccd-camera.com/t-imageintensifier.html)

\subsection{Messung des intrazellulären $\mathrm{pH}-$ Wertes $\left(\mathrm{pH}_{\mathrm{i}}\right)$}

Der NHE-1 leistet durch den elektroneutralen Austausch intrazellulärer Protonen gegen extrazelluläre Natriumionen einen wesentlichen Beitrag zur Aufrechterhaltung der $\mathrm{pH}$ Homöostase der Herzmuskelzelle. Zur Bestimmung seiner Aktivität kann man $\mathrm{pH}_{\mathrm{i}^{-}}$ Änderungen - unter bestimmten experimentellen Bedingungen - messen. 
Seit 1979 die Messung des $\mathrm{pH}_{\mathrm{i}}$ durch einen $\mathrm{pH}$-empfindlichen, fluoreszierenden Farbstoff (6Carboxyfluorescein) von John Thomas zum ersten Mal in situ (Ehrlich-Ascites-Tumorzellen) durchgeführt wurde (Thomas et. al. 1979), wird diese Methode häufig verwendet. Sie gilt als die beste Methode zur Messung von schnellen Änderungen des absoluten $\mathrm{pH}_{\mathrm{i}}$-Wertes in isolierten Kardiomyozyten ohne Zellschädigung (Fröhlich und Wallert 1995). In der vorliegenden Arbeit wurde diese Methode zur Messung subzellulärer $\mathrm{pH}_{\mathrm{i}}$-Änderungen in Verbindung mit einem Konfokalmikroskop verwendet.

\subsubsection{Das Prinzip der Fluoreszenzmikroskopie}

\subsubsection{Fluoreszenz}

Fluoreszenz ist ein Effekt, der auf einem Elektronenübergang in den Fluorochrom-Molekülen basiert. Dieser Übergang ist ein Prozess, der bei Absorption und Emission von Photonen auftritt. Er wurde von dem polnischen Physiker Alexander Jablonski mit Hilfe seiner Energiediagramme (sog. Jablonski-Diagramme) im Jahr 1935 erklärt. Am Anfang des Prozesses werden die Fluorochrom-Moleküle mit Licht bestrahlt, dabei werden Anregungsphotonen von den Fluorochrom-Molekülen absorbiert. Die dadurch aufgenommene Energie führt dazu, dass die Energiezustände der Elektronen der Fluorochrom-Moleküle aus einem Grundzustand in einen angeregten Zustand angehoben werden. Bei dem danach folgenden Übergang in den Grundzustand wird die in sehr kurzer Zeit (etwa $10^{-8}$ Sekunden) freiwerdende Energie als Fluoreszenzphoton emittiert, das Fluoreszenzlicht oder Emissionslicht verursacht, welches z.B. mittels einer Kamera detektiert werden kann.

Bei der Absorption von Photonen und der Anregung der Fluorochrom-Moleküle verschwindet ein Teil der Energie durch Wechselwirkungen mit seiner Umgebung. Aus diesem Grund ist die Energie des emittierten Photons immer geringer als die des absorbierten Photons. Man spricht hierbei vom sog. Stokes-Shift bzw. der Stokes-Verschiebung, die zum ersten Mal im Jahr 1852 von Sir George Gabriel Stokes beschrieben wurde (Stokes, 1852). Da Licht mit kürzerer Wellenlänge und höherer Frequenz eine größere Energie als Licht mit längerer Wellenlänge und niedrigerer Frequenz hat, sind die Wellenlängen des emittierten Lichtes immer länger als die des absorbierten Lichtes.

\subsubsection{Fluoreszenzmikroskop}


Das Prinzip der Fluoreszenzmikroskopie beruht auf zwei Punkten: erstens wird das Emissionslicht von dem zu beobachtenden und mit einem bestimmten Fluoreszenzfarbstoff angefärbten Objekt durch ein Mikroskop detektiert (siehe 2.6.1.1). In der vorliegenden Arbeit diente das Konfokalmikroskop als ein Fluoreszenzmikroskop. Zweitens verändern Fluoreszenzfarbstoffe, die selektiv mit bestimmten Ionen reagieren können, in Abhängigkeit von der bestimmten Ionenkonzentration ihre Fluoreszenzeigenschaften, und es werden Änderungen in der Emission dementsprechend als Änderungen der intrazellulären Ionenkonzentration interpretiert.

\subsubsection{Der pH-sensitive Fluoreszenzfarbstoff Carboxy-SNARF-1}

\subsubsection{Eigenschaften des Farbstoffs}

In der vorliegenden Arbeit wurde der Farbstoff 5-(und-6)-Carboxy-SNARF®-1 (Invitrogen/Molelular Probes: C-1272) verwendet, der im Folgenden als Carboxy-SNARF-1 bezeichnet wird. Seine Summenformel ist $\mathrm{C}_{27} \mathrm{H}_{19} \mathrm{NO}_{6}$ mit einem Molekulargewicht von 453,45 Dalton (http://probes.invitrogen.com/handbook/)

Seine chemische Struktur ist in Abbildung 2.6 dargestellt (Whitaker et al. 1991).
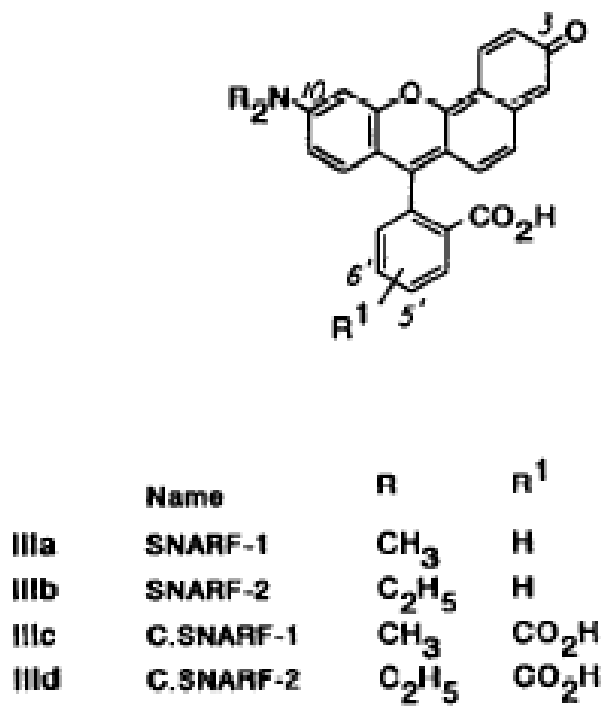

Abbildung 2.6: Struktur von 5-(und-6)-Carboxy-SNARF®

(Whitaker et al. 1991, Seite 332) 

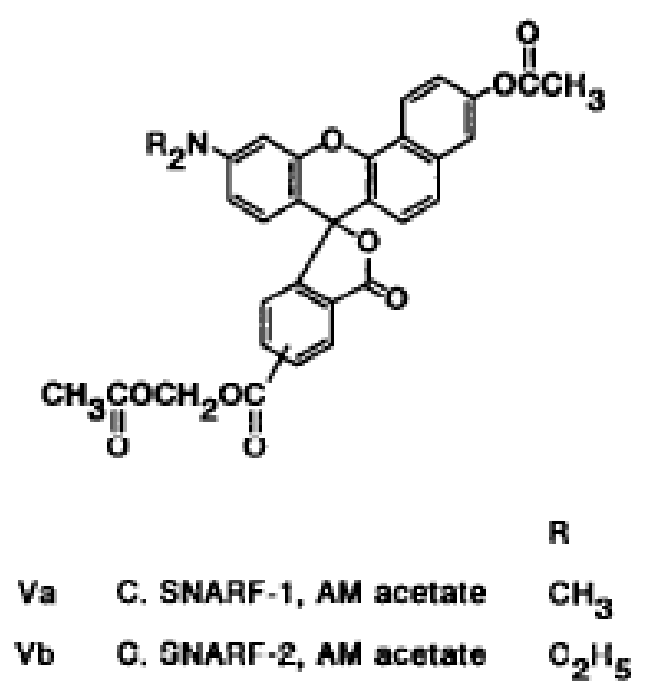

\begin{abstract}
Abbildung 2.7: Struktur von membranpermeablen SNAFL- und SNARF-Indikatoren (Whitaker et al. 1991, Seite 333).
\end{abstract}

Wie die meisten Fluorochrome hat Carboxy-SNARF-1 auch aromatische Ringstrukturen in einem System konjugierter Doppelbindungen. Der Farbstoff ist ein fluoreszierender $\mathrm{pH}-$ Indikator mit einem fast neutralen $\mathrm{pK}_{\mathrm{a}}$ von 7,3-7,4 (bei 37,0 ${ }^{\circ} \mathrm{C}$ ) (Fröhlich und Wallert 1995), der damit im physiologischen pH-Bereich liegt (Whitaker et al. 1991) und ungefähr dem pHWert der zu messenden Zellen entspricht. Deswegen ermöglicht er eine sensitive und zuverlässige Bestimmung des $\mathrm{pH}-$ Wertes.

Der Farbstoff wurde zur Beladung der Zellen in der lipophilen und damit membrangängigen Acetoxymethylester (AM)-Form Carboxy-SNARF-1-AM-Azetat verwendet (siehe Abbildung 14). Nach der Diffusion in den intrazellulären Raum wird dieser Ester durch zytosolische Esterasen hydrolysiert, wodurch die eigentlichen, hydrophilen Fluorochrom-Moleküle entstehen, welche die Zellmembran nicht mehr passieren können. Der Farbstoff verbleibt deswegen im intrazellulären Raum (Whitaker et al. 1991), während die nicht hydrolysierte, membrangängige AM-Form des Farbstoffs im extrazellulären Raum ausgewaschen werden kann.

Die deesterifizierten Fluorochrom-Moleküle besitzen freie Carboxylgruppen, die selektiv mit dem Ion $\mathrm{H}^{+}$reagieren können. Die Reaktion induziert eine Änderung der Struktur des Farbstoffs und bewirkt dadurch Veränderungen der optischen Eigenschaften (z.B. Verschiebungen der Exzitations- und Emissionsspektren), die eine fluorimetrische Bestimmung des intrazellulären $\mathrm{pH}-$ Wertes erlauben. 


\subsubsection{Anregungslicht und Filter für Carboxy-SNARF-1}

Als Anregungslicht für den Farbstoff wurde die 488 nm-Linie eines Argon-Ionen-Lasers verwendet. Da das Laserlicht für die Myozyten schädlich ist, wurde sowohl die Bestrahlungsstärke als auch die Bestrahlungszeit der Myozyten so gering wie möglich gehalten. Anfang der 1990er Jahre wurde diese Methode erstmals von Whitaker und Mitarbeitern angewendet (Whitaker et al. 1991).

In Abbildung 2.8 sind die Emissionsspektren von Carboxy-SNARF-1 bei Anregungslicht mit Wellenlängen von $488 \mathrm{~nm}, 514 \mathrm{~nm}$ und $534 \mathrm{~nm}$ dargestellt. Bei Anregungslicht mit einer Wellenlänge von $488 \mathrm{~nm}$ hat das Emissionsspektrum von Carboxy-SNARF-1 bei verschiedenen pH-Werten zwei Maxima. Bei pH 6,0 ist die Emissionsintensität bei etwa 580 $\mathrm{nm}$ maximal und nimmt mit steigendem $\mathrm{pH}$-Wert, d.h. abnehmender $\mathrm{H}^{+}$-Konzentration, stark ab. Im Gegensatz dazu erreicht die Emissionsintensität bei $640 \mathrm{~nm}$ ihr Maximum bei $\mathrm{pH} \geq$ 7,2, und nimmt mit steigendem pH-Wert zu (Buckler und Vaughan-Jones1990).

$\mathrm{Da}$ in den hier vorgestellten Experimenten der Schwerpunkt der Analysen im sauren pHBereich lag (Erholung des pH-Wertes nach einem Säurepuls), wurde die Carboxy-SNARF-1Fluoreszenz bei $580 \mathrm{~nm}$ gemessen mit Hilfe eines $580 \pm 40 \mathrm{~nm}$ Bandpass-Filters im Emissionsstrahlengang. 

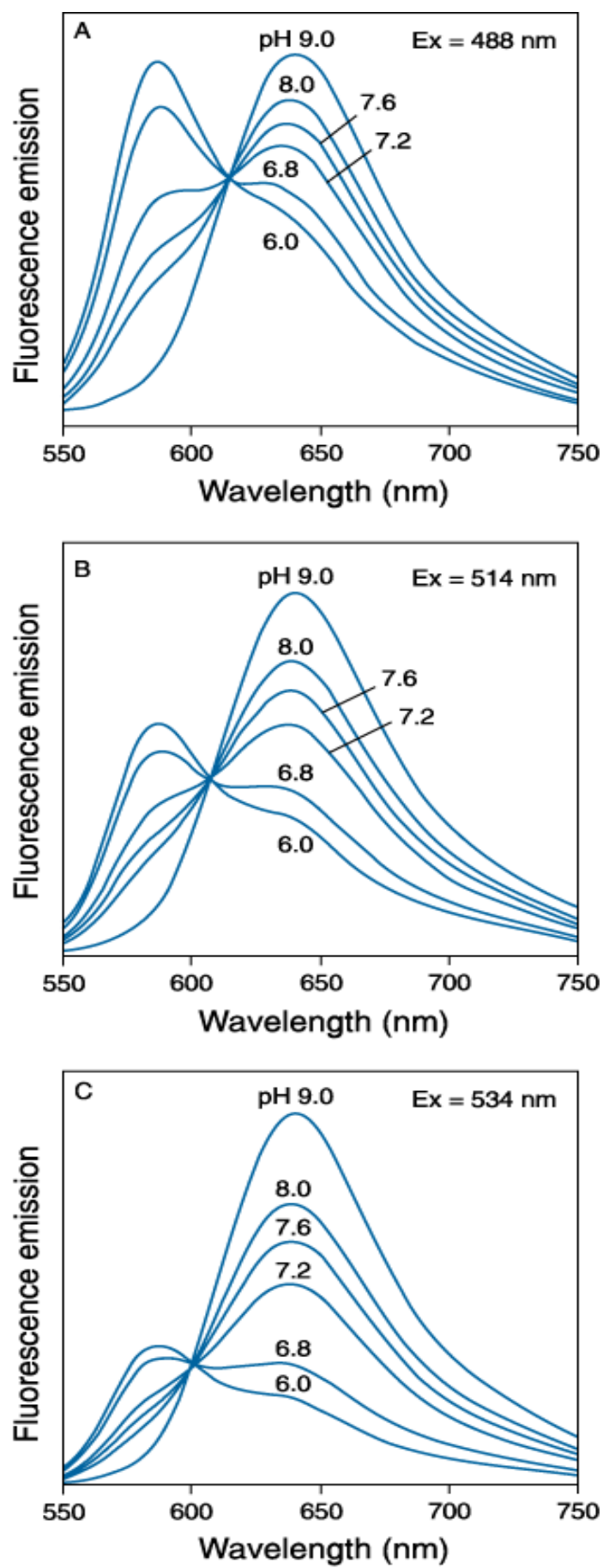

Abbildung 2.8: Die pH-abhängigen Emissionsspektren von Carboxy-SNARF-1 bei Anregungslicht mit Wellenlängen von $488 \mathrm{~nm}, 514 \mathrm{~nm}$ und $534 \mathrm{~nm}$

http:/www.invitrogen.com/site/us/en/home/References/Molecular-Probes-The-Handbook/pH-Indicators/ProbesUseful-at-Near-Neutral-pH.html\#head2 (Erklärung im Text)

\subsubsection{Herstellung der Farbstofflösung}

Zur Herstellung einer Farbstofflösung für die Beladung der Myozyten (s. u.) wurden $50 \mu \mathrm{g}$ Carboxy-SNARF-1-AM-Azetat in $20 \mu \mathrm{l}$ Pluronic (Invitrogen/Molecular Probes, Bestellnummer: P3000MP) gelöst und anschließend in $10 \mathrm{ml}$ Tyrodelösung verdünnt. Dadurch wurde eine Carboxy-SNARF-1-AM-Azetat-Lösung mit einer Konzentration von 9 
$\mu \mathrm{M}$ hergestellt. Pluronic ist ein Polyol mit einem Molekulargewicht von 567.55 Dalton. Es verbessert die Löslichkeit des Farbstoffs und trägt zu einer besseren Aufnahme und homogeneren Verteilung des Farbstoffes in den Zellen bei. Die Farbstofflösung wurde aliquotiert (10 x $1 \mathrm{ml}$ in Eppendorf-Reaktionsgefäßen) und im Gefrierschrank bei $-20^{\circ} \mathrm{C}$ aufbewahrt. Vor Versuchsbeginn wurde ein Aliquot frisch aufgetaut und gleich verwendet.

\subsubsection{Das $\mathrm{NH}_{4} \mathrm{Cl}-\mathrm{Säurepuls-Protokoll}$}

\subsubsection{Isolierung der Vorhof- und Ventrikelmyozyten}

(siehe 2.1)

\subsubsection{Ausplattierung der Myozyten}

Kulturschälchen mit einem Glasboden (WillCo, Amsterdam, Niederlande, Bestellnummer: HBSt-3522; Durchmesser: 35 mm; Innendurchmesser (Glas): $22 \mathrm{~mm}$ ) wurden laminiert. Dazu wurden $20 \mu \mathrm{l}(50 \mu \mathrm{g})$ Laminin (Maus-Laminin, Tebu-Bio, Offenbach, Bestellnummer: 0172005; Lagerung bei $-70^{\circ} \mathrm{C}$ ) in $1 \mathrm{ml}$ Tyrode verdünnt. Dann wurde mit einer Einmalpipette je 1 Tropfen dieser Laminin-Lösung auf den Boden der Kulturschälchen gegeben. Nach 60minütiger Inkubationszeit wurde die Laminin-Lösung abgesaugt. Es folgte die Ausplattierung von je einem Tropfen der Vorhof- bzw. Ventrikelmyozyten-Suspension. Den Zellen wurde 30 Minuten Zeit zum Anheften am Boden der Kulturschälchen gegeben.

\subsubsection{Beladung der Zellen mit dem Farbstoff}

Die Carboxy-SNARF-1-AM-Azetat-Lösung ( $9 \mu \mathrm{M}$; s.o.) wurde zuerst unter Lichtschutz aufgetaut. Nach der Absaugung der Tyrodelösung vom Boden der Kulturschälchen (die angehefteten Myozyten verblieben am Boden der Schälchen), wurde jeweils 1 Tropfen der Carboxy-SNARF-1-AM-Azetat-Lösung auf die Myozyten gegeben. Es folgte eine 20-30minütige Inkubationszeit. Anschließend wurde die Farbstofflösung abgesaugt, die Zellen wurden mit Tyrodelösung 2-3 Mal gewaschen und verblieben schließlich in der Tyrodelösung. Es wurde noch einmal etwa 15 Minuten gewartet, bevor die Messungen begannen, um ausreichend Zeit zur kompletten Deesterifizierung des Farbstoffs zu gewährleisten 


\subsubsection{4 $\mathrm{pH}_{\mathrm{i}}-$ Messungen}

Während der Beladung der Zellen mit dem Farbstoff wurde die Messapparatur vorbereitet. Anschließend wurde ein Kulturschälchen mit den mit Farbstoff beladenen Zellen auf dem Tisch des Umkehrmikroskops positioniert. Für die pH-Messungen wurden nur solche Zellen ausgewählt, die ausreichend mit Farbstoff beladen und deutlich quergestreift waren und die bei elektrischer Stimulation $(0,5 \mathrm{~Hz})$ über Platinelektroden im Bad rhythmisch kontrahierten. Der Auslass der Superfusionsapparatur wurde so positioniert, dass sich die untersuchte Zelle im laminaren Superfusionsstrom $(2-3 \mathrm{ml} / \mathrm{min})$ befand. Während des gesamten Versuchs wurde die Zelle mit Tyrodelösung aus einem der Vorratsgefäße überspült. Lösungswechsel wurden manuell mit Hilfe der 3-Wege-Ventile hinter dem Auslass der Vorratsbehälter vorgenommen. Ein Lösungswechsel dauerte etwa 1 s. Alle Versuche wurden bei Raumtemperatur $\left(22-25^{\circ} \mathrm{C}\right)$ durchgeführt.

Es wurden zwei Versuchsprotokolle durchgeführt (siehe Tabelle 2.5 und 2.6). Bei dem ersten Protokoll wurden die Zellen zuerst 5 Minuten mit normaler, Hepes-gepufferter Tyrodelösung (1. Schritt) überspült, anschließend 5 Minuten mit $\mathrm{NH}_{4} \mathrm{Cl}$-haltiger Tyrodelösung (2. Schritt), und zum Schluss noch einmal mehrere Minuten mit normaler Tyrodelösung (3. Schritt). Beim zweiten Protokoll wurden die Zellen zwischen dem 2. und 3. Schritt zusätzlich mit HOE642haltiger Tyrodelösung überspült. HOE642 (Cariporid) ist ein Hemmstoff des NHE1(siehe Einleitung 1.5).

\begin{tabular}{|l|l|l|l|}
\hline Schritt & 1. Schritt & 2. Schritt & 3. Schritt \\
\hline Lösung & Tyrodelösung & Tyrodelösung mit $\mathrm{NH}_{4} \mathrm{Cl}$ & Tyrodelösung \\
\hline Dauer & 5 Minuten & 5 Minuten & 10 Minuten \\
\hline
\end{tabular}

Tabelle 2.5: $\mathrm{NH}_{4} \mathrm{Cl}-\mathrm{Säurepuls-Protokoll}$

\begin{tabular}{|l|l|l|l|l|}
\hline Schritt & 1. Schritt & 2. Schritt & 3. Schritt & 4. Schritt \\
\hline Lösung & Tyrodelsg & Tyrodelsg mit $_{\text {NH }} \mathrm{Cl}$ & Tyrodelsg mit HOE642 & Tyrodelsg \\
\hline Dauer & 5 Minuten & 5 Minuten & 6 Minuten & 10 Minuten \\
\hline
\end{tabular}

Tabelle 2.6: $\left.\mathrm{NH}_{4} \mathrm{Cl}-\mathrm{Säurepuls-Protokoll} \mathrm{mit} \mathrm{HOE642} \mathrm{(6} \mu \mathrm{M}\right)$

Hepes als pH-Puffer hat in diesen Versuchen eine wichtige Bedeutung. Es ist bekannt (siehe Einleitung 1.2.1), dass nicht nur der NHE, sondern auch der NBC an der Regulierung der intrazellulären $\left[\mathrm{H}^{+}\right]$bei Azidose beteiligt ist. Um allein die Aktivität des NHE zu messen, muss also die Aktivität des NBC ausgeschaltet werden. Dazu wurde eine Bikarbonat-freie, 
Hepes-gepufferte Lösung verwendet. Da Bikarbonat $\left(\mathrm{HCO}_{3}{ }^{-}\right)$das Substrat des NBC ist, ist der NBC ohne Bikarbonat in der Lösung vollständig gehemmt. Damit wird eine $\mathrm{pH}_{\mathrm{i}}$ - $\mathrm{Regulierung}$ bei Azidose im intrazellulären Raum praktisch ausschließlich durch den NHE hervorgerufen.

Um die Aktivität des NHE zu messen, sollte diese möglichst groß sein. Wie bereits erwähnt, ist der NHE-1 hauptsächlich bei einer intrazellulären Azidose aktiviert (Aronson et al. 1982; Counillon und Pouysségur 1995). Bei einem normalen intrazellulären pH-Wert von etwa 7,2 hingegen ist die NHE1-Aktivität gering. Daher war es notwendig, eine Azidose in den Kardiomyozyten hervorzurufen, um die NHE1-Aktivität verlässlich zu bestimmen. Zur Auslösung der intrazellulären Azidose wurde die schwache Base $\mathrm{NH}_{4} \mathrm{Cl}$ (Ammoniumchlorid) als Zusatz zur extrazellulären Tyrodelösung verwendet (Roos und Boron 1981; LagadicGossmann et al. 1992; Balnave und Vaughan-Jones 2000). Diese Technik beruht auf folgendem Mechanismus: Extrazelluläres $\mathrm{NH}_{4}^{+}$dissoziiert $\mathrm{zu} \mathrm{NH}$ und $\mathrm{H}^{+}\left(\mathrm{NH}_{4}^{+} \leftrightarrow \mathrm{NH}_{3}^{+}\right.$ $\mathrm{H}^{+}$). Ungeladene $\mathrm{NH}_{3}$-Moleküle können durch die Zellmembran diffundieren, wo sie mit intrazellulären $\mathrm{H}^{+}$-Ionen reagieren und so den $\mathrm{pH}_{\mathrm{i}}$-Wert erhöhen. Dieser Prozess verläuft bis zur Gleichgewichteinstellung von $\mathrm{NH}_{3}$ im intra- und extrazellulären Raum. Wird das extrazelluläre $\mathrm{NH}_{4}{ }^{+}$entfernt, diffundiert $\mathrm{NH}_{3}$ aus der Zelle nach außen und führt so zur plötzlichen Freisetzung von $\mathrm{H}^{+}$-Ionen und einer Absenkung des $\mathrm{pH}_{\mathrm{i}}$. Auf diese Weise lässt sich durch das Auswaschen einer extrazellulären, $\mathrm{NH}_{4}{ }^{+}$-haltigen Lösung eine intrazelluläre Azidose herbeiführen (siehe Abbildung 2.9).
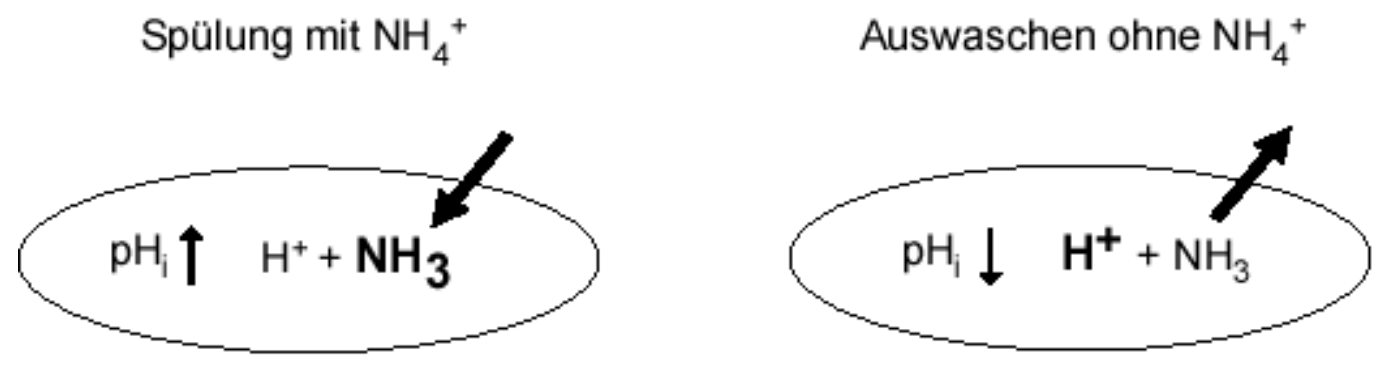

Abbildung 2.9: Prinzip der $\mathrm{pH}_{\mathrm{i}}$-Änderungen durch Gabe und Entzug von $\mathrm{NH}_{4} \mathrm{Cl}$-haltiger Tyrodelösung.

Während die Zellen mit den Lösungen überspült wurden, wurde der in den Zellen befindliche pH-Farbstoff mit Laserlicht der Wellenlänge $488 \mathrm{~nm}$ angeregt und die emittierte Fluoreszenz bei $580 \pm 40 \mathrm{~nm}$ gemessen. Änderungen des $\mathrm{pH}_{\mathrm{i}}$-Wertes sind entweder als Änderungen der normalisierten Fluoreszenz, $F / F_{0}$, angegeben $\left(F_{0}\right.$ ist die Fluoreszenz zu Versuchsbeginn) oder 
als geeichte $\mathrm{pH}_{\mathrm{i}^{-}}$Werte (s. u.). Ein Abfall von $\mathrm{F} / \mathrm{F}_{0}$ zeigt dabei einen Abfall von $\left[\mathrm{H}^{+}\right]_{\mathrm{i}}$ an (Anstieg des $\mathrm{pH}_{\mathrm{i}}$-Wertes, Alkalose), ein Anstieg von $\mathrm{F} / \mathrm{F}_{0}$ entsprechend einen Anstieg von $\left[\mathrm{H}^{+}\right]_{\mathrm{i}}\left(\right.$ Abfall des $\mathrm{pH}_{\mathrm{i}}$-Wertes, Azidose).

\subsubsection{Kalibrierung des Carboxy-SNARF-1-Fluoreszenzsignals}

\subsubsection{Prinzip}

Die primär erhobenen Daten waren keine $\mathrm{pH}_{\mathrm{i}}-\mathrm{Werte}$, sondern lediglich Änderungen der Carboxy-SNARF-1-Fluoreszenz. Die Eigenschaften von Carboxy-SNARF-1 ändern sich im Inneren von Kardiomyoyzten (verglichen mit den in-vitro-Eigenschaften des Farbstoffs). Um aus dem Rohwert der Carboxy-SNARF-1-Fluoreszenz den korrekten pH-Wert zu berechnen, war daher eine in situ-Kalibrierung erforderlich. Dazu wurde die sog. Nigericin-Methode angewandt, die darauf beruht, dass das $\mathrm{K}^{+} / \mathrm{H}^{+}$-Ionophor Nigericin in kurzer Zeit zu einem fast vollständigen Ausgleich der $\left[\mathrm{H}^{+}\right]$(und der $\left[\mathrm{K}^{+}\right]$) zwischen Extra- und Intrazellulärraum führt. Dies bedeutet, dass man mit einer extrazellulären Lösung, die Nigericin enthält, den intrazellulären $\mathrm{pH}-$ Wert vorgeben kann. Zur Vermeidung eines störenden Einflusses eines transmembranären $\left[\mathrm{K}^{+}\right]$-Gradienten auf den $\mathrm{pH}_{\mathrm{i}}$ ist eine hohe $\left[\mathrm{K}^{+}\right]$(ca. $150 \mathrm{mM}$; entspricht der intrazellulären $\left[\mathrm{K}^{+}\right]$) in der extrazellulären Lösung erforderlich. Unter diesen Bedingungen entspricht das Fluoreszenzsignal der überspülten Zellen dem jeweiligen $\mathrm{pH}$-Wert der extrazellulären Lösung (Thomas et al. 1979; Blank et al. 1992). In den hier vorgestellten Untersuchungen war in den Eichlösungen neben Nigericin $(10 \mu \mathrm{M})$ zusätzlich das $\mathrm{K}^{+}$Ionophor Valinomycin $(10 \mu \mathrm{M})$ enthalten (s. u.), um einen Ausgleich der $\left[\mathrm{K}^{+}\right]$der intra- und extrazellulären Lösung $\mathrm{zu}$ erleichtern und somit auch eine schnellere und möglichst vollständige Angleichung von intra- und extrazellulärem $\mathrm{pH}$ (über Nigericin) zu gewährleisten.

\subsubsection{Durchführung}

Zur Kalibrierung wurden die Kardiomyozyten zuerst mit Carboxy-SNARF-1 beladen, wie oben beschrieben. Es folgte eine Überspülung der Zellen zunächst mit Tyrodelösung und anschließend mit den Eichlösungen, die pH-Werte von 6,1, 6,5, 7,0, 7,5 und 8,0 aufwiesen. Die Eichlösungen hatten folgende Zusammensetzung (mM): $140 \mathrm{KCl}, 1 \mathrm{MgCl}_{2}, 0,5$ EGTA, 20 Hepes, 0,01 Nigericin, 0,01 Valinomycin. Bei pH 6,1 und 6,5 wurde $20 \mathrm{mM}$ Pipes anstelle von $20 \mathrm{mM}$ Hepes als pH-Puffer verwendet. Nigericin und Valinomycin wurden den Eichlösungen aus Stammlösungen $\left(10^{-2} \mathrm{M}\right.$ in Ethanol bzw. $10^{-2} \mathrm{M}$ in DMSO) zugesetzt. 


\subsubsection{Eichkurven}

Aus den Fluoreszenzintensitäten und den entsprechenden $\mathrm{pH}$-Werten wurden drei Eichkurven erstellt, jeweils für die ganze Zelle, den Kern sowie den Perinukleus. Mit Hilfe dieser Eichkurven konnten die Fluoreszenzwerte in die $\mathrm{pH}_{\mathrm{i}}-$ Werte bzw. die $\left[\mathrm{H}^{+}\right]_{\mathrm{i}}$ umgerechnet werden.

\subsection{Auswertungen}

\subsubsection{Einschlusskriterien}

Es wurden nur solche Zellen gemessen und analysiert, 1) die ausreichend mit dem Farbstoff beladen waren, 2) die eine sichtbare Querstreifung aufwiesen, 3) die als Antwort auf elektrische Stimulation rhythmisch kontrahierten (dies wurde vor der eigentlichen Messung überprüft, während der Messung war die Stimulation ausgeschaltet), 4) die während des Versuchs nicht spontan kontrahierten und 5) die nach dem Überspülen mit den verschiedenen Lösungen ihre Position nicht veränderten.

\subsubsection{Analyse der pH-Änderungen in verschiedenen subzellulären Regionen der Kardiomyozyten}

Zur Untersuchung der subzellulären Änderungen des pH-Wertes nach Gabe und Entzug von $\mathrm{NH}_{4} \mathrm{Cl}$ wurden SNARF-Fluroreszenzänderungen in den folgenden Regionen der Zellen gemessen und analysiert: 1) in der gesamten Zelle, 2) im Zellkern (Nukleus), 3) im perinukleären Bereich (Perinukleus), 4) im subsarkolemmalen Bereich, und zwar auf jeder Seite der Zelle, und 5) im zentralen Zytoplasma (Zentrum) (siehe Abbildung 2.10). 

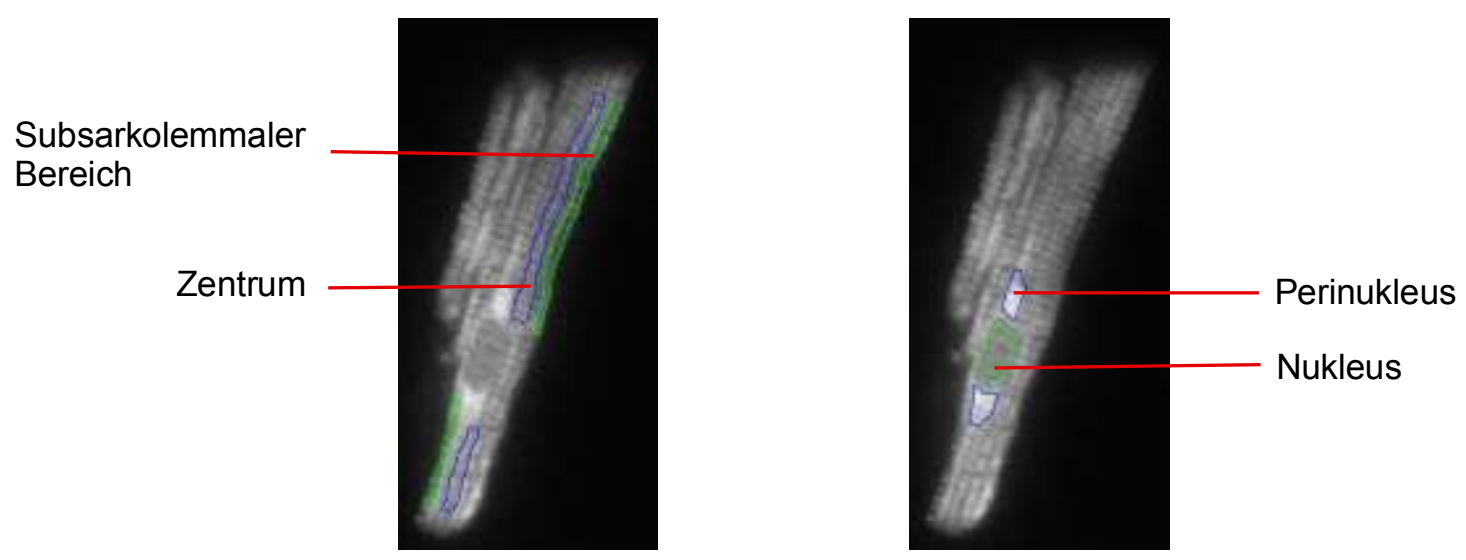

Abbildung 2.10: gemessene Regionen von Myozyten

\subsubsection{Berechnung der Zeitkonstante $\tau$, des $\mathrm{pH}_{\mathrm{i}}$ und von $\mathrm{J}_{\mathrm{H}}$ bei $\mathrm{pH} 6,9$}

Die Änderungen der Fluoreszenzintensitäten in den verschiedenen Regionen wurden mit Hilfe des Computerprogramms "Igor" ausgewertet. Durch die Eichkurven, die durch die Kalibrierung des Carbox-SNARF-1-Fluoreszenzsignals jeweils für ganze Zellen, den Zellkern sowie den Perinukleus aus den Fluoreszenzintensitäten und den entsprechenden $\mathrm{pH}-\mathrm{Werten}$ erstellt wurden, wurden die Rohdaten der Zellen von Fluoreszenzintensitäten $\mathrm{F} / \mathrm{F}_{0}$ zu den $\mathrm{pH}_{\mathrm{i}}$ Werten bzw. der $\left[\mathrm{H}^{+}\right]_{\mathrm{i}}$ umgerechnet. Die Fluoreszenzintensitäten der subsarkolemmalen und zentralen zytoplasmatischen Regionen wurden anhand der Eichkurve für ganze Zellen zu den $\mathrm{pH}_{\mathrm{i}}$-Werten umgerechnet, die Fluoreszenz des Zellkerns anhand der Eichkurve für den Zellkern und die Fluoreszenz des Perinukleus anhand der Eichkurve für den Perinukleus.

$\mathrm{J}_{\mathrm{H}}$ ist die Rate des Protonen-Efflux (in $\mathrm{mM} / \mathrm{min}$ ). $\mathrm{J}_{\mathrm{H}}$ bei $\mathrm{pH}_{\mathrm{i}} 6,9$ bedeutet die Rate des Protonen-Efflux bei $\mathrm{pH}_{\mathrm{i}}$ 6,9 in der Bikarbonat-freien, HEPES-gepufferten Lösung. Die Rate stellt ein quantitatives Maß für die Aktivität des NHE1 bei einer intrazellulären Azidose dar (Lagadic-Gossmann et al. 1992). Nach Bevensee und Boron (1995) ist die Änderung des $\mathrm{pH}_{\mathrm{i}}$ nach einer intrazellulären Azidose $\left(\mathrm{d}_{\mathrm{pHi}} / \mathrm{dt}\right)$ von der Geschwindigkeit des $\mathrm{H}^{+}$-Efflux durch die Membran und der intrazellularen Puffer-Kapazität $\left(\beta_{\mathrm{i}}\right)$ abhängig:

$$
\mathrm{d}_{\mathrm{pHi}} / \mathrm{dt}=\mathrm{J}_{\mathrm{H}} / \beta_{\mathrm{i}}
$$

Danach ist $\mathrm{J}_{\mathrm{H}}$ : 


$$
\mathrm{J}_{\mathrm{H}}=\mathrm{d}_{\mathrm{pHi}} / \mathrm{dt} * \beta_{\mathrm{i}}
$$

Die intrazelluläre Puffer-Kapazität $\left(\beta_{\mathrm{i}}\right)$ wurde von Zaniboni und Mitarbeitern in KaninchenKardiomyozyten bestimmt. Sie beträgt ca. $30 \mathrm{mM} / \mathrm{pH}$-Einheit bei $\mathrm{pH}$ 6.9. (Zaniboni et al. 2003b)

\subsubsection{Statistik}

Die erhobenen Daten sind als arithmetischer Mittelwert \pm mittlerer Fehler des Mittelwertes (standard error of mean, S.E.M.) angegeben und dargestellt. Der Vergleich zwischen 2 Gruppen erfolgte mittels Analyse über den Student-T-Test. Bei einem Vergleich mehrerer Gruppen wurde eine Varianzanalyse (ANOVA) gefolgt von einem Newman-Keuls-Test durchgeführt. Unterschiede zwischen den Gruppen wurden bei einer Irrtumswahrscheinlichkeit von $\mathrm{P}<0.05$ als signifikant angesehen. 


\subsection{Western-Immunoblot-Analyse der NHE1-Expression}

Um die Expression des NHE-1 im Vorhof- und Ventrikelmyokard zu untersuchen, wurden Immunoblots (Western Blots) durchgeführt.

\subsubsection{Material}

\subsubsection{Puffer}

\begin{tabular}{|c|c|c|c|}
\hline Puffer & Substanz & Konzentration & Firma (Bestellnummer) \\
\hline Homogenisationspuffer & $\begin{array}{l}\text { NP } 40 \text { (IPEGAL CA-630) } \\
\text { Glycerol } \\
\mathrm{NaCl} \\
\text { Tris-HCl pH=7, } 4 \\
\text { NaF } \\
\text { Natriumorthovanadat } \\
\text { Natriumpyrophosphat } \\
\text { B-Glycerophosphat } \\
\text { EDTA pH=8 } \\
\text { EGTA pH=7 } \\
\text { Aprotinin }(\mathrm{MW}=651,2) \\
\text { Leupeptin }(\mathrm{MW}=475,6) \\
\text { Pepstatin A }(\mathrm{MW}=685,9) \\
\text { PMSF }(\mathrm{MW}=174,2)\end{array}$ & $\begin{array}{l}1 \% \\
10 \% \\
137 \mathrm{mM} \\
20 \mathrm{mM} \\
20 \mathrm{mM} \\
1 \mathrm{mM} \\
1 \mathrm{mM} \\
50 \mathrm{mM} \\
10 \mathrm{mM} \\
1 \mathrm{mM} \\
4 \mu \mathrm{g} / \mathrm{ml} \\
4 \mu \mathrm{g} / \mathrm{ml} \\
4 \mu \mathrm{g} / \mathrm{ml} \\
1 \mathrm{mM}\end{array}$ & $\begin{array}{l}\text { Sigma (\#1-3021) } \\
\text { Sigma (\#G-5516) } \\
\text { Fluka (\#71381) } \\
\text { Roth (\#4855.2) } \\
\text { Sigma (\#S-7920) } \\
\text { Sigma (\#S-6508) } \\
\text { Sigma (\#S-6422) } \\
\text { Sigma (\#G-6251) } \\
\text { Sigma (\#E-5134) } \\
\text { Sigma (\#E-0369) } \\
\text { Sigma (\#A3428) } \\
\text { Sigma (\#L-2023) } \\
\text { Sigma (\#P-4265) } \\
\text { Sigma (\#P-7626) }\end{array}$ \\
\hline Transferpuffer & $\begin{array}{l}\text { Tris-Base } \\
\text { Glyzin } \\
\text { Methanol }\end{array}$ & $\begin{array}{l}32,5 \mathrm{mM} \\
192 \mathrm{mM} \\
20 \%\end{array}$ & $\begin{array}{l}\text { Roth }(\# 4855.2) \\
\text { Roth }(\# 3908.3) \\
\text { Merck }(\# 1.06012 .1000)\end{array}$ \\
\hline Laufpuffer & $\begin{array}{l}\text { Tris-Base } \\
\text { Glyzin } \\
\text { SDS }\end{array}$ & $\begin{array}{l}25 \mathrm{mM} \\
192 \mathrm{mM} \\
3,5 \mathrm{mM}\end{array}$ & $\begin{array}{l}\text { Roth (\#4855.2) } \\
\text { Roth (\#3908.3) } \\
\text { Sigma (\#39575) }\end{array}$ \\
\hline TBST-Puffer & $\begin{array}{l}\mathrm{NaCl} \\
\text { Tris-Base } \\
\text { Tween }\end{array}$ & $\begin{array}{l}50 \mathrm{mM} \\
20 \mathrm{mM} \\
0,1 \%\end{array}$ & $\begin{array}{l}\text { Fluka (\#71381) } \\
\text { Roth (\#4855.2) } \\
\text { Sigma (\#P-1379) }\end{array}$ \\
\hline 4x Lämmli-Puffer & $\begin{array}{l}\text { EGTA } \\
\text { SDS } \\
\text { Tris, pH 6, } 8 \\
\text { DTT } \\
\text { Glycerol } \\
\text { 1\% Bromophenolblau }\end{array}$ & $\begin{array}{l}16 \mathrm{mM} \\
4 \% \\
40 \mathrm{mM} \\
16 \mathrm{mM} \\
2 \% \\
0,05 \%\end{array}$ & $\begin{array}{l}\text { Sigma (\#E-0369) } \\
\text { Sigma (\#39575) } \\
\text { Roth (\#4855.2) } \\
\text { Sigma (\#D9163) } \\
\text { Sigma (\#G-5516) } \\
\text { Sigma (\#A3650) }\end{array}$ \\
\hline
\end{tabular}

Tabelle 2.7: Puffer für die Western-Blot-Analyse 


\subsubsection{Antikörper für die Western-Blot-Analyse}

Zum Nachweis des NHE-1 wurde ein polyklonaler Antikörper der Fa. Santa Cruz Biotechnology (Santa Cruz, CA, USA) verwendet: NHE-1 (T-20) (Bestellnummer: sc-16096). Der Antikörper stammt aus Ziegen und ist gegen eine Peptidsequenz des N-Terminus des humanen NHE1 gerichtet. Als sekundärer Antikörper wurde ein polyklonaler, MeerrettichPeroxidase-konjugierter Anti-Ziege-IgG-Antikörper aus Eseln eingesetzt ((Invitrogen/Molecular Probes, Bestellnummer: A-21467). Zur Normalisierung der NHE-1Expression wurde die Expression der Glycerinaldehyd-3-Phosphat-Dehydrogenase (GAPDH) und von Calsequestrin bestimmt. Zum Nachweis von GAPDH und Calsequestrin wurde ein monoklonaler Anti-GAPDH-Antikörper aus Mäusen (Bio Trend, Köln, Bestellnummer: 4699-9555) bzw. ein polyklonaler Anti-Calsequestrin-Antikörper aus Kaninchen (Dianova, Bestellnummer: PA1-913 ABR) verwendet.

\section{Antikörper}

Anti-NHE1 (T-20)

Anti-Ziege-IgG

Anti-GAPDH

Anti-Calsequestrin

Anti-Maus-IgG

Anti-Kaninchen-IgG

\section{Verdünnung in $0,5 \% \mathrm{MP} 10 \mathrm{ml}$}

1: 3000

1: 3000

1: 6000

1: 20000

$1: 10000$

$1: 10000$

\section{Firma (Bestellnummer)}

Santa Cruz Nr. sc-16096

Invitrogen Nr. A-21467

Bio Trend Nr.4699-9555

Dianova Nr. PA1-913

Amersham NA 931

Amersham NA 934

Tabelle 2.8: Antikörper und deren Verdünnungen für das Western Blotting

\subsubsection{Humanmyokard}

Die Bestimmung der Proteinexpression des NHE-1 mittels der Western-Blot-Methode fand am humanen Myokard statt. Es wurden 12 Proben aus insuffizientem Ventrikelmyokard $(\mathrm{EF} \leq$ 40\%) untersucht, die aus zwei Gruppen von 6 Patienten mit DCM (= dilatative Kardiomyopathie) und 6 Patienten mit ICM (= ischämische Kardiomyopathie) bestanden, sowie 6 Proben aus nicht-insuffizientem Ventrikelmyokard. Das insuffiziente Ventrikelmyokard wurde im Rahmen von Herztransplantationen aus den explantierten Herzen gewonnen. Die Herztransplantationen wurden in der Klinik für Thorax- und Kardiovaskularchirurgie am Herz- und Diabeteszentrum des Landes NRW, Bad Oeynhausen (Leitung: Prof. Dr. Reiner Körfer) durchgeführt. Nach der Entnahme aus dem Thorax wurden die explantierten Herzen sofort in Sauerstoff-gesättigte und gekühlte BDM-haltige Lösung überführt. Dann wurde im Labor nach leichter Säuberung das Herz in Vorhof- und Vertrikelgewebe getrennt und bei $-80^{\circ} \mathrm{C}$ eingefroren. Die nicht-insuffizenten Ventrikelproben 
stammten von Spenderherzen, die für eine Transplantation vorgesehen waren, die aber dann kurzfristig aus technischen Gründen nicht verwendet werden konnten.

Außerdem wurden Untersuchungen zur NHE1-Expression an 10 humanen Vorhofproben durchgeführt. Die Proben stammten von Patienten mit Sinusrhythmus und normaler Pumpfunktion $(\mathrm{EF}>50 \%)$. Die nicht-insuffizienten Vorhofmyokard-Proben fielen bei Bypass- oder Klappenersatz-Operationen der Abteilung Thorax-, Herz- und Gefäßchirurgie (Leiter: Prof. Dr. Friedrich Schöndube) im Universitätsklinikum Göttingen aus operationstechnischen Gründen an.

Alle Patienten, von deren Herzen Gewebeproben verwendet wurden, haben vor der Operation ihr schriftliches Einverständnis für die Verwendung der Gewebeproben erklärt. Durch die Ethikkommission des Universitätsklinikums Göttingen wurden die Vorhaben zur Entnahme von Gewebeproben zu wissenschaftlichen Zwecken genehmigt (AZ 31/9/00 und 21/10/00).

\subsubsection{Durchführung des Western Blots}

\subsubsection{Proben-Homogenisierung}

Für jede Homogenisierung wurde der Homogenisierungsspuffer (HP) frisch angesetzt, und alle Schritte wurden unter Kühlung (auf Eis) durchgeführt. Die bei $-80^{\circ} \mathrm{C}$ gelagerten Myokardproben wurden auf Eis aufgetaut und dann jeweils in einen MikroHandhomogenisator mit $50 \mu \mathrm{HP}$ gegeben und mechanisch homogenisiert. Danach wurde die Suspension bei $4^{\circ} \mathrm{C}$ für 3 Minuten bei $8000 \mathrm{~g}$ zentrifugiert und der Überstand in ein 1,5 ml Eppendorf-Gefäß dekantiert. Das Pellet wurde in $50 \mu \mathrm{l}$ HP weiter homogenisiert und anschließend wieder bei $4^{\circ} \mathrm{C}$ für 3 Minuten bei $8000 \mathrm{~g}$ zentrifugiert. Diese Schritte wurden 23 Mal wiederholt. Anschließend folgte eine Zentrifugation der gesammelten Überstände für 5 Minuten bei 14000 g. Zum Schluss wurde der Überstand bei $-80^{\circ} \mathrm{C}$ aufbewahrt.

\subsubsection{Proteinbestimmungen}

Die Proteinkonzentration der Homogenate wurde nach der Methode von Lowry (Lowry et al. 1951) mittels Photometrie bei $562 \mathrm{~nm}$ quantitativ bestimmt. Das Prinzip der Methode beruht auf einer Oxidation des Proteins durch $\mathrm{Cu}^{2+}$. Es entsteht ein Protein-Cu${ }^{+}-\mathrm{Komplex}$, der mit dem Reagenz Bicinchonin einen violett-blauen, wasserlöslichen Komplex bildet. Es gibt einen direkten, proportionalen Zusammenhang zwischen der Violettfärbung und der Proteinkonzentration. Die Violettfärbung kann dann mittels Photometrie ausgewertet werden. 
Aus einem bekannten Standard (Rinderserumalbumin) wurde eine Eichgerade erstellt und eine lineare Regression durchgeführt. Anschließend wurden damit die Proteingehalte der Homogenate quantifiziert.

\subsubsection{Blotten}

Der Western Blot gliederte sich in drei Arbeitsschritte. Im ersten Schritt wurden die Proteine der Homogenate in einem Gel elektrophoretisch aufgetrennt. Im zweiten Schritt wurden die Proteine auf eine Nitrozellulosemembran transferiert und immobilisiert. Diese Methode wurde von Towbin et al. (1979) entwickelt. Sie hat den Vorteil, dass die transferierten Proteine für die Antigen-Antikörper-Reaktionen auf der Membran leichter zugänglich sind als im Gel. Der dritte Schritt war der immunchemische Nachweis der Proteine durch Antikörper. Dazu wurde eine sog. "Sandwich"-Methode mit 2 Antikörpern angewendet, bei der der an das elektrotransferierte Protein gebundene proteinspezifische primäre Antikörper von einem Zweitantikörper gebunden wird, der an das Enzym Meerrettichperoxidase gekoppelt ist. Durch eine Enzymreaktion, bei der Lumineszenz entsteht, kann dann das Protein nachgewiesen werden.

\subsection{Elektrophorese}

Die Proteine wurden nach der Methode von Lämmli (Lämmli 1970) in einem Trenngel (10\%) vertikal elektrophoretisch aufgetrennt. Dazu wurden jeweils $20 \mu \mathrm{g}$ Proteinen einer Probe mit dem gleichen Volumen 4x Lämmli-Puffer vermischt, mit HP auf das gleiche Volumen gebracht und in die Taschen des SDS-Trenngels (10\%) pipettiert. Als Molekulargewichtsmarker diente ein Proteinstandard (BioRad Precision Protein Standard, Ca\#\# 161-0372; Control 92619; 10-250 kD). Danach erfolgte die Elektrophorese in einer mit Laufpuffer gefüllten Elektrophoresebox bei 20-30 mA und 70-100 Volt. Die Elektrophorese dauerte ca. 1 Stunde, bis die blaue Lauffront am unteren Rand der Glasplatten herausgelaufen war.

\subsection{Elektrotransfer}

Die elektrophoretisch aufgetrennten Proteine wurden anschließend im sog. SemidryVerfahren vom Trenngel durch Filterpapiere auf eine Nitrozellulose-Membran transferiert. Das Transfersandwich war wie folgt zusammengesetzt: Kathode, 2 Filterpapiere (Whatman), Gel, Nitrozellulose-Membran, 2 Filterpapiere, Anode. Die Elektrophoresebox wurde in Eis gestellt. Der Transfer fand bei $150 \mathrm{~mA}$ und $4^{\circ} \mathrm{C}$ über Nacht statt. 


\subsection{Immunchemischer Nachweis der Proteine}

Um später unspezifische Bindungen zu vermeiden, wurde die Nitrozellulose-Membran nach dem Elektroblotten mit Blockpuffer (5\%igem fettfreiem Milchpulver in 1xTBST (Trisgepufferte Salzlösung)) bei $4^{\circ} \mathrm{C}$ für 3 Stunden inkubiert. Nach 2 x 10-minütigem Waschen mit 1xTBST erfolgte die Inkubation mit dem primären Antikörper (NHE-1 (T-20), Verdünnung 1:3000) bei $4^{\circ} \mathrm{C}$ über Nacht. Zum Auswaschen der ungebundenen Antikörper wurde die Nitrozellulose-Membran anschließend mit 1xTBST für 3 x 10 Minuten gewaschen. Danach wurde die Inkubation mit dem zweiten Antikörper (Anti-Ziege-IgG, Verdünnung 1:3000) bei Raumtemperatur für 60 Minuten durchgeführt. Es folgte erneut ein 4 x 10-minütiges Waschen in $1 \mathrm{xTBST}$.

Zur Normalisierung der Proteinexpression des NHE-1 wurden außerdem GAPDH und CS nachgewiesen. Dazu erfolgte eine 30-minütige Inkubation mit dem jeweiligen Primärantikörper, und anschließend eine 60-minütige Inkubation mit Anti-Maus-IgG (für GAPDH) oder Anti-Kaninchen-IgG (für CS) mit den oben genannten Verdünnungen (siehe Tabelle 9).

\subsubsection{Filmen}

Zur Quantifizierung der Proteine wurde eine Chemolumineszenzreaktion mit ECL-Lösung $\left(E C L=\right.$ enhanced chemoluminescence; Luminol: $\mathrm{H}_{2} \mathrm{O}_{2}=1: 1$ gemischt $)$ ausgelöst. Während einer 4-5-minütigen Inkubation der Membran mit der ECL-Lösung erfolgte eine Oxidation des Luminols durch das an die sekundären Antikörper gekoppelte Enzym Meerrettichperoxidase. Dadurch entsteht Chemolumineszenz. Zur Detektierung der Chemolumineszenz wurde ein Film belichtet und entwickelt. Der Schwärzungsgrad der Proteinbanden entspricht der Proteinkonzentration. Bei den hier durchgeführten Experimenten wurden meistens 15 Sekunden Belichtungszeit benötigt.

\subsubsection{Analyse und Auswertung}

Zur Analyse wurden die Banden mit einem CCD-Kamerasystem (Multiimager, AlphaInnotech) digitalisiert und quantifiziert. Unterschiede zwischen den Gruppen wurden mit der Varianzanalayse (ANOVA) gefolgt von einem Newman-Keuls-Test überprüft. Eine Irrtumswahrscheinlichkeit von $\mathrm{P}<0.05$ wurde als signifikant betrachtet. 


\section{Ergebnisse}

\subsection{Die Beladung der Kardiomyozyten mit carboxy-SNARF-1}

Abbildung 3.1 zeigt als Beispiel zwei isolierte Ventrikelmyozyten von Kaninchen. Die Bilder wurden nach einer 25-minütigen Beladung mit dem pH-Farbstoff carboxy-SNARF-1/AMAzetat $(9 \mu \mathrm{M})$ gemacht. Die Zellgröße liegt innerhalb des normalen Bereiches (Tytgat 1994):

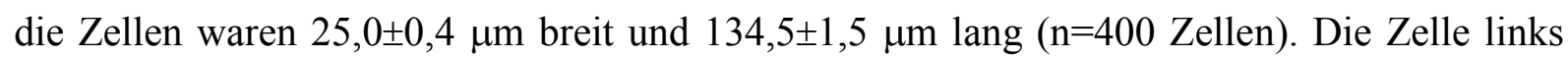
(siehe Abbildung 3.1) zeigt eine inhomogene SNARF-Fluoreszenz. Man erkennt darin einen ovalen, dunklen Bereich, der einem Zellkern entspricht (N, Nukleus). Der Kern wird zu beiden Seiten eingefasst von Bereichen mit sehr starker Fluoreszenz, die als perinukleäre Regionen (P) bezeichnet werden. Die perinukleären Regionen erhöhter Fluoreszenz entsprechen vermutlich den perinukleären Mitochondrien, da die gleichen Regionen auch sichtbar werden, wenn man die FAD-abhängige Autofluoreszenz der Mitochondrien misst. Das übrige Zytosol ist durch geringere Fluoreszenz gekennzeichnet. Nicht alle Myozyten zeigten eine derartige Verteilung der SNARF-Fluoreszenz. Ein Teil der Myozyten war beladen wie die Zelle auf der rechten Seite (siehe Abbildung 3.1). In diesen Myozyten war ein Zellkern nicht erkennbar. Stattdessen zeigte sich ein regelmäßiges, gitternetzartiges Muster mit Bereichen höherer und niedrigerer Fluoreszenz. Die Bereiche höherer Fluoreszenz entsprechen dabei den Mitochondrien, die Bereiche niedrigerer Fluoreszenz dem Zytosol.

Zur Auswertung der SNARF-Fluoreszenz wurde das über die gesamte Zelle gemittelte Fluoreszenzsignal analysiert. Außerdem wurden Fluoreszenzsignale aus dem subsarkolemmalen (SS) und zentralen Bereich der Zelle miteinander verglichen. In Myozyten, die eine inhomogene SNARF-Fluoreszenz aufwiesen, wie sie in Abbildung 3.1 (links) zu sehen ist, wurden neben dem Ganzzellsignal und den Fluoreszenzsignalen aus dem subsarkolemmalen (SS) und zentralen Bereich der Zelle auch das Fluoreszenzsignal des Zellkerns und der perinukleären Region analysiert. 

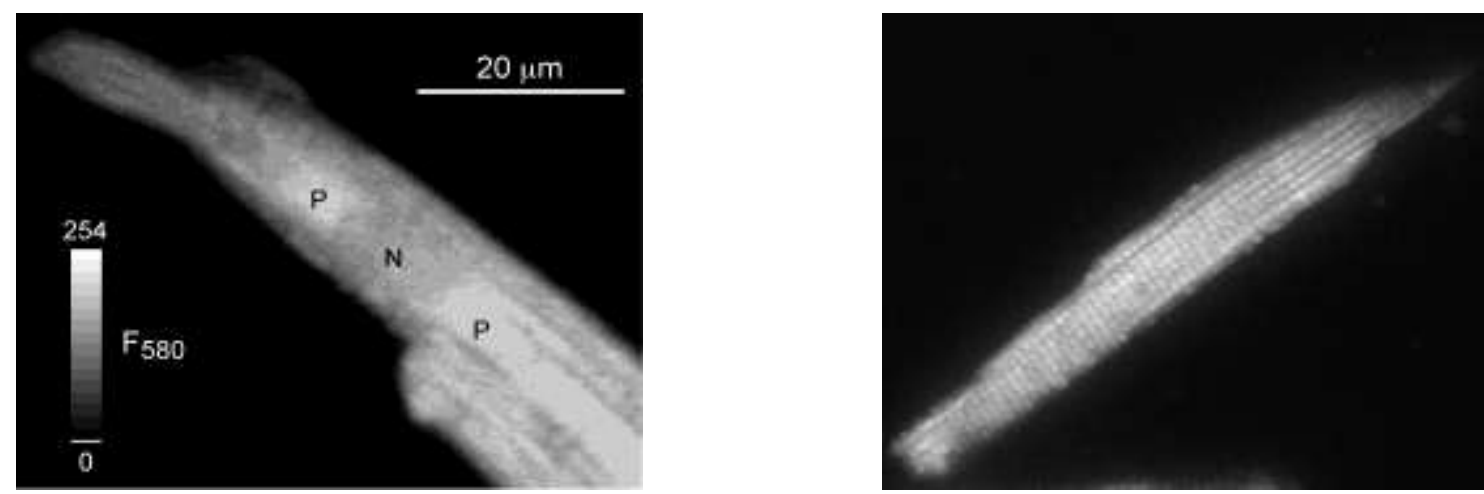

Abbildung 3.1: Bilder von Ventrikelmyozyten, die mit carboxy-SNARF-1 beladen waren.

Links: Inhomogenitäten in der SNARF-Fluoreszenz. N, Nukleus; P, Perinukleärer Bereich. Rechts: Zelle ohne sichtbaren Kern.

\subsection{Kalibrierung}

\subsubsection{Ganze Zelle}

Änderungen des $\mathrm{pH}_{\mathrm{i}}$ werden als Änderungen der carboxy-SNARF-1-Fluoreszenz sichtbar. Die $\mathrm{pH}_{\mathrm{i}}$ - Änderungen können entweder als normierte Fluoreszenzänderungen $\left(\mathrm{F} / \mathrm{F}_{0}\right.$, dabei stellt $\mathrm{F}_{0}$ den Fluoreszenzwert zu Beginn der Messung dar) quantifiziert werden oder als geeichte $\mathrm{pH}_{\mathrm{i}}$-Werte. Abbildung 3.2A zeigt eine Eichkurve, die durch in situ Kalibrierung (siehe Material und Methoden 2.5.4) in 16 Ventrikelmyozyten gewonnen wurde. Die Messwerte sind Mittelwerte der über die gesamte Zelle gemittelten Fluoreszenzänderungen. Die Kurve stellt einen Fit der Hill-Gleichung an die Messwerte dar. Der $\mathrm{K}_{0.5}$-Wert beträgt 102 $\mathrm{nM} \mathrm{H}^{+}(\mathrm{pH}=6,99)$. Aus der Eichkurve läßt sich außerdem der $\mathrm{pH}_{\mathrm{i}^{-}}$Wert der Ventrikelzellen unter Ruhebedingungen, d.h. zu Beginn der Messungen $\left(\mathrm{F} / \mathrm{F}_{0}=1,0\right)$, ablesen. Er beträgt 7,2 . 

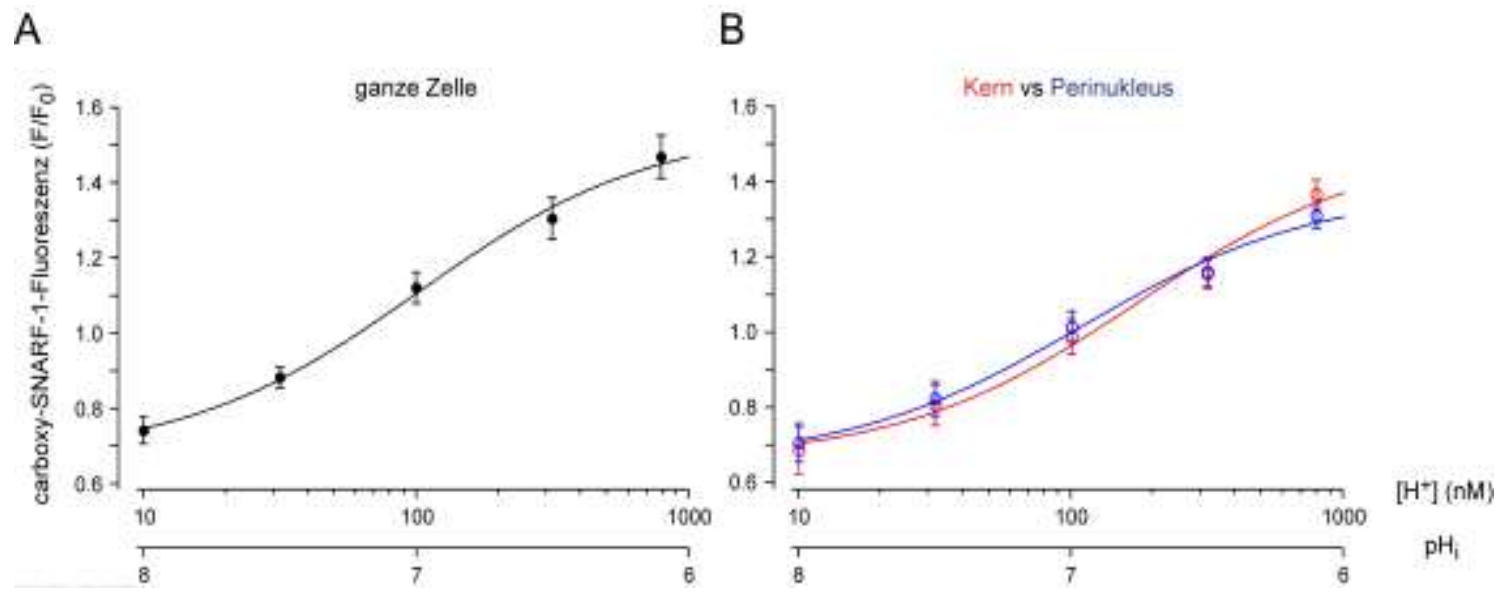

Abbildung 3.2: Eichkurven für die carboxy-SNARF-1-Fluoreszenz in Ventrikelmyozyten.

A. Eichkurve für die SNARF-Fluoreszenz gemittelt über die gesamte Zelle $(n=16)$. B. Eichkurven für die lokale SNARF-Fluoreszenz im Zellkern (rot) und in der perinukleären Region (blau) ( $n=10)$.

\subsubsection{Zellkern und perinukleäre Region}

In Zellen, in denen der Zellkern und die perinukleäre Region deutlich unterschiedlich gefärbt waren (z.B. Abbildung 3.1 links), wurden zudem Eichkurven für lokale Fluoreszenzänderungen im Zellkern und in der benachbarten perinukleären Region ermittelt $(\mathrm{n}=10)$. Diese Eichkurven sind in Abb. 3.2B dargestellt (rot: Zellkern; blau: Perinukleus). Die beiden Kurven zeigen einen ähnlichen Verlauf. Die $\mathrm{K}_{0.5}$-Werte betragen $173 \mathrm{nM} \mathrm{H}^{+}(\mathrm{pH}=$ 6,76) für den Zellkern und $109 \mathrm{nM} \mathrm{H}^{+}(\mathrm{pH}=6,96)$ für den Perinukleus. Für die $\mathrm{pH}-$ Werte unter Ruhebedingungen ergeben sich Werte von 6,9 für den Kern und $\sim 7,0$ für die perinukleäre Region.

\subsection{Die Bestimmung der NHE-1-Aktivität mit Hilfe des $\mathrm{NH}_{4} \mathrm{Cl}$-Säurepuls- Protokolls}

\subsubsection{Globale pH-Änderungen eines Kaninchen-Ventrikelmyozyten während eines $\mathrm{NH}_{4} \mathrm{Cl}-\mathrm{Säurepuls-Protokolls}$}

In Abbildung 3.3 A sind die originalen Bilder eines Kaninchen-Ventrikelmyozyten während eines $\mathrm{NH}_{4} \mathrm{Cl}$-Säurepuls-Protokolls zu sehen. Dabei befand sich die Zelle zum Zeitpunkt von Bild a in normaler Tyrodelösung (der 1. Schritt), zum Zeitpunkt von Bild b, dem Zeitpunkt 
der niedrigsten Fluoreszenz, in Tyrodelösung mit $\mathrm{NH}_{4} \mathrm{Cl}(20 \mathrm{mM})$ (der 2. Schritt), und zu den Zeitpunkten von Bild c, d und e wieder in normaler Tyrodelösung (der 3. Schritt) (siehe Tabelle 3.1).

\begin{tabular}{|l|l|l|l|}
\hline Schritt & 1. Schritt & 2. Schritt & 3. Schritt \\
\hline Lösung & Tyrodelösung & Tyrodelösung mit $\mathrm{NH}_{4} \mathrm{Cl}$ & Tyrodelösung \\
\hline Dauer & 5 Minuten & 5 Minuten & 10 Minuten \\
\hline Abbildung & A & b & c, d, e \\
\hline
\end{tabular}

\section{Tabelle 3.1: $\mathrm{NH}_{4} \mathrm{Cl}-\mathrm{Säurepuls-Protokoll}$}

Auf den Bildern kann man erkennen, dass die Zelle nach Gabe von $\mathrm{NH}_{4} \mathrm{Cl}$ (20 mM, Bild b) deutlich dunkler wurde als in normaler Tyrodelösung (Bild a). Unmittelbar nach dem Auswaschen des $\mathrm{NH}_{4} \mathrm{Cl}$ dagegen (Bild c) wurde die Zelle deutlich heller als auf den Bildern a und b. Im weiteren Verlauf des Auswaschens wurde die Fluoreszenz der Zelle dann langsam wieder normal (Bilder d und e) und kehrte zum Ausgangszustand zurück. Die Änderungen der Fluoreszenz der Zelle sind in Abbildung 3.3B dargestellt. Abbildung 3.3C zeigt die Änderungen des $\mathrm{pH}_{\mathrm{i}}$-Wertes, der anhand der Eichkurve errechnet wurde. Die Gabe von 20 $\mathrm{mM} \mathrm{NH} \mathrm{N}_{4} \mathrm{Cl}$ verursachte einen deutlichen Abfall der Fluoreszenz und einen Anstieg des $\mathrm{pH}$ Wertes; nach dem Auswaschen des $\mathrm{NH}_{4} \mathrm{Cl}$ erfolgten ein deutlicher Anstieg der Fluoreszenz und ein Abfall des $\mathrm{pH}$-Wertes. Dies ist darauf zurückzuführen, dass $\mathrm{NH}_{3}$ in die Zelle diffundiert und Protonen bindet. Das Auswaschen des $\mathrm{NH}_{4} \mathrm{Cl}$ führt dann zu einer Azidifizierung, da nun $\mathrm{NH}_{3}$ aus der Zelle diffundiert und die zuvor gebundenen Protonen freigesetzt werden (siehe Material und Methoden 2.5.3.4). 

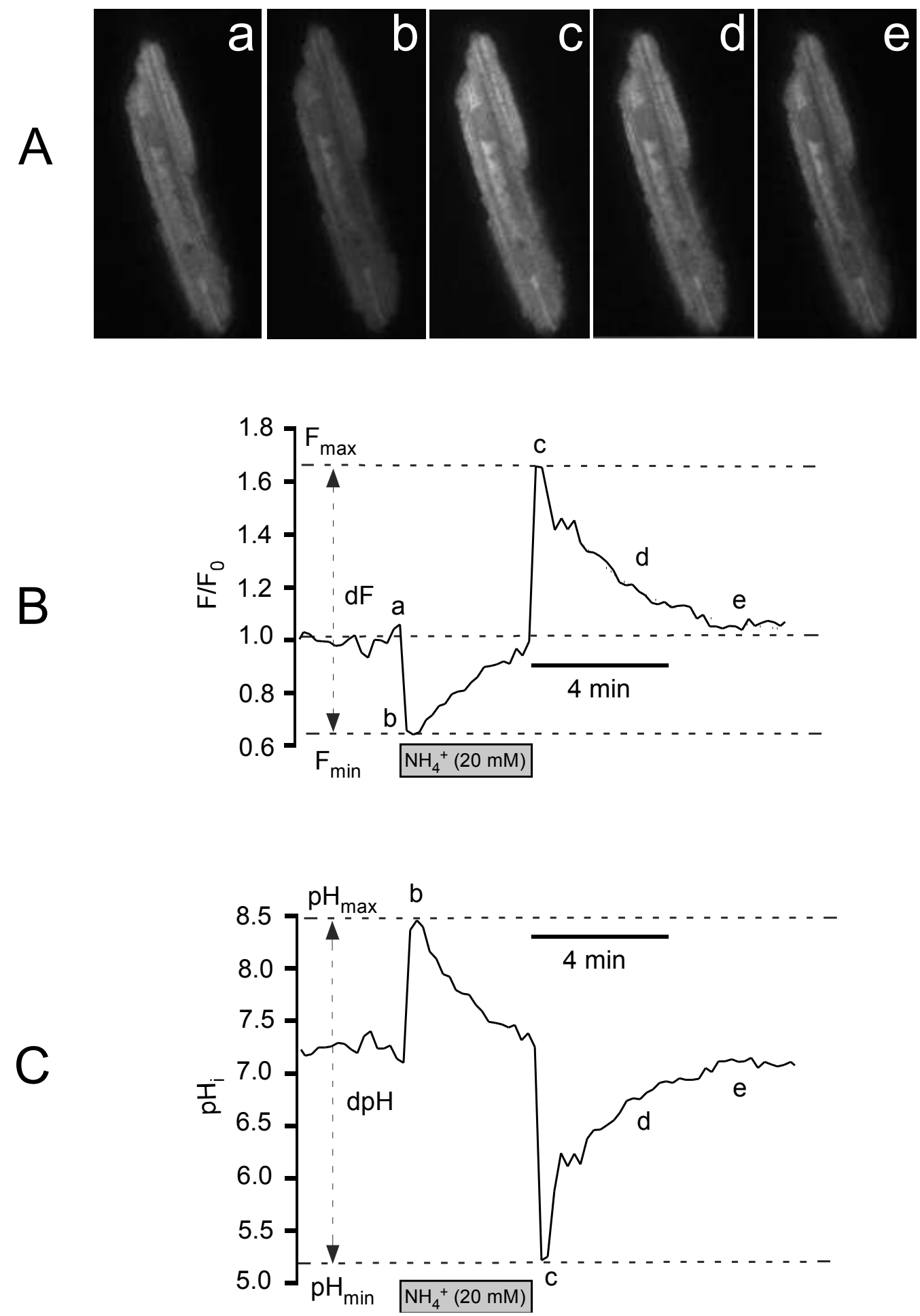

Abbildung 3.3: Änderungen der carboxy-SNARF-1-Fluoreszenz und des $\mathrm{pH}_{\mathrm{i}}$-Wertes eines KaninchenVentrikelmyozyten während eines $\mathrm{NH}_{4} \mathrm{Cl}$-Säurepuls-Protokolls

A. Originalabbildungen eines Kaninchen-Ventrikelmyozyten, B. die Änderungen der globalen Fluoreszenz der Zelle und C. die Änderungen des globalen $\mathrm{pH}_{\mathrm{i}}$-Wertes der Zelle während eine $\mathrm{NH}_{4} \mathrm{Cl}$-Säurepuls-Protokolls. 


\subsubsection{Globale pH-Änderungen eines Kaninchen-Ventrikelmyozyten während eines $\mathrm{NH}_{4} \mathrm{Cl}-\mathrm{Säurepuls-Protokolls} \mathrm{mit} \mathrm{HOE642}$}

Im zweiten Teil des $\mathrm{NH}_{4} \mathrm{Cl}$-Säurepuls-Protokolls zur Bestimmung der NHE-1-Aktivität wurde der NHE-1-Inhibitor HOE642 $(6 \mu \mathrm{M})$ verwendet. Abbildung 3.4A zeigt eine Serie von Originalabbildungen eines Kaninchen-Ventrikelmyozyten während eines $\mathrm{NH}_{4} \mathrm{Cl}$ Säurepuls-Protokolls mit HOE642 $(6 \mu \mathrm{M})$. Die Zeitpunkte der Bilder a bis c entsprechen denen in Abbildung 3.3A, mit dem Unterschied, dass Bild c in Gegenwart des NHE-1Inhibitors HOE642 aufgenommen wurde. Bild d wurde 6 Minuten nach Gabe von HOE642 (6 $\mu \mathrm{M})$ gemacht, und die Bilder e und f 4 bzw. 8 Minuten nach dem Wechsel zu normaler Tyrodelösung (siehe Tabelle 3.2)

\begin{tabular}{|l|l|l|l|l|}
\hline Schritt & 1. Schritt & 2. Schritt & 3. Schritt & 4. Schritt \\
\hline Lösung & Tyrodelsg & Tyrodelsg ${\text { mit } \mathrm{NH}_{4} \mathrm{Cl}}$ & Tyrodelsg mit HOE642 & Tyrodelsg \\
\hline Dauer & 5 Minuten & 5 Minuten & 6 Minuten & 10 Minuten \\
\hline Abbildung & A & B & c & d, e, $\mathrm{f}$ \\
\hline
\end{tabular}

Tabelle 3.2: $\left.\mathrm{NH}_{4} \mathrm{Cl}-\mathrm{Säurepuls-Protokoll} \mathrm{mit} \mathrm{HOE642} \mathrm{(6} \mu \mathrm{M}\right)$

In Abbildung 3.4B ist die Änderung des $\mathrm{pH}_{\mathrm{i}}$-Wertes während des $\mathrm{NH}_{4} \mathrm{Cl}$-SäurepulsProtokolls mit HOE642 $(6 \mu \mathrm{M})$ dargestellt. Im Vergleich zu Abbildung 3.3 (ohne HOE642) zeigte sich die Fluoreszenz nach dem Auswaschen des $\mathrm{NH}_{4} \mathrm{Cl}$ in Gegenwart des NHE-1Hemmstoffes HOE642 (6 $\mu \mathrm{M})$ nahezu unverändert und der $\mathrm{pH}_{\mathrm{i}^{-}}$Wert blieb nahezu konstant sauer. Erst nach dem Auswaschen des NHE-1-Inhibitors erholte sich der pH-Wert mit einem exponentiellen Zeitverlauf. Dabei wurde der pH-Wert sogar deutlich alkalischer als zu Beginn der Messungen (Bild f). 


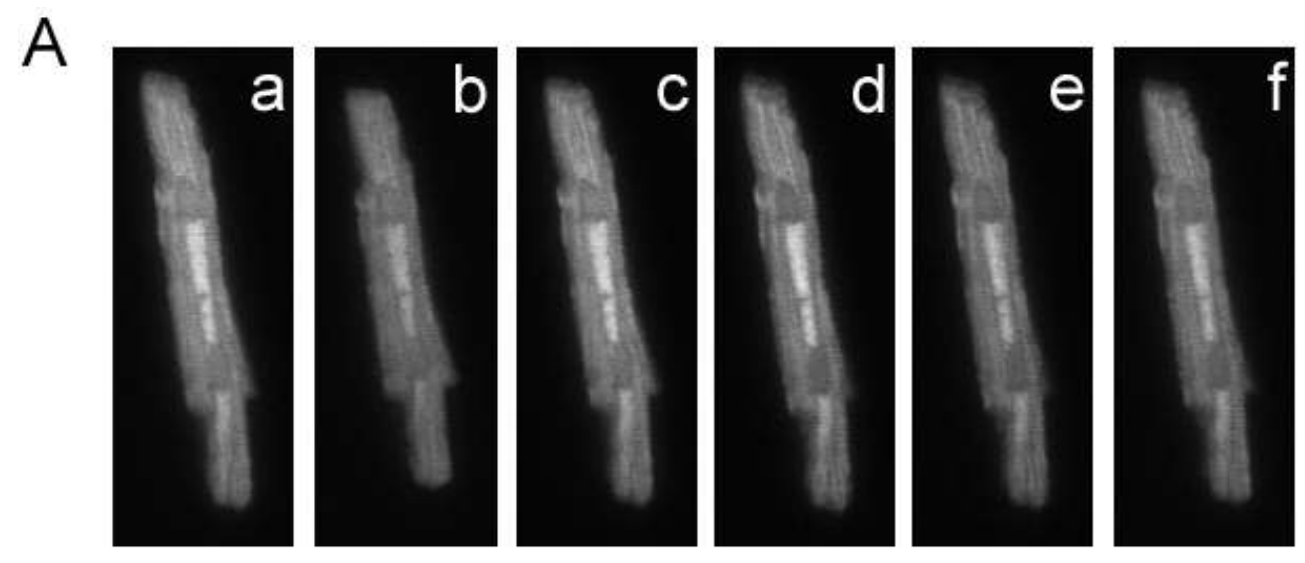

B

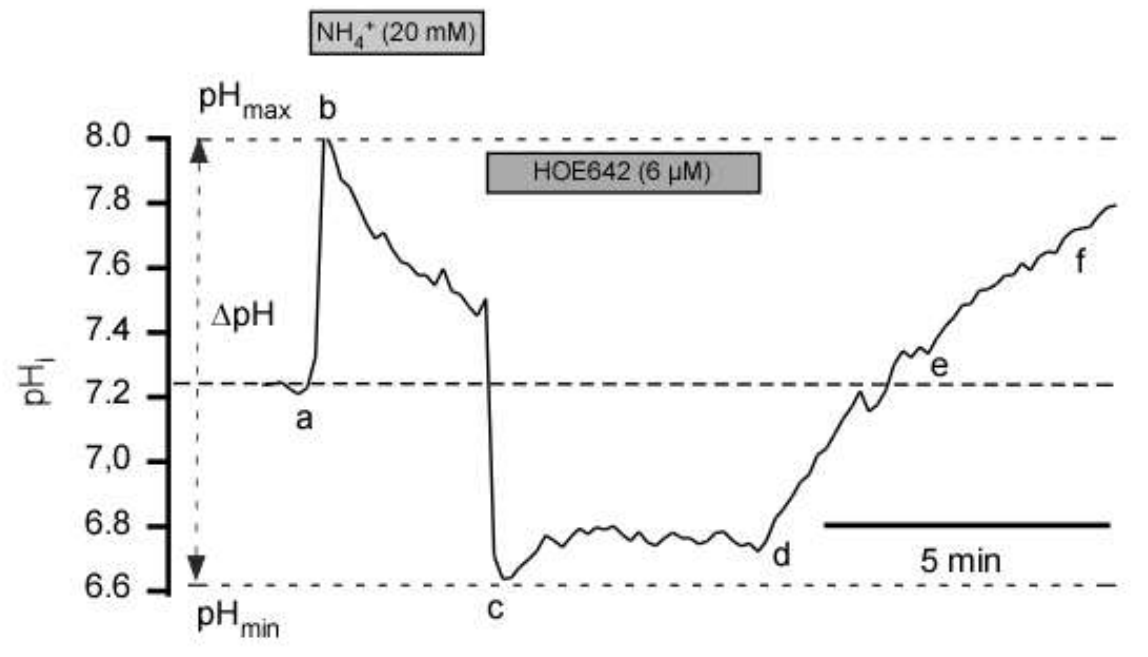

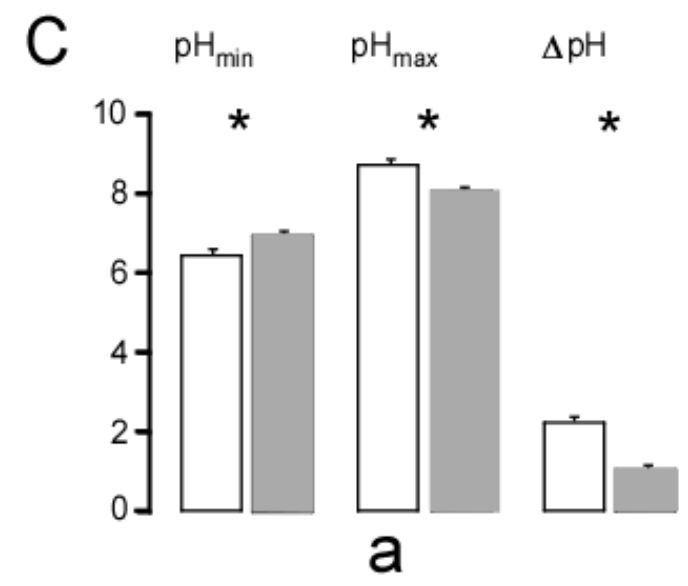

mit HOE642 $(6 \mu \mathrm{M})$

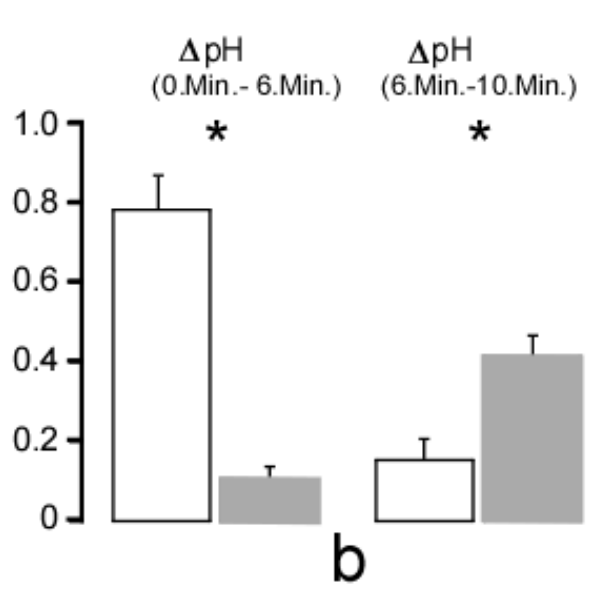

ohne HOE642 $(6 \mu \mathrm{M})$

Abbildung 3.4: Änderungen des $\mathrm{pH}_{\mathrm{i}}$-Wertes eines Kaninchen-Ventrikelmyozyten während eines $\mathrm{NH}_{4} \mathrm{Cl}$ Säurepuls-Protokolls mit HOE642

A. Originalabbildungen eines Kaninchen-Ventrikelmyozyten, B. Die Änderungen des $\mathrm{pH}_{\mathrm{i}}$-Wertes der Zelle. C. Vergleich der $\mathrm{NH}_{4} \mathrm{Cl}$-induzierten $\mathrm{pH}_{\mathrm{i}}$ - ̈̈nderungen nach Azidose zwischen dem $\mathrm{NH}_{4} \mathrm{Cl}$-Säurepuls-Protokoll ohne und mit HOE642 $(6 \mu \mathrm{M})(\mathrm{n}=29 ; *$, $\mathrm{P}<0,05)$ 
In Abbildung 3.4C werden die $\mathrm{NH}_{4} \mathrm{Cl}$-induzierten $\mathrm{pH}_{\mathrm{i}}$ - Änderungen nach Azidose zwischen dem $\mathrm{NH}_{4} \mathrm{Cl}$-Säurepuls-Protokoll ohne und mit HOE642 $(6 \mu \mu \mathrm{M})$ verglichen. In 29 Ventrikelmyozyten, die nicht mit HOE642 behandelt wurden, betrug die pH-Erholung in den ersten sechs Minuten nach Azidose $~ 0,7-0,9$ pH-Einheiten und zwischen 6 und 10 Minuten nach Azidose $\sim 0,1-0,3 \mathrm{pH}$-Einheiten. In 11 Ventrikelmyozyten, die in den ersten 6 Minuten nach dem Auswaschen des $\mathrm{NH}_{4} \mathrm{Cl}$ mit HOE642 behandelt wurden, betrug die pH-Erholung in den ersten sechs Minuten nach Azidose $\sim 0,1 \mathrm{pH}$-Einheiten und zwischen 6 und 10 Minuten nach Azidose, während HOE642 ausgewaschen wurde, 0,3-0,5 pH-Einheiten (beide $\mathrm{P}<0,05$ versus ohne HOE642).

Die Messungen zeigen, dass unter den gegebenen Versuchsbedingungen die Erholung des pH-Wertes in den Kaninchen-Ventrikelmyozyten nahezu ausschließlich auf der Aktivität des NHE-1 beruht. Das $\mathrm{NH}_{4} \mathrm{Cl}$-Säurepulsprotokoll stellt damit unter den gewählten Versuchsbedingungen eine geeignete Methode zur Analyse der NHE-1-abhängigen $\mathrm{pH}_{\mathrm{i}^{-}}$ Regulation in den Kardiomyozyten dar.

\subsubsection{Globale pH-Änderungen von Kaninchen-Vorhofmyozyten während eines $\mathrm{NH}_{4} \mathrm{Cl}$ - Säurepuls-Protokolls}

In Abbildung. 3.5A sind die Originalabbildungen eines Kaninchen-Vorhofmyozyten während eines $\mathrm{NH}_{4} \mathrm{Cl}$-Säurepuls-Protokolls zu sehen. Die Bilder a, b, c, d und e wurden zu den gleichen Zeitpunkten aufgenommen wie die in Abbildung 3.3A. Abbildung 3.5B zeigt die entsprechende $\mathrm{pH}_{\mathrm{i}}$-Spur; der Verlauf ist ähnlich wie im Ventrikelmyozyten (Abbildung 3.3C). In Abbildung 3.5C und $\mathrm{D}$ werden die $\mathrm{NH}_{4} \mathrm{Cl}$-induzierten $\mathrm{pH}_{\mathrm{i}}$ - $\mathrm{A}$ nderungen und die NHE1Aktivität zwischen Ventrikel- und Vorhofmyozyten verglichen. Dabei zeigt Abbildung 3.5C $\mathrm{pH}_{\max }, \mathrm{pH}_{\min }$ und $\Delta \mathrm{pH}$, und Abbildung 3.5D den Protonen-Efflux bei $\mathrm{pH}_{6,9}\left(\mathrm{~J}_{\mathrm{pH}, 9.9}\right)$. Es gab keinen nennenswerten Unterschied in Bezug auf $\mathrm{pH}_{\max }, \mathrm{pH}_{\min }$ und $\Delta \mathrm{pH}$. Der Protonen-Efflux bei $\mathrm{pH}_{6,9}\left(\mathrm{~J}_{\mathrm{pH} 6,9}\right)$ war in Ventrikelmyozyten mit 5,0 $0,5 \mathrm{mM} / \mathrm{min}(\mathrm{n}=29)$ jedoch deutlich größer als in Vorhofmyozyten $(3,2 \pm 0,3 \mathrm{mM} / \mathrm{min}, \mathrm{n}=17, \mathrm{P}<0,05)$. 
A
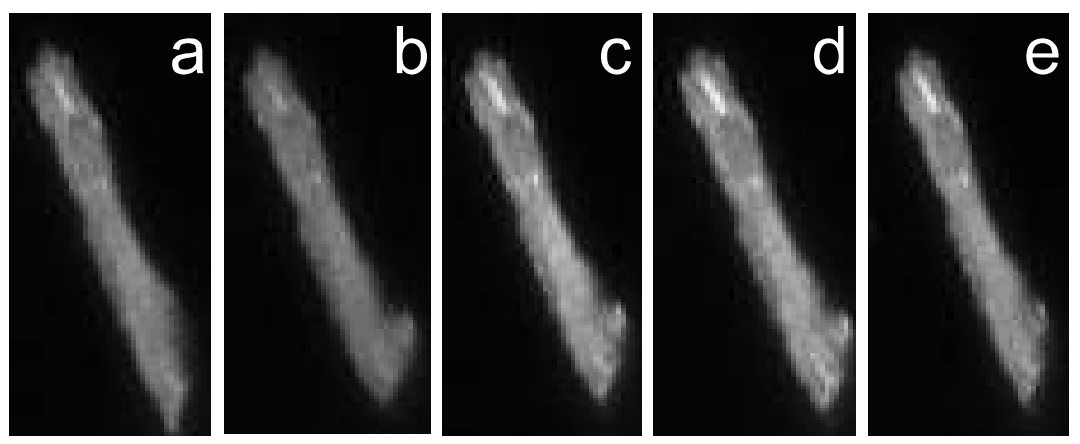

B

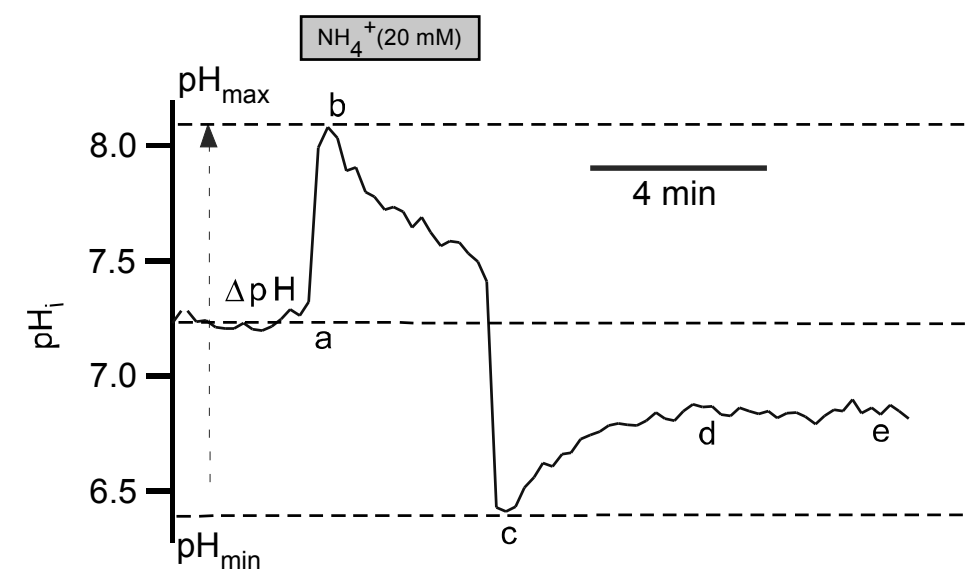

C

$\mathrm{pH}_{\min } \quad \mathrm{pH}_{\max } \quad \Delta \mathrm{pH}$

$\mathrm{D}$

$\mathrm{J}_{\mathrm{pH} 6,9}$

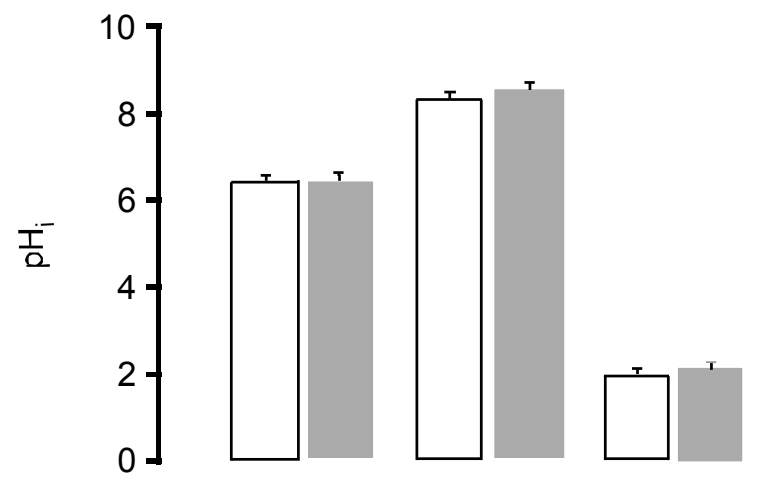

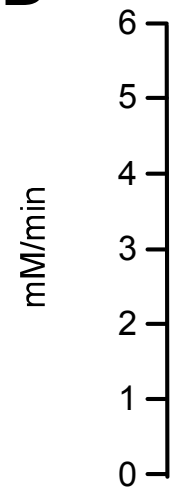

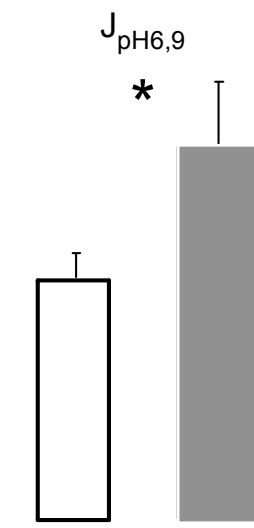

\section{Vorhofmyozyten Ventrikelmyozyten}

Abbildung 3.5: Änderungen des $\mathrm{pH}_{\mathrm{i}}$-Wertes bei einer mit carboxy-SNARF-1 beladenen Vorhofmyozyte eines Kaninchens während eines $\mathrm{NH}_{4} \mathrm{Cl}$-Säurepulses ohne HOE642

A. Die originalen Bilder eines Vorhofmyozyten eines Kaninchens; B. die Änderungen des $\mathrm{pH}_{\mathrm{i}}-\mathrm{Wertes}$ der ganzen Zelle; C. Vergleich der $\mathrm{NH}_{4} \mathrm{Cl}$-induzierten $\mathrm{pH}_{\max }$ (links), $\mathrm{pH}_{\min }$ (Mitte) und $\Delta \mathrm{pH}$ (rechts) zwischen Vorhof- (weiße Balken, $\mathrm{n}=17$ ) und Ventrikelmyozyten (schwarze Balken, $\mathrm{n}=29$ ); D. Vergleich der $\mathrm{J}_{\mathrm{pH}, 9}$ nach Azidose (rechts) zwischen Vorhof- (weiße Balken, $\mathrm{n}=17$ ) und Ventrikelmyozyten (schwarze Balken, $\mathrm{n}=29$ ); *, $\mathrm{P}<0,05$ 


\subsection{Subzelluläre $\mathrm{pH}_{\mathrm{i}}$ - Änderungen während eines $\mathrm{NH}_{4} \mathrm{Cl}$-Säurepuls-Protokolls}

Um subzelluläre Änderungen des pH-Wertes während eines $\mathrm{NH}_{4} \mathrm{Cl}$-Säurepuls-Protokolls zu untersuchen, wurden SNARF-Fluoreszenzänderungen in verschiedenen Regionen der Zellen gemessen und analysiert (siehe Material und Methoden 2.5).

\subsubsection{Subzelluläre $\mathrm{pH}_{\mathrm{i}}$-̈̈nderungen in Ventrikelmyozyten}

Abbildung. 3.6A zeigt Originalabbildungen eines Ventrikelmyozyten während eines $\mathrm{NH}_{4} \mathrm{Cl}$ Säurepuls-Protokolls. Die Bilder a, b, c, d und e wurden zu den gleichen Zeitpunkten aufgenommen wie in Abbildung 3.3A, d.h. vor (a), während (b) und nach (c-e) der Gabe von $\mathrm{NH}_{4} \mathrm{Cl}$. In A1 sind der Kern (grün) und die perinukleären Regionen (blau) markiert, in A2 die subsarkolemmalen (grün) und zentralen Regionen (blau), in denen die subzellulären SNARFFluoreszenzänderungen bzw. $\mathrm{pH}_{\mathrm{i}}$-Änderungen gemessen und analysiert wurden. Abbildung 3.6B zeigt die entsprechenden $\mathrm{pH}_{\mathrm{i}}$-Spuren des Nukleus, des perinukleären Bereichs, einer subsarkolemmalen Region und einer zentralen Region. 

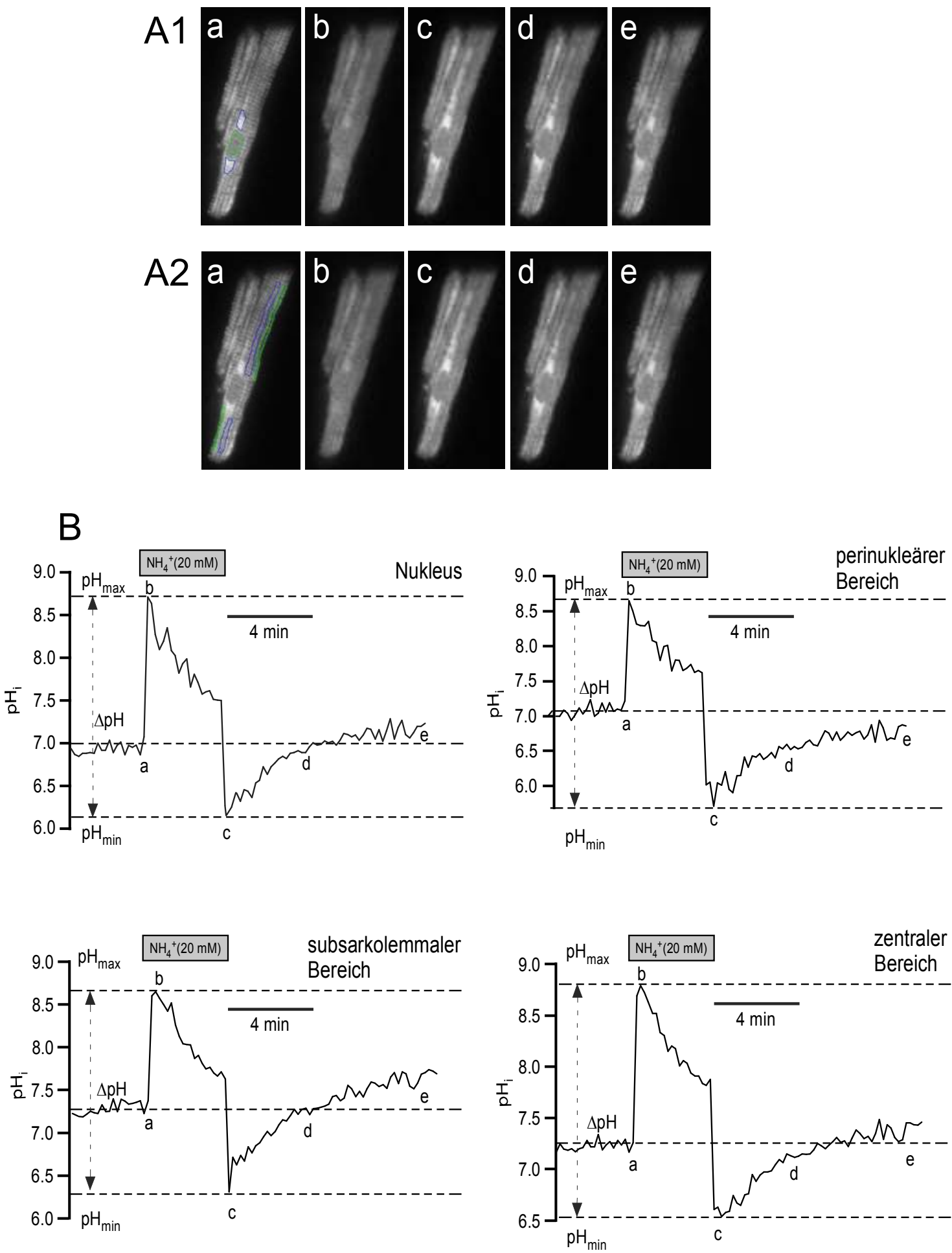

\section{Abbildung. 3.6A, B: Subzelluläre $\mathrm{pH}_{\mathrm{i}}$-Änderungen in einem Ventrikelmyozyten}

A1: Originalbilder eines Ventrikelmyozyten mit einem analysierten Kern (grün) und den perinukleären Regionen (b). A2: Originalbilder eines Ventrikelmyozyten mit den analysierten subsarkolemmalen (SS, grün) und zentralen Regionen (blau). B: Die $\mathrm{pH}_{\mathrm{i}}$-Änderungen im Nukleus, in einem perinukleären Bereich, in einer subsarkolemmalen (SS) Region und in einer zentralen Region. 
In Abbildung 3.6C und D werden die $\mathrm{NH}_{4} \mathrm{Cl}$-induzierten $\mathrm{pH}_{\mathrm{i}}$ - $\mathrm{A}$ nderungen und die NHE-1Aktivität zwischen den oben genannten Regionen in den Ventrikelmyozyten miteinander verglichen. Abbildung 3.6C zeigt $\mathrm{pH}_{\max }, \mathrm{pH}_{\min }$ und $\Delta \mathrm{pH}$, Abbildung 3.6D zeigt $\mathrm{J}_{\mathrm{pH} 6,9}$.
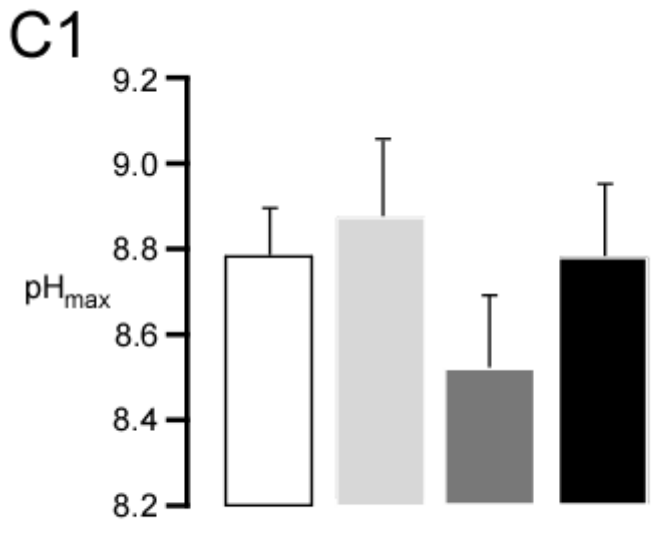

C3

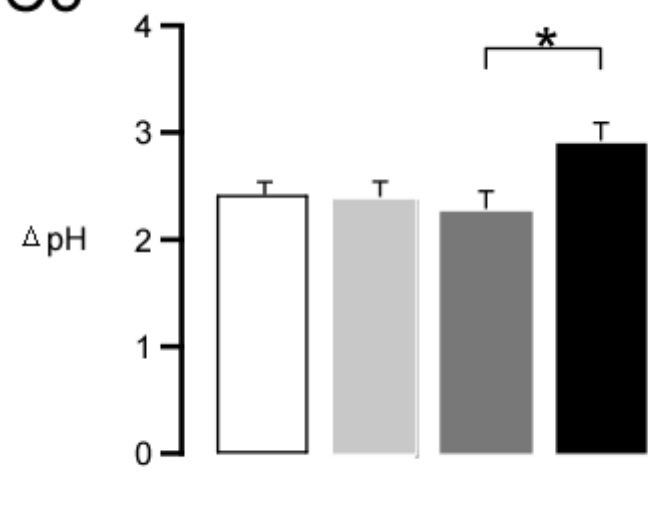

$\square$ ss $\quad$ Zentrum

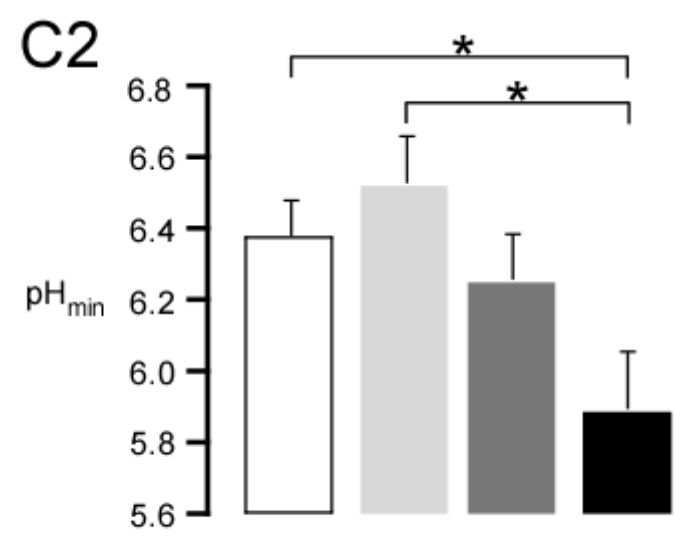

D

$\mathrm{mM} / \mathrm{min}$
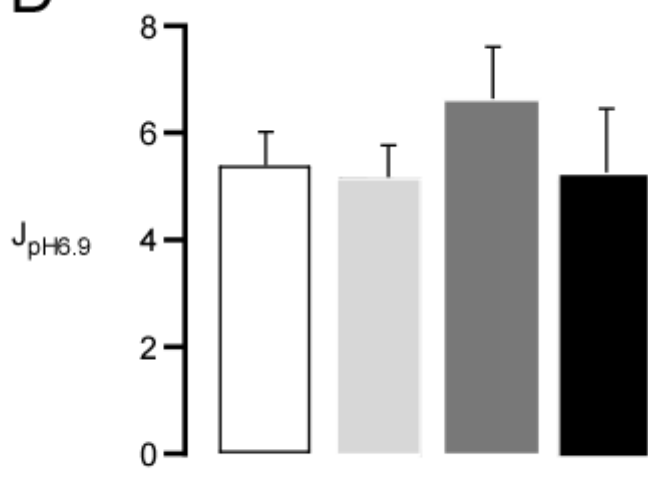

Nukleus

Perinukleus

Abbildung 3.6C, D: Lokale $\mathrm{pH}_{\mathrm{i}}$ - Änderungen und lokaler $\mathrm{J}_{\mathrm{pH} 6,9}$ während des $\mathrm{NH}_{4} \mathrm{Cl}-\mathrm{Säurepulsprotokolls}$ in Ventrikelmyozyten

C: Vergleich der $\mathrm{NH}_{4} \mathrm{Cl}$-induzierten Alkalose $\left(\mathrm{pH}_{\max } \mathrm{C} 1\right)$ und Azidose $\left(\mathrm{pH}_{\min } \mathrm{C} 2\right)$ zwischen den unterschiedlichen subzellulären Regionen $(\mathrm{n}=20 ; *, \mathrm{P}<0,05)$. D: Vergleich des $\mathrm{J}_{\mathrm{pH} 6,9}$ für die $\mathrm{pH}_{\mathrm{i}}$-Erholung nach $\mathrm{NH}_{4} \mathrm{Cl}$-induzierter Azidose zwischen den unterschiedlichen subzellulären Regionen $(\mathrm{n}=20 ; *, \mathrm{P}<0,05)$

Es gab keine Unterschiede zwischen den subzellulären Regionen im Hinblick auf den $\mathrm{pH}_{\max }$ nach Gabe von $\mathrm{NH}_{4} \mathrm{Cl}$. Er betrug 8,5-8,9. Die Azidose $\left(\mathrm{pH}_{\min }\right)$ nach dem Auswaschen des $\mathrm{NH}_{4} \mathrm{Cl}$ war jedoch in der perinukleären Region am stärksten ausgeprägt ( $\mathrm{pH}$ 5,8 versus $\mathrm{pH} \sim 6,4-6,7)$. Sie war signifikant größer als im subsarkolemmalen Bereich und im Zentrum 
der Zelle. Die Differenz von $\mathrm{pH}_{\max }$ und $\mathrm{pH}_{\min }, \Delta \mathrm{pH}$, war im perinukleären Bereich mit $~ 2,9$ größer als in den übrigen Regionen ( 2,0-2,5). Der Unterschied war jedoch nur im Vergleich zum Nukleus statistisch signifikant. Der Protonen-Efflux bei $\mathrm{pH}_{6,9}$ war in allen Regionen etwa gleich groß. Er betrug zwischen 4,6 und 5,2 $\mathrm{mM} / \mathrm{min}$.

\subsubsection{Subzelluläre $\mathrm{pH}_{\mathrm{i}}$-Änderungen in Vorhofmyozyten}

Abbildung 3.7A zeigt die Originalbilder eines Vorhofmyozyten während eines $\mathrm{NH}_{4} \mathrm{Cl}$ Säurepuls-Protokolls. Die Bilder a, b, c, d und e wurden zu den gleichen Zeitpunkten aufgenommen wie in Abbildung. 3.1A, d. h. vor (a), während (b) und nach (c-e) der Gabe von $\mathrm{NH}_{4} \mathrm{Cl}$. In A1 sind der Kern (grün) und die perinukleären Regionen (blau) markiert, in A2 die subsarkolemmalen Regionen (grün, violett) und eine zentrale Region (blau), in denen die subzellulären SNARF-Fluoreszenzänderungen bzw. $\mathrm{pH}_{\mathrm{i}}$-Änderungen gemessen und analysiert wurden. Abbildung 3.7B zeigt die entsprechenden $\mathrm{pH}_{\mathrm{i}}-\mathrm{Spuren}$. 

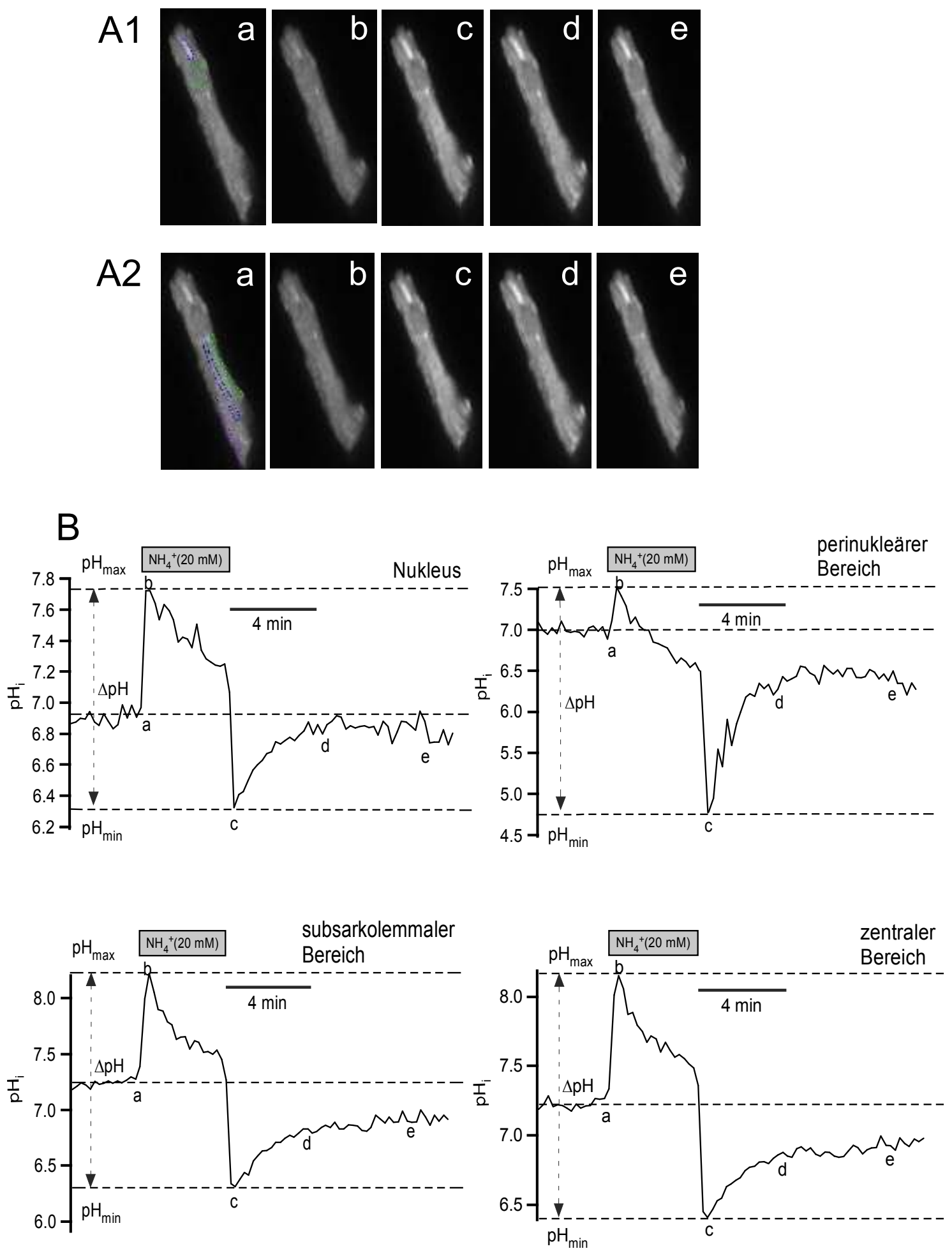

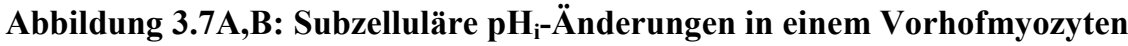

A1: Originalbilder eines Vorhofmyozyten mit einem analysierten Kern (grün) und den perinukleären Regionen (b). A2: Originalbilder eines Vorhofmyozyten mit den analysierten subsarkolemmalen (SS, grün) und zentralen Regionen (blau). B: Die $\mathrm{pH}_{\mathrm{i}}$-Änderungen im Nukleus, in einem perinukleären Bereich, in einer subsarkolemmalen (SS) Region und in einer zentralen Region. 
Wie in Abbildung 3.6C und $\mathrm{D}$ sind in Abbildung 3.7C und $\mathrm{D}$ die $\mathrm{NH}_{4} \mathrm{Cl}$-induzierten $\mathrm{pH}_{\mathrm{i}^{-}}$ Änderungen und die NHE-1-Aktivität zwischen den oben genannten Regionen in den Vorhofmyozyten miteinander verglichen. Abbildung 3.7C zeigt $\mathrm{pH}_{\max }, \mathrm{pH}_{\min }$ und $\Delta \mathrm{pH}$, und Abbildung 3.7D zeigt $\mathrm{J}_{\mathrm{pH} 6,9}$.
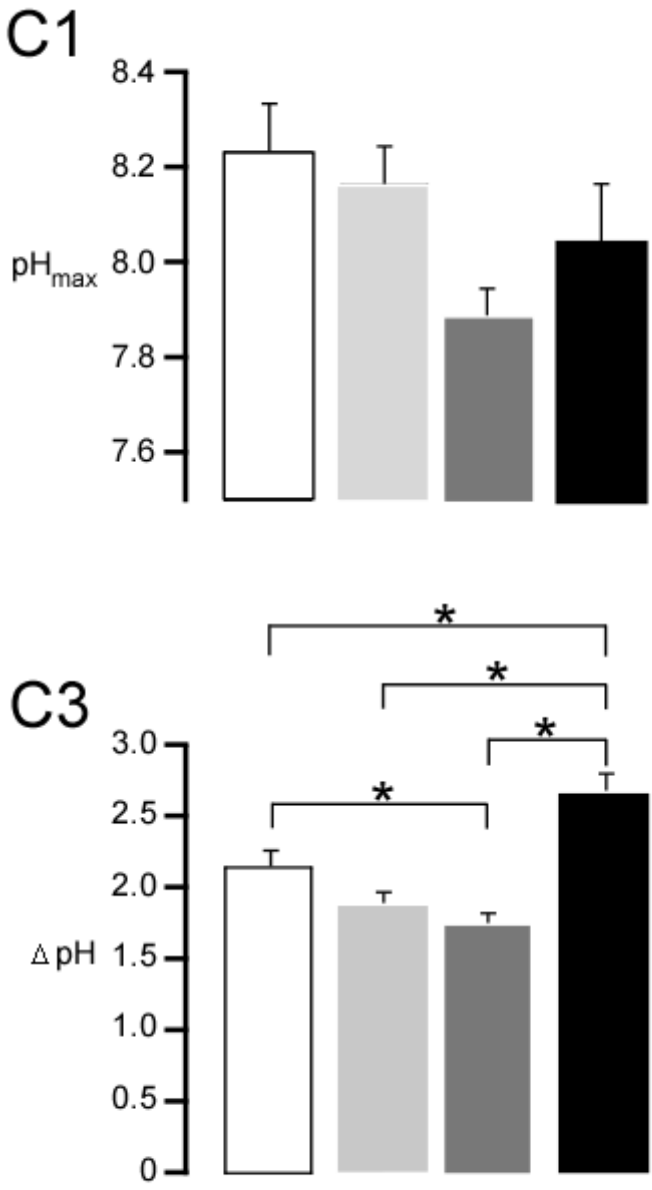

SS Zentrum

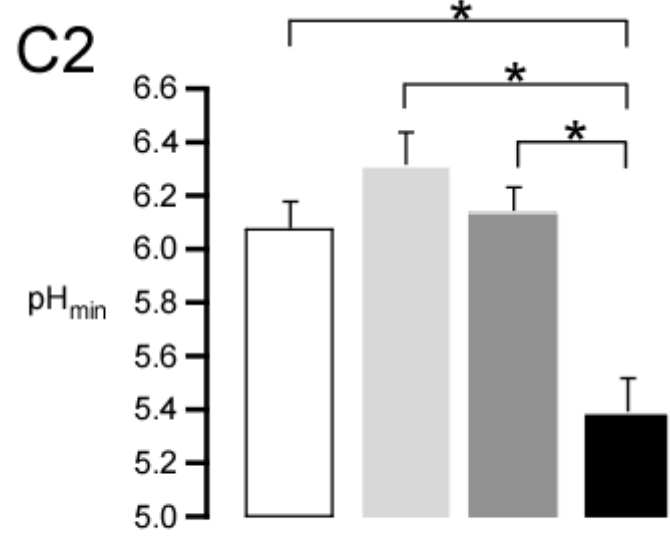

D $\quad \mathrm{mM} / \mathrm{min}$

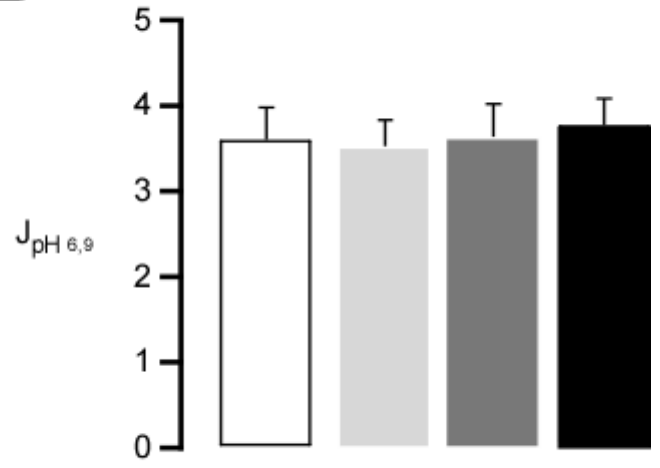

Nukleus

Perinukleus

Abbidlung 3.7C,D: Lokale $\mathrm{pH}_{\mathrm{i}}$ - Änderungen und lokaler $\mathrm{J}_{\mathrm{pH} 6,9}$ während des $\mathrm{NH}_{4} \mathrm{Cl}$-Säurepulsprotokolls in Vorhofmyozyten

$\mathrm{C}$ : Vergleich der $\mathrm{NH}_{4} \mathrm{Cl}$-induzierten Alkalose $\left(\mathrm{pH}_{\max } \mathrm{C} 1\right)$ und Azidose $\left(\mathrm{pH}_{\min } \mathrm{C} 2\right)$ zwischen den unterschiedlichen subzellulären Regionen $(\mathrm{n}=20 ; *, \mathrm{P}<0,05)$. D: Vergleich des $\mathrm{J}_{\mathrm{pH} 6,9}$ für die $\mathrm{pH}_{\mathrm{i}}$-Erholung nach $\mathrm{NH}_{4} \mathrm{Cl}$-induzierter Azidose zwischen den unterschiedlichen subzellulären Regionen. $(\mathrm{n}=16$; *, $\mathrm{P}<0,05)$.

In Abbildung. 3.7C ist zu sehen, dass die durch $\mathrm{NH}_{4} \mathrm{Cl}$-Säurepuls induzierte Alkalose $\left(\mathrm{pH}_{\max }\right)$ zwischen den verschiedenen Regionen nicht unterschiedlich war. Im Hinblick auf den $\mathrm{pH}_{\text {min }}$ gab es jedoch deutliche Unterschiede zwischen der perinukleären und allen anderen Regionen der Vorhofmyozyten, d.h. nach Auswaschen von $\mathrm{NH}_{4} \mathrm{Cl}$ zeigte sich eine stärkere Azidose 
$\left(\mathrm{pH}_{\text {min }}\right)$ im Perinukleus als in den anderen Regionen $(\mathrm{pH} \sim 5,2-5,5$ versus $\mathrm{pH} \sim 6,0-6,4)$. Beim Vergleich des $\mathrm{NH}_{4} \mathrm{Cl}$-induzierten $\Delta \mathrm{pH}$ in den 16 Vorhofmyozyten war der $\Delta \mathrm{pH}$ im Perinukleus ausgeprägt größer als in allen anderen Regionen ( $\mathrm{pH} 2,5-2,8$ versus $\mathrm{pH} \sim 1,7-2,3$ ). Der mittlere Wert des $\mathrm{J}_{\mathrm{pH} 6,9}$ nach $\mathrm{NH}_{4} \mathrm{Cl}$-induzierter Azidose in diesen 16 Vorhofmyozyten betrug in den verschiedenen subzellulären Regionen zwischen 3,1 und 4,0 $\mathrm{mM} / \mathrm{min}$. Es zeigten sich keine signifikanten Unterschiede des Protonen-Efflux bei $\mathrm{pH}_{6,9}$ zwischen diesen Regionen in der Vorhofmyozyten (Abbildung 3.7 D).

\subsubsection{Vergleich der subzellulären $\mathrm{pH}_{\mathrm{i}}$-Änderungen zwischen Vorhof- und Ventrikelmyozyten}

Die $\mathrm{NH}_{4} \mathrm{Cl}$-induzierten $\mathrm{pH}_{\mathrm{i}}$-Änderungen und die $\mathrm{pH}_{\mathrm{i}}$-Erholung nach einem Säurepuls (als funktionelles Maß für die NHE-1-Aktivität) in verschiedenen Regionen der Zelle wurden zwischen den Vorhof- und Ventrikelmyozyten verglichen. Abbildung 3.8 zeigt Mittelwerte für die $\mathrm{NH}_{4} \mathrm{Cl}$-induzierte Alkalose $\left(\mathrm{pH}_{\max }\right)$, die Azidose $\left(\mathrm{pH}_{\min }\right)$, den $\Delta \mathrm{pH}$ und $\mathrm{J}_{\mathrm{pH} 6,9}$ nach $\mathrm{NH}_{4} \mathrm{Cl}$-induzierter Azidose. Es zeigten sich deutlich weniger stark ausgeprägte $\mathrm{NH}_{4} \mathrm{Cl}$ induzierte Alkalosen $\left(\mathrm{pH}_{\max }\right)$ in allen Regionen der Vorhofmyozyten im Vergleich zu den Ventrikelmyozyten. Außerdem ergaben sich deutliche Unterschiede des $\Delta \mathrm{pH}$ im Zellkern und Zentrum, die in den Vorhofmyozyten größer waren als in den Ventrikelmyozyten. Im Hinblick auf die Azidose $\left(\mathrm{pH}_{\min }\right)$ zeigten sich keine subzellulären Unterschiede zwischen den Vorhof- und Ventrikelmyozyten. Zwischen den Vorhof- und Ventrikelmyozyten wurde jedoch ein statistisch signifikanter Unterschied des $\mathrm{J}_{\mathrm{pH} 6,9}$ im Zentrum der Zelle beobachtet, $\mathrm{d}$. h. ein größerer Protonen-Efflux bei $\mathrm{pH} 6,9\left(\mathrm{~J}_{\mathrm{pH} 6,9}\right)$ in Ventrikelmyozyten als in Vorhofmyozyten. 

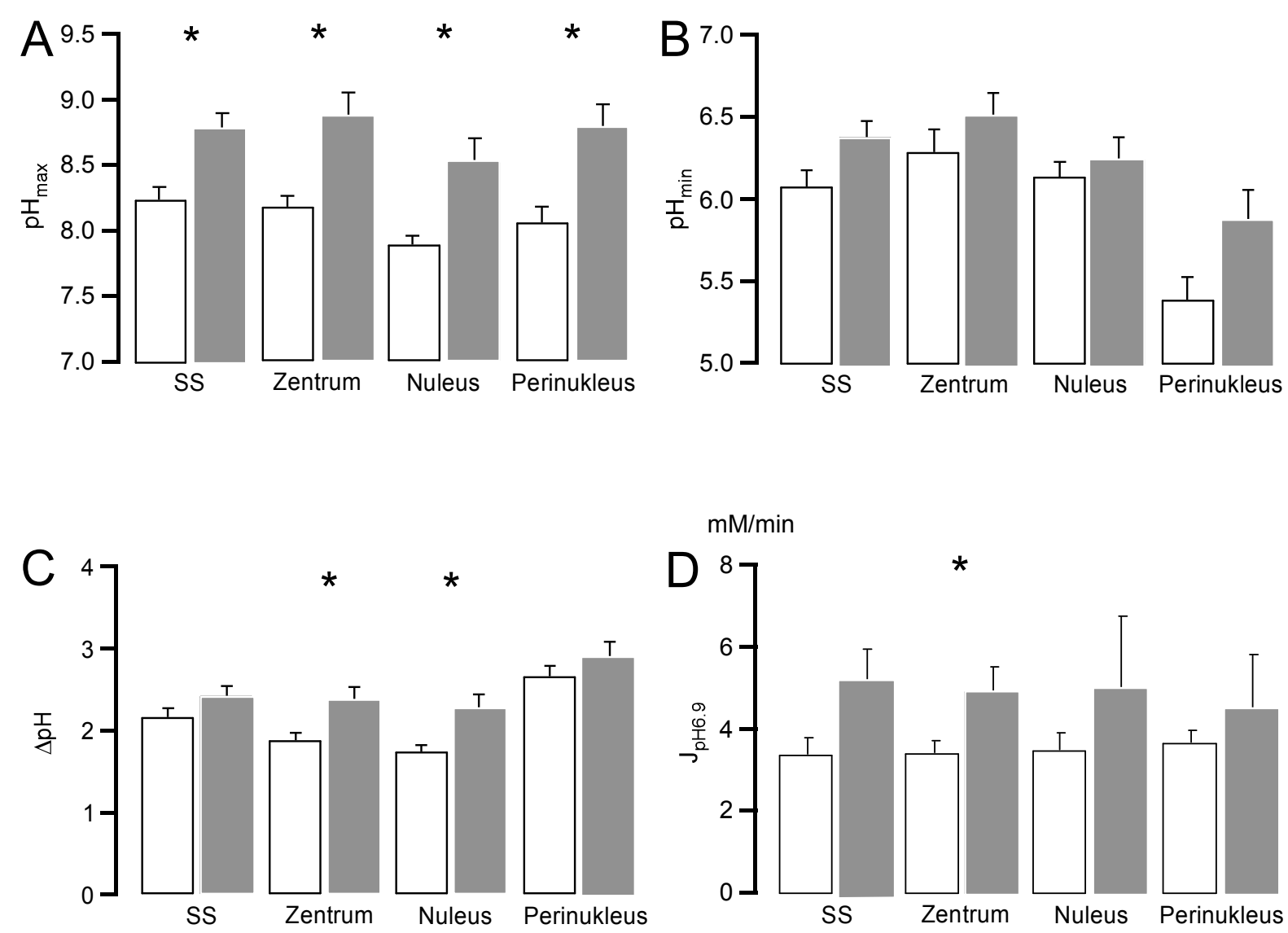

Abbildung 3.8: Vergleich der subzellulären $\mathrm{pH}_{\mathrm{i}}$-Änderungen und des subzellulären $\mathrm{J}_{\mathrm{pH}, 9}$ während des $\mathrm{NH}_{4} \mathrm{Cl}-\mathrm{Säurepulsprotokolls} \mathrm{zwischen} \mathrm{Vorhof-} \mathrm{und} \mathrm{Ventrikelmyozyten.}$

Vergleich der Mittelwerte \pm S.E.M. von $\mathrm{pH}_{\max }(\mathrm{A}), \mathrm{pH}_{\min }(\mathrm{B}), \Delta \mathrm{pH}$ (C) und $\mathrm{J}_{\mathrm{pH} 6,9}$ (D) der verschiedenen subzellulären Regionen zwischen Vorhof- (weiße Balken, $\mathrm{n}=15$ ) und Ventrikelmyozyten (schwarze Balken, $\mathrm{n}=20) ; *, \mathrm{P}<0,05$

\subsection{Die Expression des NHE-1 im humanen Vorhof- und Ventrikelmyokard}

Um die Expression des NHE-1 im Vorhof- und Ventrikelmyokard zu untersuchen, wurden Immunoblots (Western Blots) durchgeführt. Um Unterschiede in der Expression zu detektieren ist es üblich, das $\mathrm{zu}$ untersuchende Protein auf ein House-Keeping-Protein zu normalisieren. In der vorliegenden Arbeit wurde zur Normalisierung die Glycerinaldehyd-3Phosphat-Dehydrogenase (GAPDH) verwendet. 


\subsubsection{Vergleich der NHE-1-Expression zwischen nicht-insuffizientem menschlichen Vorhof- und Ventrikelmyokard}

Abbildung. 3.9A zeigt Original-Immunoblots von nicht-insuffizientem, humanen Vorhof- und Ventrikelgewebe. Das durch den Anti-NHE-1-Antikörper nachgewiesene Protein bei $\sim 100$ $\mathrm{kDa}$ ist der NHE-1. Bei der unteren schwarzen Bande bei $\sim 37 \mathrm{kDa}$ handelt es sich um GAPDH. Abbildung. 3.9B. zeigt die Mittelwerte \pm S.E.M. der auf GAPDH normierten NHE-1Expression (NHE-1/GAPDH), die anhand von 9 Vorhof- und 6 Ventrikelmyokard-Proben ermittelt wurden. Es zeigte sich kein signifikanter Unterschied in der NHE-1-Expression zwischen nicht-insuffizientem Vorhof- und Ventrikelmyokard.

\subsubsection{Vergleich der NHE-1-Expression zwischen nicht-insuffizientem und insuffizientem, humanen Ventrikelmyokard}

Um die NHE1-Expression im nicht-insuffizienten und insuffizienten, humanen Ventrikelmyokard zu vergleichen, wurden Immunoblots mit humanen Proben von nichtinsuffizientem Ventrikelmyokard (NF) und insuffizientem Ventrikelmyokard von Patienten mit ischämischer Kardiomyopathie (ICM) oder dilatativer Kardiomyopathie (DCM) durchgeführt. Abbildung 3.10A zeigt Original-Immunoblots von NHE-1 und GAPDH. Mittelwerte der auf GAPDH normierten NHE-1-Expression aus 6 Proben nicht-insuffizenten Myokards und je 6 ICM- und DCM-Proben sind in Abbildung 3.10B dargestellt. Daraus wird deutlich, dass die NHE-1-Expression im humanen Ventrikelmyokard bei Herzinsuffizienz ansteigt. 
A

A $\quad$ A $V \quad$ V

$\mathrm{NHE}-1(\sim 100 \mathrm{kDa}) \longrightarrow$

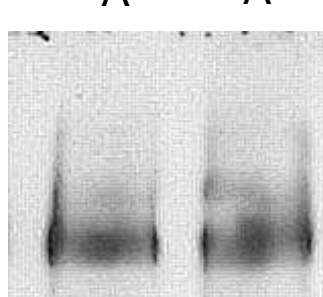

GAPDH ( 37 kDa)

B

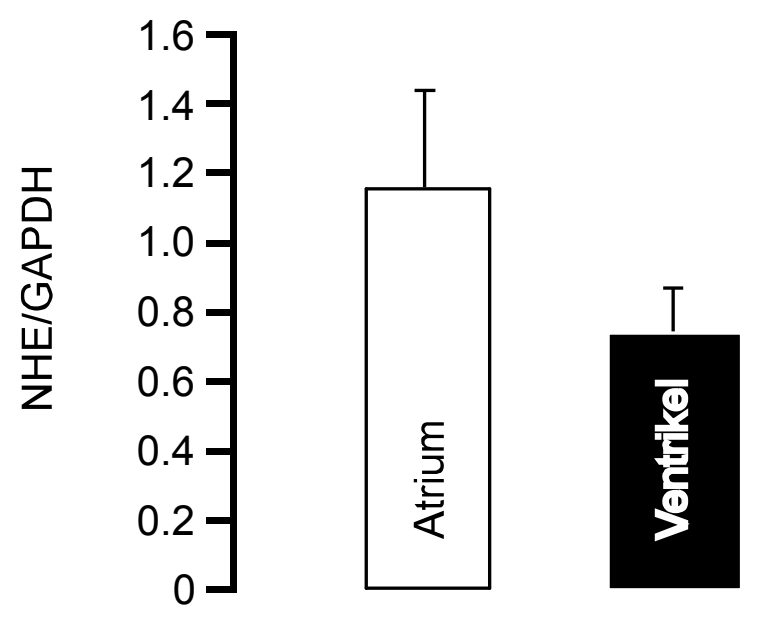

Abbildung 3.9: Die NHE-1-Expression im nicht-insuffizienten humanen Vorhof- und Ventrikelmyokard.

A. Original-Immunoblots zur Bestimmung der Expression des NHE-1 (oben) und der GAPDH (unten) in Homogenaten aus nicht-insuffizientem humanen Vorhof- (A, Atrium) und Ventrikelmyokard (V). B. Vergleich der Mittelwerte \pm S.E.M. der auf GAPDH normierten NHE1-Expression in nicht-insuffizientem humanen Vorhof$(n=9)$ und Ventrikelmyokard ( $n=6 ; P=N . S$.$) .$ 


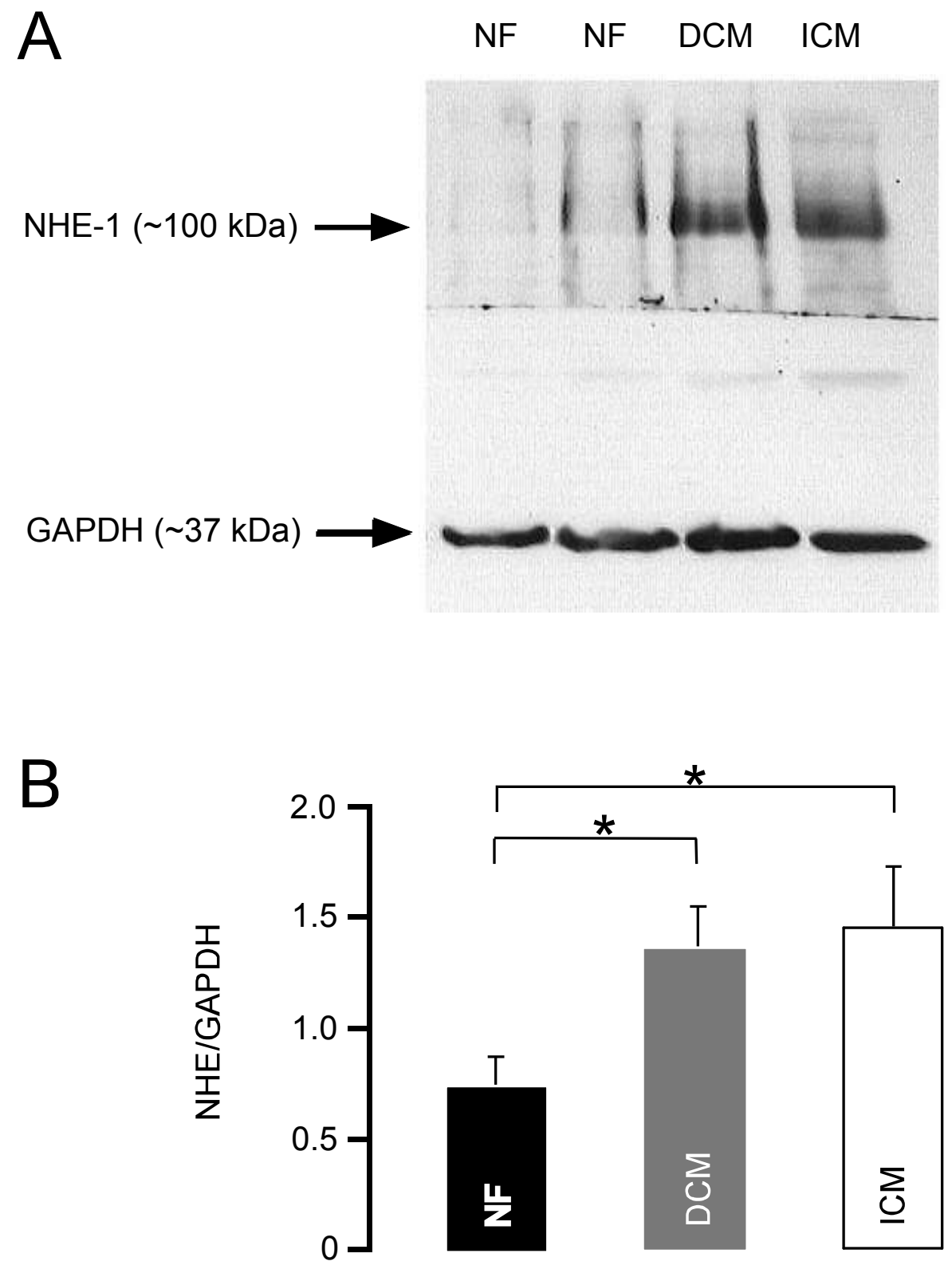

Abbildung 3.10: Die NHE-1-Expression in nicht-insuffizientem und insuffizientem humanen Ventrikelmyokard.

A. Original-Immunoblots zur Bestimmung der Expression des NHE-1 (oben) und der GAPDH (unten) in Homogenaten aus nicht-insuffizientem (NF, non-failing) und insuffizientem (ICM, DCM) humanen

Ventrikelmyokard. B. Vergleich der Mittelwerte \pm S.E.M. der auf GAPDH normierten NHE-1-Expression zwischen nicht-insuffizientem $(n=6)$ und insuffizientem Ventrikelmyokard (ICM, $\mathrm{n}=6$; und DCM, $\mathrm{n}=6$; *, $\mathrm{P}<0,05)$. 


\section{Diskussion}

Der $\mathrm{Na}^{+} / \mathrm{H}^{+}$-Austauscher (NHE) ist maßgeblich an der intrazellulären pH-Regulation beteiligt. In Herzmuskelzellen wird vermutlich ausschließlich der NHE-1 exprimiert. Aus pathophysiologischer Sicht ist der kardiale NHE-1 von besonderer Bedeutung. Seine Aktivierung spielt eine wichtige Rolle bei Ischämie-Reperfusionsschäden, dem myokardialen Remodelling nach Myokardinfarkt und der Entwicklung von Hypertrophie und Herzinsuffizienz nach mechanischer Überlastung des Herzens.

Da die Aktivität des NHE-1 durch die NHE-abhängigen $\mathrm{pH}_{\mathrm{i}}$-Änderungen dargestellt werden kann, wurden in der vorliegenden Arbeit die NHE-1-abhängigen $\mathrm{pH}_{\mathrm{i}}$-Änderungen global und in verschiedenen subzellulären Regionen in Vorhof- und Ventrikelmyozyten aus Kaninchen gemessen, um die NHE-abhängige pH-Regulation zwischen Vorhof und Ventrikel zu vergleichen, und um die Frage zu beantworten, ob es subzelluläre Unterschiede in den $\mathrm{pH}$ Änderungen nach einem Säurepuls gibt und welche Unterschiede sich zwischen verschiedenen subzellulären Regionen, sowie zwischen Vorhofmyozyten und Vertrikelmyozyten ergeben. Zur Messung der NHE-1-abhängigen $\mathrm{pH}_{\mathrm{i}}$ - Änderungen, wurde die $\mathrm{NH}_{4} \mathrm{Cl}$-Säurepuls-Methode mit einer Hepes-gepufferten Lösung und einem $\mathrm{pH}$-sensitiven Fluoreszenzfarbstoff, 5-Carboxy-SNARF®-1, verwendet. Die Spezifität der Methode für die Messung der Aktivität des NHE-1 wurde durch Kontrollexperimente mit einem NHE-1spezifischen Hemmstoff, HOE642, nachgewiesen. Die Fluoreszenzänderungen wurden geeicht und in $\mathrm{pH}_{\mathrm{i}}$ - ̈̈nderungen umgerechnet. Die Kombination von 5-Carboxy-SNARF-1 mit der Konfokalmikroskopie erlaubte die Messung subzellulärer $\mathrm{pH}$-Änderungen.

In der vorliegenden Arbeit wurde außerdem die NHE-1-Expression in insuffizienten und nicht-insuffizienten humanen Vorhof- und Ventrikelmyokarden mit der Western-BlotMethode quantitativ gemessen.

Im Folgenden werden die Ergebnisse dieser Arbeit im Einzelnen diskutiert.

\subsection{Identifizierung und Quantifizierung der NHE-1-Aktivität in den Kaninchen-Kardiomyozyten}

Zur Messung der NHE-1-abhängigen $\mathrm{pH}_{\mathrm{i}}$-Änderungen wurde die $\mathrm{NH}_{4} \mathrm{Cl}$-Säurepuls-Methode mit einer Hepes-gepufferten Lösung verwendet. HEPES (2-(4-(2-Hydroxyethyl)-1piperazinyl)-ethansulfonsäure) ist eine Protonen-Puffersubstanz. In Hepes-gepufferter Lösung kann auf Bikarbonat $\left(\mathrm{HCO}_{3}{ }^{-}\right)$als Puffer verzichtet werden. Dies dient dazu, die Aktivität des NBC auszuschalten, der sich ebenso an der Regulierung der intrazellulären $\left[\mathrm{H}^{+}\right]$bei Azidose 
beteiligt. Ohne $\mathrm{HCO}_{3}{ }^{-}$als Substrat kann der $\mathrm{NBC}$ nicht funktionieren. Damit ist die $\mathrm{pH}_{\mathrm{i}^{-}}$ Regulierung bei der durch den $\mathrm{NH}_{4} \mathrm{Cl}$-Säurepuls induzierten Azidose im Intrazellulärraum allein durch den NHE-1 hervorgerufen. Dies wurde durch die Experimente in Gegenwart des NHE-1-spezifischen Hemmstoffes HOE642 (6 $\mu \mathrm{M})$ (Cariporide) an Ventrikelmyozyten aus dem Kaninchenherzen in der vorliegenden Arbeit bestätigt. Während sich der abgefallene $\mathrm{pH}_{\mathrm{i}}$-Wert ohne HOE642 nach dem Auswaschen des $\mathrm{NH}_{4} \mathrm{Cl}$ schnell wieder normalisierte, blieb der pH-Wert in Gegenwart von HOE642 nahezu konstant sauer. Erst nach dem Auswaschen des NHE-1-Inhibitors erholte sich der pH-Wert. Da Cariporide sich als NHE-1-selektiv erwies (Scholz et al. 1993; Counillon et al. 1993b; Scholz et al. 1995), zeigen die Messungen, dass unter den gegebenen Versuchsbedingungen die Erholung des pH-Wertes in Ventrikelmyozyten von Kaninchen nahezu ausschließlich auf der Aktivität des NHE-1 beruht und diese Methode daher zur Bestimmung der NHE-1-Aktivität geeignet ist. Dies ist mit zahlreichen Studien vereinbar, die belegt haben, dass der NHE-1 eine wichtige Rolle bei der Regulation des $\mathrm{pH}_{\mathrm{i}}$ in Kardiomyozyten spielt (siehe Einleitung).

In Bezug auf die Konzentration von HOE642 zur Entfaltung der vollen Wirksamkeit berichteten Scholz et al., dass in vitro am zellulären Modell die $\mathrm{IC}_{50} 0,05 \mu \mathrm{M}$ beträgt. Zur vollständigen Blockierung des NHE-1 braucht man in vitro $10 \mu \mathrm{M}$ HOE642 (Scholz et al. 1995). Ähnliche Konzentrationsbereiche für die vollständige Blockierung des NHE-1 wurden auch von Hoshino und Avkiran beschrieben (Hoshino und Avkiran 2001). In der vorliegenden Arbeit wurde $6 \mu \mathrm{M}$ HOE642 verwendet. Nach dem Bericht von Scholz und Mitarbeitern ist es daher möglich, damit mehr als 95\% der Aktivität des NHE-1 zu blockieren. Das Fehlen einer 100\%igen Blockade könnte eine Erklärung dafür sein, wie es in den vorliegenden Experimenten beobachtet wurde, dass die pH-Spuren nach dem Auswaschen von $\mathrm{NH}_{4} \mathrm{Cl}$ in Anwesenheit von HOE642 eine geringfügige Erholung zeigten.

Darüber hinaus wurde beobachtet, dass die pH-Spuren nach dem Auswaschen von HOE642 eine Alkalisierung der Zelle über den $\mathrm{pH}_{\mathrm{i}}$-Ausgangswert hinaus zeigten. Dies könnte daran liegen, dass die Hemmung des NHE-1 durch HOE642 zu einer mehrminütigen Akkumulation von Protonen im Intrazellulärraum führte, welche über eine Aktivierung des ERK-p90 ${ }^{\text {rsk }}$ Signalweges eine Phosphorylierung des NHE-1 und damit eine Stimulierung seiner Aktivität bewirkte (Haworth et al. 2003). So kommt es zu einem überschießenden Ausschleusen der Protonen aus dem Intrazellulärraum. Als Folge zeigte sich eine über die $\mathrm{pH}_{\mathrm{i}}$-Ausgangswerte hinausgehende Alkalisierung der Zelle.

$\mathrm{J}_{\mathrm{H}}$ ist die Geschwindigkeit des $\mathrm{H}^{+}$-Efflux. $\mathrm{J}_{\mathrm{pH} 6,9}$ ist die Geschwindigkeit des $\mathrm{H}^{+}$-Efflux bei $\mathrm{pH}_{\mathrm{i}}$ 6,9. Laut Leem et al. ist die Aktivität des NHE-1 bei einem pH-Wert von 6,9 deutlich erhöht. 
Insgesamt gilt: je sauerer der intrazelluläre pH-Wert ist, desto höher ist die Aktivität des NHE-1 (Leem et al. 1999). $\mathrm{J}_{\mathrm{pH} 6,9}$ kann im Vergleich zu anderen Methoden über die qualitative Messung hinaus direkt die quantitative Aktivität des NHE1 bei einer intrazellulären Azidose darstellen (Lagadic-Gossmann et al. 1992). $\mathrm{J}_{\mathrm{pH} 6,9}$ wurde daher in dieser Arbeit als quantitatives Maß für die Aktivität des NHE verwendet.

Zusammenfassend stellt das $\mathrm{NH}_{4} \mathrm{Cl}$-Säurepulsprotokoll damit unter den gewählten Versuchsbedingungen, d.h. in Abwesenheit von Bikarbonat, eine geeignete Methode zur Analyse der NHE-1-abhängigen $\mathrm{pH}_{\mathrm{i}}$-Regulationen in Kardiomyozyten dar, die durch die Experimente mit dem NHE-1-selektiven Hemmstoff HOE642 (Cariporide) nachgewiesen werden konnte. Dabei wurde die Rate des $\mathrm{H}^{+}$-Efflux bei $\mathrm{pH} 6,9, \mathrm{~J}_{\mathrm{pH} 6,9}$, als ein funktionelles Maß für die Aktivität des NHE-1 ermittelt.

\subsection{Unterschiede der globalen $\mathbf{p H}-\mathrm{Änderungen} \mathrm{und} \mathrm{von} \mathrm{J}_{\mathrm{pH6,9}}$ zwischen Vorhof- und Ventrikelmyozyten}

Der physiologische intrazelluläre pH-Wert $\left(\mathrm{pH}_{\mathrm{i}}\right)$ liegt im Bereich 7,1-7,3 (Leem et al. 1999; Yamamoto et al. 2005). In der vorliegenden Arbeit befanden sich die $\mathrm{pH}_{\mathrm{i}}-\mathrm{Werte}$ der $\mathrm{Zellen} \mathrm{zu}$ Beginn der Messungen unter Ruhebedingungen $\left(\mathrm{pH}_{0}\right)$ bei ca. 7,2 , d.h. im physiologischen Bereich. Das spricht dafür, dass die Zellen in einem guten Zustand waren und dass die Eichung gelungen war, da sich der $\mathrm{pH}_{0}$-Wert unter Ruhebedingungen durch die Fluoreszenzänderungen $\left(\mathrm{F} / \mathrm{F}_{0}=1,0\right)$ aus der Eichkurve ablesen lässt. Der basale pH-Wert war in Vorhof- und Ventrikelmyozyten nahezu identisch; es gab keine wesentlichen Unterschiede zwischen den beiden Zelltypen.

In der vorliegenden Arbeit zeigte sich, dass es bei den globalen $\mathrm{pH}-$ Änderungen während des $\mathrm{NH}_{4} \mathrm{Cl}$-Säurepuls-Protokolls keine signifikanten Unterschiede von $\mathrm{pH}_{\min }, \mathrm{pH}_{\max }$ und $\Delta \mathrm{pH}$ zwischen den Vorhof- und Ventrikelmyozyten gab. Es zeigte sich jedoch ein signifikanter Unterschied der Rate des $\mathrm{H}^{+}$-Efflux bei $\mathrm{pH}$ 6,9, $\mathrm{J}_{\mathrm{pH} 6,9}$, zwischen den beiden Zelltypen: $\mathrm{J}_{\mathrm{pH} 6,9}$ war in Ventrikelmyozyten $(5 \mathrm{mM} / \mathrm{min})$ deutlich größer als in Vorhofmyozyten $(3,2 \mathrm{mM} / \mathrm{min})$. Dies bedeutet, dass mehr Protonen pro Zeiteinheit aus der Ventrikelmyozyten als aus den Vorhofmyozyten eliminiert wurden. 
Der Unterschied könnte auf das T-tubuläre System zurückzuführen sein, das aus transversalen Einstülpungen der Oberflächenmembran besteht. Der NHE-1 ist ein Membranprotein. Petrecca et al. zeigten mittels Immunhistochemie im Rattenmyokard, dass der NHE-1 sich im T-tubulären System befindet (Petrecca et al. 1999). Das T-tubuläre System sorgt dafür, dass die Oberflächenmembran praktisch überall in der Zelle zu finden ist, sich also immer in der Nähe des Zytoplasmas befindet.

Ein wichtiger Unterschied zwischen Ventrikel- und Vorhofmyozyten betrifft genau das Ttubuläre System. Vorhofmyozyten besitzen in der Regel keine oder nur sehr wenige T-Tubuli, während Ventrikelmyozyten ein regelmäßiges T-tubuläres System besitzen (Blatter et al. 2003). Diese physiologische Verteilung der T-Tubli in Ventrikelmyozyten führt dazu, dass der in den T-Tubuli lokalisierte NHE-1 die Protonen aus dem Zellinneren schnell und effektiv eliminieren kann. Im Vergleich dazu können intrazelluläre Protonen in Vorhofmyozyten nur über die Oberflächenmembran durch den NHE entfernt werden, da sich keine T-Tubli im Zentrum der Zellen befinden. Die Protonen müssen aus dem Zellinneren zuerst zur Oberflächenmembran gelangen und die Membrantransporter (den NHE) erreichen, bevor sie entfernt werden können. Es lässt sich schlussfolgern, dass in Zellen mit T-tubulärem System, also in Ventrikelmyozyten, mehr Protonen pro Zeiteinheit entfernt werden können als in Vorhofmyozyten.

Diese Erklärung wird auch durch die Ergebnisse der pH-Änderungen in verschiedenen subzellulären Regionen der Zellen unterstützt. Hier wurden statistisch signifikante Unterschiede der pH-Änderungen im Zentrum zwischen Ventrikel- und Vorhofmyozyten beobachtet: Die $\mathrm{J}_{\mathrm{pH} 6,9}$ im Zentrum der Ventrikelmyozyten war signifikant größer als in Vorhofmyozyten, d.h. dass in Ventrikelmyozyten mehr Protonen pro Zeiteinheit eliminiert werden können als in Vorhofmyozyten.

In der Arbeit von Satoh et al. wurde der Zusammenhang zwischen der Zelloberfläche und dem Zellvolumen der Kardiomyozyten erforscht. Es wurde gezeigt, dass es eine positive lineare Korrelation zwischen der Zelloberfläche und dem Zellvolumen unter physiologischen Bedingungen in jeder Tierspezies gibt (Satoh et al. 1996), und dass das OberflächenVolumen-Verhältnis in hypertrophen und nicht-hypertrophen Kardiomyozyten unverändert ist (Delbridge et al. 1997). In einigen Arbeiten wurde das Oberflächen-Volumen-Verhältnis in Vorhof- und Ventrikelmyozyten gemessen. Michailova et al. haben in Vorhofmyozyten vom Meerschweinchen ein Oberflächen-Volumen-Verhältnis von $2.56 \mathrm{pF} / \mathrm{pl}$ beschrieben (Michailova et al. 2002). Das ist deutliche kleiner als in Ventrikelmyozyten, die ein Oberflächen-Volumen-Verhältnis im Bereich von 4.58-8.44 pF/pl aufweisen (Satoh et al. 
1996). Ventrikelmyozyten haben also ein 2-4-fach größeres Oberflächen-Volumen-Verhältnis als Vorhofmyozyten. Es lässt sich schlussfolgern, dass sich mehr T-Tubli und damit mehr NHE-1-Protein in Ventrikelmyozyten als in Vorhofmyozyten ergeben. Das kann erklären, warum die Rate des $\mathrm{H}^{+}$-Efflux in Ventrikelmyozyten höher als in Vorhofmyozyten ist, wie es in der vorliegenden Arbeit gezeigte wurde.

Es gibt eine weitere mögliche Erklärung für die unterschiedliche Aktivität des NHE-1 zwischen den Vorhof- und Ventrikelmyozyten: die Dichte des NHE-1 in der Membran von Ventrikelmyoyzten könnte größer sein als in Vorhofmyozyten. In der vorliegenden Arbeit wurde jedoch kein signifikanter Unterschied der Expression des NHE-1 zwischen humanem nicht-insuffizienten Ventrikel- und Vorhofmyokard durch die Western-Blot-Methode nachgewiesen. Auch Buckendahl konnte zeigen, dass die mRNA-Expression des NHE-1 in Proben aus menschlichem nicht-insuffizienten Vorhof- und Ventrikelmyokard keine signifikanten Unterschiede aufweist (Buckendahl 2006).

Unsere Ergebnisse zur NHE-1-Aktivität stammen von Kaninchenmyozyten, die Ergebnisse zur Expression des NHE-1 jedoch vom menschlichen Myokard. Im Kaninchenmyokard konnten wir die NHE-1-Expression nicht bestimmen, da kein geeigneter Antikörper zur Verfügung stand. Es könnte Speziesunterschiede geben, die zu einem Unterschied der NHE1-Expression zwischen dem Kaninchenmyokard und dem humanen Myokard führen. Es ist daher nicht auszuschließen, dass es im Kaninchenmyokard doch einen Unterschied in der NHE-1-Expression zwischen Ventrikel- und Vorhofmyokard gibt. Dies sollte in zukünftigen Untersuchungen überprüft werden, sobald ein geeigneter Antikörper zur Verfügung steht.

Schließlich ist es denkbar, dass die höhere NHE-1-Aktivität in den Ventrikelmyozyten auf eine unterschiedlich starke posttranslationale Modifikation (z.B. Phosphorylierung) zurückzuführen ist. Dies wurde bereits unter pathologischen Bedingungen wie bei der Herzinsuffizienz gezeigt (Cutaia et al. 1998; Phan et al. 1997; Soleimani et al. 1995 siehe untern). Diese Autoren haben gezeigt, dass der NHE-1 durch verschiedene Faktoren (insbesondere Kinasen) direkt oder indirekt stimuliert werden kann. So könnte die erhöhte Gesamtaktivität des NHE-1 auf eine vermehrte Phosphorylierung des NHE-1 in den Ventrikelmyozyten zurückzuführen sein. 


\subsection{Subzelluläre pH-Änderungen in Vorhof- und Ventrikelmyozyten}

\subsubsection{Subzelluläre pH-Änderungen in den Ventrikelmyozyten}

In Ventrikelmyoyzten, die ein regelmäßiges T-tubuläres System besitzen, haben wir keine oder nur sehr geringe intrazelluläre pH-Unterschiede erwartet, da durch das T-tubuläre System praktisch überall Oberflächenmembran mit dem NHE-1 vorhanden ist. $\mathrm{J}_{\mathrm{pH} 6,9}$ sollte überall in den Ventrikelmyozyten gleich sein. Insbesondere sollte es keinen Unterschied der $\mathrm{J}_{\mathrm{pH} 6,9}$ Zwischen den subsarkolemmalen und zentralen Regionen der Ventrikelmyozyten geben. In der vorliegenden Arbeit ergaben sich beim Vergleich der $\mathrm{pH}$-Änderung in den subzellulären Regionen in den Ventrikelmyozyten nur wenige signifikante Unterschiede, so beim $\mathrm{pH}_{\min }$ zwischen der subsarkolemmalen und perinuklären Region, sowie zwischen dem Zellkern und perinuklären Region. Eine mögliche Erklärung hierfür könnte eine subzellulär unterschiedliche Pufferkapazität der Regionen sein. Es wurde kein signifikanter Unterschied bei $\mathrm{pH}_{\max }$ und $\mathrm{J}_{\mathrm{pH} 6,9}$ festgestellt. $\mathrm{J}_{\mathrm{pH} 6,9}$ zeigte sich überall in den Ventrikelmyozyten gleich, so dass sich die Ausgangshypothese für die Ventrikelmyozyten im Wesentlichen bestätigte.

\subsubsection{Subzelluläre pH-Änderungen in den Vorhofmyozyten}

Weil Vorhofmyozyten gar kein oder nur ein sehr schwach ausgeprägtes T-Tubulus-System besitzen, haben wir erwartet, dass sich möglicherweise subzelluläre $\mathrm{pH}$ - und $\mathrm{J}_{\mathrm{pH} 6,9^{-}}$ Unterschiede in den Vorhofmyozyten zeigen, insbesondere zwischen dem subsarkolemmalen und zentralen Bereich. Da es kein T-Tubulus-System im Zentrum der Vorhofmyozyten gibt, müssen die $\mathrm{H}^{+}$-Ionen aus dem Zentrum der Vorhofmyozyten eine längere Strecke bis zu den NHE-Membrantransportern zurücklegen. Aus diesen Gründen, so unsere Ausgangshypothese, sollte es bei einer Azidose $\mathrm{zu}$ einer Differenz der $\mathrm{H}^{+}$-Konzentration und der $\mathrm{J}_{\mathrm{pH} 6.9}$ zwischen den zentralen und subsarkolemmalen Regionen in Vorhofmyozyten kommen.

In der vorliegenden Arbeit wurden in den Vorhofmyozyten statistisch signifikante Unterschiede des $\mathrm{pH}_{\min }$ und des $\Delta \mathrm{pH}$ zwischen der perinukleären Region und den übrigen Regionen festgestellt. Zwischen den übrigen Regionen gab es jedoch kaum pH-Unterschiede, insbesondere auch nicht zwischen den subsarkolemmalen und zentralen Regionen. Die $\mathrm{J}_{\mathrm{pH} 6.9}$ zeigte ebenfalls keine Unterschiede zwischen den verschiedenen subzellulären Regionen, sondern sie war in allen Kompartimenten in den Vorhofmyozyten gleich. Der $\mathrm{H}^{+}$-Efflux war 
daher, entgegen unserer Ausgangshypothese, trotz des Fehlens eines T-Tubulus-Systems in allen subzellulären Regionen der Vorhofmyozyten etwa gleich groß.

Swietach und Vaughan-Jones konnten in Experimenten an Ratten-Ventrikelmyozyten einen longitudinalen intrazellulären $\mathrm{pH}_{\mathrm{i}}$-Gradienten während der Erholung der intrazellulären Azidose nach einem Ammoniumchlorid-Puls feststellen, der nach der Normalisierung des $\mathrm{pH}_{\mathrm{i}}$ verschwand. Dazu wurden Bedingungen geschafft, die zu einer maximalen Aktivierung des NHE führen $\left(37^{\circ} \mathrm{C}\right.$, starke Azidose $(\mathrm{pH})$ ); lange andauernde Azidose, die über eine Phosphorylierung des NHE eine zusätzliche Stimulierung bewirkt). Unter diesen Bedingungen war die pH-Erholung nach Azidose an den Zellenden stärker ausgeprägt als im Zentrum der Zelle. Es zeigte sich, dass ein Unterschied der Geschwindigkeit der $\mathrm{H}^{+}$-Extrusion zwischen den Zellenden und dem Zentrum der Zelle besteht. Dieser Unterschied wurde dadurch erklärt, dass der sarkolemmale NHE-1 die Protonen am Zellende schnell ausschleusen kann, während die $\mathrm{H}^{+}$-Mobilität im Zentrum der Zelle langsamer ist (Swietach und Vaughan-Jones, 2005). Ihre experimentellen Befunde haben die Autoren anhand von Computer-Modellen bestätigt. Mit Hilfe dieser Modelle haben sie auch untersucht, ob transversale $\mathrm{pH}$-Gradienten zwischen dem subsarkolemmalen Raum und dem Zentrum der Zelle zu erwarten sind. Sie konnten dies aufgrund der geringen radialen Diffusionsstrecke ausschließen. Dies bestätigt die Befunde der vorliegenden Arbeit, in der weder in Ventrikelnoch Vorhofmyozyten ein transversaler $\mathrm{pH}$-Gradient beobachtet werden konnte. Zusammengenommen lassen die hier vorgestellten Ergebnisse und die Untersuchungen von Swietach und Vaughan-Jones (2005) daher den Schluss zu, dass aufgrund der geringen radialen Diffusionstrecke kein messbarer transversaler $\mathrm{pH}$-Gradient zwischen zentralem und subsarkolemmalen Zytoplasma zustande kommt. Auch in Vorhofmyozyten, denen ein TTubulus-System fehlt, ist die $\mathrm{H}^{+}$-Extrusion über den sarkolemmalen NHE nicht groß genug, um einen solchen Gradienten zu erzeugen. Hier kommt hinzu, dass die $\mathrm{H}^{+}$-Transportrate $\left(\mathrm{J}_{\mathrm{pH} 6,9}\right)$ des NHE signifikant kleiner ist als in Ventrikelmyozyten.

\subsubsection{Unterschiede der subzellulären Regionen zwischen Vorhof und Ventrikel}

Wie im Vergleich der globalen $\mathrm{pH}_{\mathrm{i}}$-Änderungen zwischen Vorhof- und Ventrikelmyozyten waren $\mathrm{pH}_{\max }, \mathrm{pH}_{\min }, \Delta \mathrm{pH}_{\min }$ und $\mathrm{J}_{\mathrm{pH} 6,9}$ in allen Regionen in den Ventrikelmyozyten tendenziell größer als in den Vorhofmyozyten. In den meisten Fällen waren diese 
Unterschiede jedoch nicht statistisch signifikant. Ein signifikanter Unterschied ergab sich jedoch zwischen subsarkolemmalem und zentralem Zytoplasma. Hier war die pH-Änderung und die $\mathrm{J}_{\mathrm{pH} 6,9}$ im Zentrum der Ventrikelmyozyten deutlich größer als in den Vorhofmyozyten, ähnlich wie beim Vergleich der globalen $\mathrm{pH}$ - und $\mathrm{J}_{\mathrm{pH} 6,9}$-Änderungen. Es lässt sich schlussfolgern, dass der Unterschied der $\mathrm{J}_{\mathrm{pH} 6,9}$ zwischen Ventrikel- und Vorhofmyozenten zu großen Teilen an dem Unterschied der $\mathrm{J}_{\mathrm{pH} 6,9}$ im Zentrum zwischen Ventrikel- und Vorhofmyozyten liegen kann. Wie vorher erwähnt, ist dies vermutlich auf das Vorhandsein des T-tubulären Systems im Zentrum von Ventrikelmyozyten zurückzuführen.

Diese Arbeit hat damit wichtige Unterschiede in der globalen und subzellulären NHEabhängigen pH-Regulation zwischen Ventrikel- und Vorhofmyozyten aufgedeckt. Ventrikelmyoyzten besitzen eine deutlich größere NHE-1-vermittelte $\mathrm{H}^{+}$-Elimination (5 $\mathrm{mM} / \mathrm{min}$ versus $3,2 \mathrm{mM} / \mathrm{min}$ in Vorhofmyoyzten). Diese beruht im Wesentlichen auf der größeren $\mathrm{H}^{+}$-Elimination aus dem Zentrum der Zellen, was mit dem Vorhandensein des $\mathrm{T}$ Tubulus-Systems in den Ventrikelmyozyten erklärt werden kann. Messbare radiale $\mathrm{pH}$ Gradienten konnten weder in Ventrikel- noch in Vorhofmyoyzten beobachtet werden. Dies deutet darauf hin, dass die Diffusion von Protonen vom Zellinneren zur Zellmembran, die die NHE-Transporter enthält, schnell genung ist, um die im subsarkolemmalen Raum eliminierten Protonen zu ersetzen.

\subsection{NHE-1-Expression in humanem Vorhof- und Ventrikelmyokard}

Mit Hilfe der Western-Blot-Methode wurde in der vorliegenden Arbeit eine Quantifizierung der Proteinexpression des NHE-1 in Ventrikelmyokardproben von Patienten mit und ohne Herzinsuffizienz (NF, DCM, ICM) sowie in Vorhofmyokardproben von Patienten mit Sinusrhythmus und ohne Herzinsuffizienz durchgeführt. Zur Quantifizierung wurde die NHE1-Expression auf die GAPDH-Expression normiert. Beim Vergleich der NHE-1-Expression von nicht-insuffizientem Vorhof- und Ventrikelmyokard zeigten sich keine Unterschiede, beim Vergleich der NHE-1-Expression zwischen insuffizientem und nicht-insuffizientem Vertrikel-myokard konnte hingegen eine statistisch signifikant erhöhte Expression des NHE-1 im insuffizienten Vertrikelmyokard nachgewiesen werden. 


\subsubsection{NHE-1-Expression in nicht-insuffizientem Vorhof- und Ventrikelmyokard}

Nach unserer Hypothese sollte es, wie zuvor erwähnt, wegen der histologischen Unterschiede zwischen Vorhof- und Ventrikelmyozyten (letztere mit einem regelmäßigen T-tubulären System und einem größeren Oberflächen-Volumen-Verhältnis) eine vermehrte Expression des NHE-1 im Ventrikelmyokard geben. In der vorliegenden Arbeit konnte jedoch kein signifikanter Unterschied der NHE-1-Expression zwischen nicht-insuffizientem Ventrikelund Vorhofmyokard beobachtet werden.

Ähnliche Befunde wurden auch von anderen Arbeitsgruppen erhoben. Buckendahl (2006) zeigte, dass die mRNA-Expression des NHE-1 in Proben aus insuffizientem und nichtinsuffizientem menschlichen Vorhof- und Ventrikelmyokard nicht unterschiedlich war (Buckendahl 2006). Microarray-Untersuchungen von Kääb und Mitarbeitern (2004) mit humanen Vorhof- und Ventrikelmyokardproben konnten insgesamt 549 Gene identifizieren, die eine unterschiedliche Expression zwischen Vorhof und Ventrikel zeigten. Dabei wurde jedoch das NHE-1-Gen nicht genannt (Kääb et al. 2004). Gleiches gilt für MicroarrayUntersuchungen mit Vorhof- und Ventrikelgewebe aus Mäusen (Zhao et al.2002).

Bisher wurde die regional unterschiedliche Expression des NHE-1 kaum untersucht. Die wenigen Untersuchungen $\mathrm{zu}$ diesem Thema deuten jedoch darauf hin, dass es keine signifikanten Unterschiede der NHE-1-Expression zwischen nicht-insuffizientem Ventrikelund Vorhofmyokard gibt.

\subsubsection{Unterschiede der NHE-1-Expression zwischen insuffizientem und nicht- insuffizientem Ventrikelmyokard}

In der vorliegenden Arbeit wurde beim Vergleich der insuffizienten (ICM und DCM) und nicht-insuffizienten Ventrikelmyokardproben eine signifikant erhöhte NHE-1-Expression im insuffizienten Vertrikelmyokard beobachtet.

Ähnliche Ergebnisse wurden auch bei zahlreichen Untersuchungen mit verschiedenen Tierarten erzielt. So wurde im ischämisch geschädigten ventrikulären Rattenmyokard eine vermehrte mRNA-Expression des NHE-1 nachgewiesen (Sandmann et al. 2001). Dyck et al. (1995) beobachteten, dass Ischämie zu einer Steigerung der NHE-1-Message führt (Dyck et al. 1995). Takewaki et al. (1995) konnten an hypertrophen ventrikulären Kardiomyozyten von Kaninchen zeigen, dass die mRNA-Expression des NHE-1-erhöht ist und mit einer Aktivitätserhöhung des NHE-1 einhergeht. Fliegel und Wang (1997) beschreiben, dass 
Druck-induzierte Umbauprozesse im Myokard auch zu einer Steigerung der mRNAExpression des NHE-1 führen (Fliegel und Wang 1997).

Es gibt allerdings auch einige Untersuchungen, die zeigen, dass eine erhöhte Aktivität des NHE-1 nicht immer mit einer erhöhten mRNA-Expression einhergehen muss. Yokoyama und Mitarbeiter (2000) zeigten, dass Ventrikelmyokard von Patienten mit terminaler Herzinsuffizienz zwar eine höhere Aktivität nicht aber eine höhere Expression des NHE-1 als im nicht-insuffizenten Myokard aufwies (Yokoyama et al. 2000). In Glattmuskelzellen wurde beobachtet, dass eine erhöhte NHE-1-Aktivität auf erhöhte Kinase-Aktivitäten zurückgeführt werden kann (Phan et al. 1997; Soleimani et al. 1995).

Dyck et al. (1995) haben gezeigt, dass moderate Myokardischämie zu einer Steigerung der mRNA-Expression des NHE-1 führt, während bei einer starken Ischämie (weiter reduzierte Perfusion des Myokards) dieser Effekt aufgehoben war (Dyck et al. 1995). Es scheint also nach der initialen Erhöhung der Genexpression des NHE-1 mit der Zunahme der Ischämie des Myokardes zu einer Senkung der Genexpression des NHE-1 zu kommen. Dies könnte eine Erklärung dafür sein, warum in manchen Untersuchungen keine vermehrte Genexpression des NHE-1 bei Herzinsuffizienz nachweisbar war (z. B. Yokoyama et al. 2000).

Die Regulation der Expression des NHE-1 scheint multifaktoriell und komplex zu sein. Bisher wurden mehrere die Genexpression des NHE-1 steigernde Faktoren beschrieben: eine Azidose bei einer Ischämie (Yang et al. 1996; Fliegel und Fröhlich 1993); eine chronische metabolische Azidose (Moe et al. 1991; Igarashi et al. 1992); eine Aktivierung des RAS sowie eine folgende Stimulation des $\mathrm{AT}_{1}$-Rezeptors (Sandmann et al. 2001); eine Drucküberlast-induzierte Hypertrophie; $\alpha_{1}$-adrenerge Stimulation; Endothelin und Thrombin (Fliegel und Wang 1997); ischämische Metabolite (Karmazyn et al. 1996); die Aktivierung von G-Proteinen $\left(\mathrm{G}_{\alpha 13}\right.$ und $\mathrm{G}_{\alpha \mathrm{q}}$ ) (Kitamura et al. 1995); die Aktivierung der Proteinkinase C (Horie et al. 1992; Wakabayashi et al. 1997; Soleimani et al. 1995).

Besonders nach der Klonierung der Promotor-Region des NHE-1-Gens wurden die Mechanismen der transkriptionellen Regulation des NHE-1 weitergehend erforscht. Dabei spielt der Transkriptionsfaktor AP-2 eine wichtige Rolle bei der Regulation der Expression des NHE-1 in Kardiomyozyten (Yang et al. 1996). Nach Fliegel und Wang könnte sowohl die erhöhte Aktivität als auch die erhöhte Expression des NHE-1 nach Gabe von $\alpha_{1}$-adrenergen Agonisten, Endothelin, Thrombin sowie nach Drucküberlast auf AP-2-verursachte 
Änderungen der mRNA-Expression des NHE-1 zurückzuführen sein (Fliegel und Wang 1997).

Zusammengefasst ergeben sich dadurch überzeugende Anhaltspunkte dafür, dass bei einer ischämischen Schädigung des Myokards eine erhöhte mRNA- und Proteinexpression des NHE-1 - ausgelöst durch verschiedene Faktoren - resultiert mit einer erhöhten NHE-1Aktivität. Da die häufigsten Ursachen für eine Herzinsuffizienz die ischämische Kardiomyopathie und eine Hypertension sind, kann man davon ausgehen, dass sich eine vermehrte Proteinkonzentration des NHE-1 im insuffizienten Myokard ergibt, wie in der vorliegenden Arbeit gezeigt wurde. Es ist jedoch noch nicht klar, wie der genaue Zusammenhang zwischen der NHE1-Stimulierung und der vermehrten Expression des NHE-1 in verschieden Stadien der Herzinsuffizienz ist.

Die Untersuchungen, die eine Steigerung der Aktivität des NHE-1 auch ohne eine erhöhte Expression des NHE-1 zeigen, deuten darauf hin, dass es auch posttranslationale Mechanismen gibt, die zu einer Stimulierung des NHE-1 bei der Herzinsuffizienz führen. 


\section{Zusammenfassung}

Der intrazelluläre $\mathrm{pH}-\mathrm{Wert}\left(\mathrm{pH}_{\mathrm{i}}\right)$ spielt eine kritische Rolle bei der Aufrechterhaltung der physiologischen Funktionen der Zelle. Der $\mathrm{Na}^{+} / \mathrm{H}^{+}$-Austauscher (NHE) ist ein Membranprotein und schleust Protonen 1:1 im Austausch gegen extrazelluläres $\mathrm{Na}^{+}$aus der Zelle heraus. Er ist maßgeblich an der $\mathrm{pH}_{\mathrm{i}}$-Regulation beteiligt. In Herzmuskelzellen wird vermutlich ausschließlich der NHE-1 exprimiert. Seine Aktivierung ist pathophysiologisch von besonderer Bedeutung, insbesondere bei Ischämie-Reperfusionsschäden und der Entwicklung von Herzinsuffizienz.

$\mathrm{Zu}$ den Fragen, ob es Unterschiede in der NHE-1-abhängigen, globalen und subzellulären $\mathrm{pH}_{\mathrm{i}}$ - Regulation zwischen Vorhof- und Ventrikelmyozyten gibt, und ob es Unterschiede in der NHE-Expression zwischen humanem Vorhof- und Ventrikelgewebe und bei verschiedenen Herzerkrankungen gibt, wurde in dieser Arbeit die subzelluläre $\mathrm{H}^{+}$-Homöostase und die Aktivität des NHE-1 in verschiedenen subzellulären Regionen von Vorhof- und Ventrikelmyozyten aus dem Kaninchenherzen gemessen und die Expression des NHE-1 in gesundem und insuffizientem humanen Myokard durch die Western-Blot-Methode gemessen und verglichen. Die Aktivität des NHE-1 wurde anhand von NHE-abhängigen $\mathrm{pH}_{\mathrm{i}^{-}}$ Änderungen ermittelt in verschiedenen subzellulären Regionen in Vorhof- und Ventrikelmyozyten aus Kaninchen. Dazu wurde die $\mathrm{NH}_{4} \mathrm{Cl}$-Säurepuls-Methode in Verbindung mit einem pH-sensitiven Fluoreszenzfarbstoff, 5-Carboxy-SNARF®-1, verwendet. Der Einsatz der Konfokalmikroskopie erlaubte die Messung subzellulärer Fluoreszenzänderungen. Die Spezifität der Methode wurde durch Kontrollexperimente mit einem NHE-1-spezifischen Hemmstoff, HOE642, nachgewiesen. Die Fluroreszenzänderungen wurden geeicht und in $\mathrm{pH}_{\mathrm{i}}-$ Änderungen umgerechnet. Die Rate des $\mathrm{H}^{+}$-Efflux bei pH 6,9 $\left(\mathrm{J}_{\mathrm{pH} 6,9}\right)$ wurde als Maß für die Aktivität des NHE-1 bestimmt.

Es zeigte sich, dass die globale NHE-1-abhängige- $\mathrm{J}_{\mathrm{pH} 6,9}$ in Ventrikelmyozyten deutlich größer als in Vorhofmyozyten bzw. die $\mathrm{J}_{\mathrm{pH} 6,9}$ im Zentrum der Ventrikelmyozyten signifikant größer als in Vorhofmyozyten war. Die subzelluläre NHE-1-abhängige- $\mathrm{J}_{\mathrm{pH} 6,9}$ war sowohl in den Ventrikelmyozyten als auch in den Vorhofmyozyten in allen subzellulären Regionen ähnlich groß. Bei den quantitativen Messungen des NHE-1-Proteins wurde ebenfalls kein Unterschied zwischen humanem nicht-insuffizientem Ventrikel- und Vorhofmyokard durch die WesternBlot-Methode nachgewiesen. Diese Arbeit hat damit wichtige Unterschiede in der globalen und subzellulären NHE-abhängigen $\mathrm{pH}_{\mathrm{i}}$-Regulation zwischen Ventrikel- und Vorhofmyozyten aufgedeckt. Ventrikelmyoyzten besitzen eine deutlich größere NHE-1vermittelte $\mathrm{H}^{+}$-Elimination ( $5 \mathrm{mM} / \mathrm{min}$ versus $3,2 \mathrm{mM} / \mathrm{min}$ in Vorhofmyoyzten). Diese beruht 
im Wesentlichen auf der größeren $\mathrm{H}^{+}$-Elimination aus dem Zentrum der Zellen, was mit dem Vorhandensein des T-Tubulus-Systems in den Ventrikelmyozyten erklärt werden kann. Messbare radiale pH-Gradienten konnten weder in Ventrikel- noch in Vorhofmyoyzten beobachtet werden. Dies deutet darauf hin, dass die Diffusion von Protonen vom Zellinneren zur Zellmembran, die die NHE-Transporter enthält, schnell genug ist, um die im subsarkolemmalen Raum eliminierten Protonen zu ersetzen.

Beim Vergleich der NHE-1-Expression zwischen insuffizientem und nicht-insuffizientem Vertrikelmyokard konnte eine erhöhte Expression des NHE-1 im insuffizienten humanen Vertrikelmyokard nachgewiesen werden. Dies spricht für eine erhöhte NHE-1-Aktivität im insuffizienten Myokard. Es deutet darauf hin, dass der kardiale NHE-1 ein pharmakologisches Ziel für die Behandlung der menschlichen Herzinsuffizienz darstellen könnte, ähnlich wie dies in Tiermodellen bereits gezeigt wurde. 


\section{Literaturverzeichnis}

Aharonovitz O, Zaum HC, Balla T, York JD, Orlowski J, Grinstein S (2000): Intracellular $\mathrm{pH}$ regulation by $\mathrm{Na}^{+} / \mathrm{H}^{+}$exchanger requires phosphatidylinositol 4, 5bisphosphate. J Cell Biol 150, 213-224

Alper SL (2006): Molecular physiology of SLC4 anion exchangers. Exp Physiol 91(1), 15361

Alvarez BV, Kieller DM, Quon AL, Markovich D, Casey JR (2004): Slc26a6: a cardiac chloride-hydroxyl exchanger and predominant chloride-bicarbonate exchanger of the mouse heart. J Physiol 561(Pt 3), 721-34

Aronson PS, Nee J, Suhm MA (1982): Modifier role of internal $\mathrm{H}^{+}$with the $\mathrm{Na}^{+} / \mathrm{H}^{+}$ exchangers in renal microvillus membrane vesicles. Nature 299, 161-163

Avkiran M, Haworth RS (2003): Regulatory effects of G protein-coupled receptors on cardiac sarcolemmal $\mathrm{Na}^{+} / \mathrm{H}^{+}$exchanger activity: signalling and significance. Circ Res $\underline{57}$, 942-952

Avkiran M, Yokoyama H (2000): Adenosine A(1) receptor stimulation inhibits alpha(1)adrenergic activation of the cardiac sarcolemmal $\mathrm{Na}^{+} / \mathrm{H}^{+}$exchanger. Br. J. Pharmacol 131(4), 659-662

Avkiran M, Cook AR, Cuello F (2008): Targeting $\mathrm{Na}^{+} / \mathrm{H}^{+}$exchanger regulation for cardiac protection: a RSKy approach? Curr Opin Pharmacol $\underline{8}, 133-40$

Balnave CD, Vaughan-Jones RD (2000): Effect of intracellular $\mathrm{pH}$ on spontaneous $\mathrm{Ca}^{2+}$ sparks in rat vertricular myocytes. J Physiol 528.1, 25-37

Benos DJ (1982): Amilorid: A molecular probe of sodium transport in tissues and cells. Am J Physiol 242, C131-C145

Bers DM: Excitation-Contraction Coupling and Cardiac Contractile Force. 2. Auflage; Kluwer Academic Publishers, Amsterdam 2001

Bevensee MO, Boron WF (1995): Manipulatio and regulation of cytosolic $\mathrm{pH}$. Methods Neurosci 27, 252-272

Biemesderfer D, Pizzonia J, Abu-Alfa A, Exner M, Reilly R, Igarashi P and Aronson PS (1993): NHE3: a Na $/ \mathrm{H}^{+}$exchanger isoform of renal brush border. Am J Physiol 265, F736742

Blank PS, Silverman HS, Chung OY, Hongue BA, Stern MD, Hansford RG, Lakatta EG, Capogrossi MC (1992): Cytosolic $\mathrm{pH}$ measurements in single cardiac myocytes using carboxy-seminaphthorhodafluor-1. Am J Physiol 263, H276-H284

Blatter LA, Kockskämper J, Sheehan KA, Zima AV, Hüser J, Lipsius SL (2003): Local calcium gradients during excitation-contraction coupling and alternans in atrial myocytes. J Physiol 546(Pt 1), 19-31 
Bookstein C, Musch MW, DePaloli A, Xie Y, Rabenau K, Villereal M, Rao MC, Chang EB (1996): Characterization of the rat $\mathrm{Na}^{+} / \mathrm{H}^{+}$exchanger isoform NHE4 and localization in rat hippocampus. Am J Physiol 271, C1629-C1638

Bookstein C, Xie Y, Rabenau K, Musch MW, McSwine RL, Rao MC, Chang EB (1997): Tissue distribution of $\mathrm{Na}^{+} / \mathrm{H}^{+}$exchanger isoforms NHE2 and NHE4 in rat intestine and kidney. Am J Physiol 273(5 Pt 1), C1496-505

Bountra C, Vaughan-Jones RD (1989): Effect of intracellulat and extracellulat $\mathrm{pH}$ on contraction in isolated mammalian cardiac muscle. J Physiol 418, 163-187

Boyarsky G, Ganz MB, Sterzel RB, Boron WF (1988): pH regulation in single glomerular mesangial cells II. $\mathrm{Na}^{+}$-dependent and - independent $\mathrm{Cl}^{-}-\mathrm{HCO}_{3}{ }^{-}$-exchangers. Am J Physiol 255, C857-C869

Brant SR, Yun CH, Donowitz M, Tse CM (1995): Cloning, tissue distribution, and functional analysis of the human $\mathrm{Na}^{+} / \mathrm{H}^{+}$exchanger isoform, NHE3. Am J Physiol 269(1 Pt 1), C198-206

Brett CL, Wei Y, Donowitz M, Rao R (2002): Human $\mathrm{Na}^{+} / \mathrm{H}^{+}$exchanger isoform 6 is found in recycling endosomes of cells, not in mitochondria. Am J Physiol 282, C1031-C1041

Brunner F, Opie LH (1998): Role of endothelin-A receptors in ischemic contracture and reperfusion injury. Circulation $\underline{97}, 391-398$

Buckendahl J: Die NHE-1-mRNA-Expression im Myokard von herzinsuffizienten Patienten. Med. Diss. Berlin 2006

Buckler KJ, Vaughan-Jones RD (1990): Application of a new pH-sensitive fluoroprobe (carboxy-SNARF-1) for intracellular $\mathrm{pH}$ measurement in small, isolated cells. Pflugers Arch $\underline{417(2)}, 234-239$

Cabado AG, Yu FH, Kapus A, Gergely L, Grinstein S, Orlowski J (1996): Distinct structural domains confer cAMP sensitivity and ATP dependence to the $\mathrm{Na}^{+} / \mathrm{H}^{+}$exchanger NHE3 isoform. J Biol Chem 271, 3590-3599

Camilión de Hurtado MC, Portiansky EL, Perez NG, Rebolledo OR, Cingolani HE (2002): Regression of cardiomycyte hypertrophy in SHR following chronic inhibition of the $\mathrm{Na}^{+}-\mathrm{H}^{+}$exchanger. Cardiovasc Res 53(4), 862-868

Choi I, Romero MF, Khandoudi N, Bril A, Boron WF (1999): Cloning and characterization of a human electrogenic $\mathrm{Na}^{+}-\mathrm{HCO}_{3}{ }^{-}$cotransporter isoform (hhNBC). Am J Physiol 276(3 Pt 1), C576-584

Connolly AJ, Ishihara H, Kahn ML, Farese RV, Coughlin SR (1996): Role of the thrombin receptor in development and evidence for a second receptor. Nature $\underline{381}, 516-519$

Coughlin SR (1994): Thrombin receptor function and cardiovascular disease. Trends Cardiovasc Med $\underline{4}, 77-83$ 
Counillon L, Pouysségur J (1995): Structure-function studies and molecular regulation of the growth factor activatable sodium-hydrogen exchanger (NHE-1). Cardiovasc Res 29, 147154

Counillon L, Pouysségur J (2000): The expanding family of eucaryotic $\mathrm{Na}^{+} / \mathrm{H}^{+}$exchangers. J Biol Chem 275, 1-4

Counillon L, Franchi A, Pouysségur J (1993a): A point mutation of the $\mathrm{Na}^{+} / \mathrm{H}^{+}$exchanger gene (NHE1) and amplification of the mutated allele confer amiloride resistance upon chronic acidosis. Proc Natl Acad Sci USA 90, 4508-4512

Counillon L, Scholz W, Lang HJ, Pouyssegur J (1993b): Pharmacological characterization of stably transfected $\mathrm{Na}^{+} / \mathrm{H}^{+}$antiporter isoforms using amiloride analogs and a new inhibitor exhibiting antiischemic properties. Mol Pharmacol 44, 1041-1045

Counillon L, Pouysségur J, Reithmeier RA (1994): The $\mathrm{Na}^{+} / \mathrm{H}^{+}$exchanger NHE-1 possesses $\mathrm{N}$ - and O-linked glycosylation restricted to the first $\mathrm{N}$-terminal extracellular domain. Biochemistry 33(34), 10463-9

Cowie MR, Wood DA, Coats AJ, Thompson SG, Poole-Wilson PA, Suresch V, Sutton GC (1999): Incidence and aetiology of heart failure: a Population-based study. Eur Heart J $\underline{20(6)}, 421-428$

Cutaia MV, Parks N, Centracchio J, Rounds S, Yip KP, Sun AM (1998): Effect of hypoxie exposure on $\mathrm{Na}^{+} / \mathrm{H}^{+}$antiport activity, isoform expression, and localization in endothelial cells. Am J Physiol (Lung Cellular Molecular Physiology) 275, 442-451

Delbridge LM, Satoh H, Yuan W, Bassani JW, Qi M, Ginsburg KS, Samarel AM, Bers DM (1997): Cardiac myocyte volume, $\mathrm{Ca}^{2+}$ fluxes, and sarcoplasmic reticulum loading in pressure-overload hypertrophy. Am J Physiol 272(5 Pt 2), 2425-35

Diiring HJ (1996): Das isoliert perfundierte Herz nach Langendorff-Geschichte und Gegenwart, Modifikationen und Applikationen. Acta Chir Austriaca 9(6)

Dyck JR, Maddaford TG, Pierce GN, Fliegel L (1995): Induction of expression of the sodium-hydrogen exchanger in rat myocardium. Cardiovasc Res $\underline{29}$, 203-208

Engelhardt S, Hein L, Keller U, Klämbt K, Lohse MJ (2002): Inhibition of $\mathrm{Na}^{+} / \mathrm{H}^{+}$ exchange prevents hypertrophy, fibrosis, and heart failure in beta(1)-adrenergic receptor transgenic mice. Circ Res 90(7), 814-9

Fafournoux P, Noël J, Pouysségur $\mathbf{J}$ (1994): Evidence that $\mathrm{Na}^{+} / \mathrm{H}^{+}$exchanger isoforms NHE1 and NHE3 exist as stable dimmers in membranes with a high degree of specificity for homodimers. J Biol Chem 269, 2589-2596

Fareh J, Touyz RM, Schiffrin EL, Thibault G (1996): Endothelin-1 and angiotensin II receptors in cells from rat hypertrophied heart. Receptor regulation and intracellular $\mathrm{Ca}^{2+}$ modulation. Circ Res $\underline{78}$, 302-311

Fleischer LA, Newmann MF, St. Aubin LB, Cropp AB, Billing CB, Bonney S, Mackey WC, Poldermans D, Corbalan R, Pereira AH, et al. (2005): Efficacy of zoniporide , an 
$\mathrm{Na}^{+} / \mathrm{H}^{+}$Exchanger inhibitor, for reducing perioperative cardiovascular events in vascular surgery patients. J Cardiothorac Vasc Anesth 19(5), 570-576

Fliegel L: The $\mathrm{Na}^{+} / \mathrm{H}^{+}$Exchanger. 1. Auflage; Springer Verlag, Heidelberg, Germany 1996 P.127

Fliegel L (1999): Functional and cellular regulation of myocardial $\mathrm{Na}^{+} / \mathrm{H}^{+}$exchanger. $\mathbf{J}$ Thromb Thrombolysis, 8-13

Fliegel L, Fröhlich O (1993): The $\mathrm{Na}^{+} / \mathrm{H}^{+}$Exchanger: an update on structure, regulation and cardic physiology. Biochem J 296, 273-285

Fliegel L, Wang $\mathbf{H}$ (1997): Regulation of the $\mathrm{Na}^{+}-\mathrm{H}^{+}$exchanger in the Mammalian Myocardium. J Mol Cell Cardiol 29, 1991-1999

Fliegel L, Haworth RS, Dyck JRB (1993): Characterization of the placental brush border membrane $\mathrm{Na}^{+} / \mathrm{H}^{+}$exchanger: identification of thiol-dependent transitions in apparent molecular size. Biochem J 289, 101-107

Fröhlich O, Wallert MA (1995): Methods of measuring intracellular $\mathrm{pH}$ in the heart. Cardiovasc Res 29, 194-202

Fuller SJ, Gaitanaki CJ, Sugden PH (1990): Effects of catecholamines on protein synthesis in cardiac myocytes and perfused heart isolated from adult rats. Biochem J 266, 727-736

Garlid, KD (1988): Sodium/proton antiporters in the mitochondrial inner membrane. Adv Exp Med Biol 232, 37-46

Genka C, Ishida H, Ichimori K, Hirota Y, Tanaami T, Nakazawa H (1999): Visualization of biphasic $\mathrm{Ca}^{2+}$ diffusion from cytosol to nucleus in contracting adult rat cardiac myocytes with an ultra-fast confocal imaging system. Cell Calcium 25, 199-208

Glembotski CC, Irons CE, Krown KA, Murray SF, Sprenkle AB, Sei CA (1993): Myocaridial $\alpha$-thrombin recepteor activation induces hypertrophy andincreases atrial natriuretic factor gene expression. J Biol Chem $\underline{268}, 20646-52$

Goldberg EB, Arbel T, Chen J, Karpel R, Mackie GA, Schuldiner S, Padan E (1987): Characterization of $\mathrm{Na}^{+} / \mathrm{H}^{+}$antiporter gene of E.Coli. Proc Natl Acad Sci USA $\underline{84}, 2615-2619$

Goss GG, Woodside M, Wakabayashi S, Pouysségur J, Waddell T, Downey GP, Grinstein S (1994): ATP dependence of NHE-1, the ubiquitous isoform of the $\mathrm{Na}^{+} / \mathrm{H}^{+}$ antiporter. Analysis of phosphorylation and subcellular localization. J Biol Chem $\underline{269}$, 87418748

Goyal S, Vanden- Heuvel G, Aronson PS (2003): Renal expression of novel $\mathrm{Na}^{+} / \mathrm{H}^{+}$ exchange isoform NHE-8. Am J Physiol 284, F467-F473

Grace AA, Metcalfe JC, Weissberg PL, Bethell HWL, Vandenberg JI (1996): Angiotensin II Stimulates sodium-dependent proton extrusion in perfused ferret heart. Am J Physiol 279, C1687-C1694 
Gu JW, Anand V, Shek EW, Morre MC, Brady AL, Kelly WC, Adair TH (1998): Sodium induces hypertrophy of cultured myocardial myoblasts and vascular smooth muscle cells. Hypertension $\underline{31}$, 1083-1087

Gunasegaram S, Haworth RS, Hearse DJ, Avkiran M (1999): Regulation of sarcolemmal $\mathrm{Na}^{+} / \mathrm{H}^{+}$exchanger activity by angiotensin II in adult rat ventriculat myocytes: opposing actions via AT1 versus AT2 receptors. Circ Res $\underline{85}$, 919-930

Halestrap AP, Meredith D (2004): The SLC16 gene family-from monocarboxylate transporters (MCTs) to aromatic amino acid transporters and beyond. Pflugers Arch 447(5), $619-28$

Haworth RS, McCann C, Snabaitis AK, Roberts NA, Avkiran M (2003): Stimulation of the plasma membrane $\mathrm{Na}^{+} / \mathrm{H}^{+}$exchanger NHE1 by sustained intracellular acidosis. Evidence for a novel mechanism mediated by the ERK pathway. J Biol Chem 278(34), 31676-84

Hoogerwerf WA, Tsao SC, Devuyst O, Levine SA, Yun CH, Yip JW, Cohen ME, Wilson PD, Lazenby AJ, Tse CM, Donowitz M (1996): NHE2 and NHE3 are human and rabbit intestinal brush-border proteins. Am J Physiol 270(1 Pt 1), G29-41

Horie S, Moe O, Yamaji Y, Cano A, Miller RT, Alpern RJ (1992): Role of protein kinase $\mathrm{C}$ and transcription factor AP-1 in the acid-induced increase in $\mathrm{Na} / \mathrm{H}$ antiporter activity. Proc Natl Acad Sci USA 89 (12), 5236-5240

Hoshino K, Avkiran M (2001): Effects of moderate hypothermia on sarcolemmal $\mathrm{Na}^{+} / \mathrm{H}^{+}$ exchanger activity and its inhibition by cariporide in cardiac ventricular myocytes. $\mathrm{Br} \mathrm{J}$ Pharmacol 134(7), 1587-95

Howard AD, McAllister G, Feighner SD, Liu Q, Nargund RP, Van der Ploeg LHT, Patchett AA (2001): Orphan G-protein-coupled receptors and natural ligand discovery. Trends Phamacol Sci 22, 132-140

Humphreys RA, Haist JV, Chakrabarti S, Feng QP, Arnold JMO, Karmazyn M (1999): Orally administered NHE1 inhibitor cariporide reduces acute response to coronary occlusion and reperfusion. Am J Physiol 276, H749-H757

Igarashi P, Freed MI, Ganz MB, Reilly RF (1992): Effects of chronic metabolic acidosis on $\mathrm{Na}^{+}-\mathrm{H}^{+}$exchangers in LLC-PK1 renal epithelial cells. Am J Physiol 263, F83-88

Ishida H, Genka C, Hirota Y, Nakazawa H, Barry WH (1999): Formation of Planar and Spiral Ca21 Waves in Isolated Cardiac Myocytes. Biophys J 77, 2114-2122

Ishihara H, Connolly AJ, Zeng D, Kahn ML, Zheng YW, Timmons C, Tram T, Coughlin SR (1997): Protease-activated receptor 3 is a second thrombin receptor in humans. Nature 386, 502-506

Jandeleit-Dahm K, Hannan KM, Farrelly CA, Allen Tj, Rumble JR, Gilbert RE, Cooper ME, Little PJ (2000): Diabetes-induced vascular hypertrophy is accompanied by activation of $\mathrm{Na}^{+}-\mathrm{H}^{+}$exchanger and prevented by $\mathrm{Na}^{+}-\mathrm{H}^{+}$exchanger inhibition. Circ Res $\underline{87}, 113-1149$ 
Kahn AM, Cragoe EJ, Allen JC, Seidel CL, Shelat $\mathbf{H}$ (1991): Effects of $\mathrm{pH}_{\mathrm{i}}$ on $\mathrm{Na}^{+}-\mathrm{H}^{+}$, $\mathrm{Na}^{+}$-dependent, and $\mathrm{Na}^{+}$-independent $\mathrm{Cl}^{-}-\mathrm{HCO}_{3}{ }^{-}$exchange in vascular smooth muscle. Am J Physiol 261, C837-C844

Kaila K, Vaughan-Jones RD (1987): Influence of sodium-hydrogen exchange on intracellular $\mathrm{pH}$, solidum and tension in sheep cardiac purkinje fibres. J Physiol (Lond) $\underline{390}$, 93-118

Karmazyn M (1996): The sodium-hydrogen exchange system in the heart: its role in ischemic and reperfusion injury and therapeutic implications. Can J Cardiol 12(10), 1074-82

Karmazyn M (2001): Role of sodium-hydrogen exchange in cardiac hypertrophy and heart failure: a novel and promising therapeutic target. Basic Res Cardiol 96, 325-328

Karmazyn M, Gan XT, Humphreys RA, Yoshida H, Kusumoto K (1999): The Myocardial $\mathrm{Na}^{+} / \mathrm{H}^{+}$Exchange Structrue, Regulation, and Its Role in Heart Disease. Circ Res $\underline{85}, 777-786$

Karmazyn M, Sostaric JV and Gan XT (2001): The myocyrdial $\mathrm{Na}^{+} / \mathrm{H}^{+}$exchanger: A potential therapeutic target for prevention of myocardial ischaemic and reperfusion injury and attenuation of postinfarction heart failure. Drugs $\underline{61(3)}, 375-389$

Kääb S, Barth AS, Margerie D, Dugas M, Gebauer M, Zwermann L, Merk S, Pfeufer A, Steinmeyer K, Bleich M, et al. (2004): Global gene expression in human myocardiumoligonucleotide microarray analysis of regional diversity and transcriptional regulation in heart failure. J Mol Med 82(5), 308-16

Khandoudi N, Ho J, Karmazyn M (1994a): Role of $\mathrm{Na}^{+}-\mathrm{H}^{+}$exchange in mediating effects of endothelin-1 on normal and ischemic/reperfused hearts. Circ Res $\underline{75}, 369-378$

Khandoudi N, Moffar MP, Karmazyn M (1994b): Adnosine-sensitive $\alpha 1$-adrenoceptor effects on reperfused ischaemic hearts: comparison with phorbol ester. Br J Pharmacol $\underline{112}$, $1007-1016$

Kitamura K, Singer WD, Cano A, Miller RT (1995): Gaq and Ga13 regulate NHE-1 and intracellular calcium in epithelial cells. Am J Physiol 268, C101-C110

Klämbt K: Untersuchung zur Wirkung und Wirkmechanismus von NHE-1-Inhibitoren auf die Hypertrophie adulter Rattenkardiomyozyten.Med. Diss. Frankfurt am Main 2005

Kleyman TR, Cragoe EJ Jr (1988): Amiloride and its analogs as tools in the study of ion transport. J Membr Biol 105(1), 1-21

Kovar A, Peters T, Beier N, Derendorf H (2001): Pharmacokinetic/pharmacodynamic evaluation of the NHE inhibitor eniporide. J Clin Pharmacol 41(2), 139-48

Krämer BK, Smith TW, Kelly RA (1991): Endothelin and increased contractility in adult rat ventricular myocytes. Circ Res $\underline{68}, 269-279$ 
Kusumoto K, Haist JV, Karmazyn M (2001): $\mathrm{Na}^{+} / \mathrm{H}^{+}$exchange inhibition reduces hypertrophy and heart failure following myocardial infarction in rats. Am J Physiol 280, H738-H745

Kusumoto K, Igata H, Abe A, Ikeda S, Tsuboi A, Imamiya E, Fukumoto S, Shiraishi M, Watanabe T (2002): In vitro and in vivo pharmacology of a structurally novel $\mathrm{Na}^{+} / \mathrm{H}^{+}$ exchange inhibitor, T-162559. Br J Pharmacol 135(8), 1995-2003.

Laemmli UK (1970): Cleavage of structural proteins during the assembly of the head of bacteriophage $\mathrm{T}_{4}$. Nature, 227(5259), 680-685.

Lagadic-Gossmann D, Buckler KJ, Vaughan-Jones RD (1992): Role of bicarbonate in pH recovery from intracellular acidosis in the guinea-pig vertricular myocyte. J Physiol $\underline{458}, 361$ 384

Leem CH, Lagadic-Gossman D, Vaughan-Jones RD (1999): Characterisation of intracellular pH regulation in the guinea-pig vertricular myocyte. J Physiol 517, 159-180.

Lidofsky SD, Fritz JG, Scharschmidt BF (1993): Mechanisms and functional role of intracellular $\mathrm{pH}$ regulation in hepatocytes. Prog Liver Dis 11, 69-83

Lin X, Barber DL (1996): A calcineurin homologous protein inhibits GTPase- stimulated $\mathrm{Na}^{+} / \mathrm{H}^{+}$exchanger. J Biol Chem $\underline{93}, 12631-12636$

Linz WJ, Busch AE (2003): NHE-1 inhibition: from protection during acute ischaemia/reperfusion to prevention/reversal of myocardial remodelling. NaunynSchmiedeberg's Arch Pharmacol 368, 239-246

Lowry OH, Rosebrough NJ, Farr AL, Randall RJ (1951): Protein measurement with the Folin phenol reagent. J Biol Chem 193(1), 265-75)

Mahnensmith RL, Aronson PS (1985): The plasma membrane sodium-hydrogen exchanger and its role in physiological and pathophysiological processes. Circ Res $\underline{56}, 773-788$

Meng HP, Pierce GN (1990): Protective effects of 5-(N1 N-dimethyl) amiloride on ischemia-reperfusion injury in hearts. Am J Physiol 258, H1615-1619

Michailova A, DelPrincipe F, Egger M, Niggli E (2002): Spatiotemporal Features of Ca2 ${ }^{+}$ Buffering and Diffusion in Atrial Cardiac Myocytes with Inhibited Sarcoplasmic Reticulum. Biophys J $\underline{83}$, 3134-3151

Mitchell P (1961): Coupling of phosphorylation to electron and hydrogen transfer by a chimiosmotic type of mechanism. Nature 191, 144-146.

Mitchell P, Moyle J. (1967): Respiration -driven proton translocation in rat liver mitochondria. Biochem J 105, 1147-1162

Moe OW (1999): Acute regulation of proximal tubule apical membrane $\mathrm{Na}^{+} / \mathrm{H}^{+}$exchanger NHE-3: role of phosphorylation, protein trafficking, and regulatory factors. J Am Soc Nephrol 10(11), 2412-25 
Moe OW, Tejedor A, Levi M, Seldin DW, Preisig PA, Alpern RJ (1991): Dietary NaCl modulates $\mathrm{Na}^{+}-\mathrm{H}^{+}$antiporter activity in renal cortical apical membrane vesicles. Am J Physiol $\underline{260}$, F130-137

Moor AN, Fliegel L (1999): Protein kinase mediated regulation of the $\mathrm{Na}^{+} / \mathrm{H}^{+}$exchanger in the rat myocardium by MAP-kinase-dependent pathways. J Biol Chem $\underline{274}$, 22985-229992

Mosterd A, Cost B, Hoes AW, de Bruijne MC, Deckers JW, Hofman A, Grobbee DE (2001): The prognosis of heart failure in The general population: the Rotterdam Study. Eur Heart J 22(15), 1318-1327

Mulieri LA, Hasenfuss G, Ittleman F, Blanchard EM, Alpert NR (1989): Protection of human left ventricular myocardium from cutting injury with 2, 3-butanedione monaxime. Cir Res $\underline{65}, 1441-1449$

Murer H, Hopfer U, Kinne R (1976): Sodium/proton antiport in brush bordermembrane vesicles isolated from rat small intestine and kidney. Biochem J 154, 597-604

Murphy E, Allen DG (2009): Why did the NHE inhibitor clinical trials fail? J Mol Cell Cardiol $\underline{46}, 137-141$

Murphy E, Perlman M, London RE, Steenbergen C (1991): Amilorid delays the ischemic induced rise in cytosolic calcium. Circ Res $\underline{68}, 1250-1258$

Myers ML, Mathur S, Li GH, Karmazyn M (1995): Sodium-hydrogen exchange inhibitors improve postischaemic recovery of function in the perfused rabbit heart. Cardiovasc Res $\underline{29}$, 209-214

Nakamura N, Tanaka S, Teko Y, Mitsui $\mathbf{K}$ and Kanazawa $\mathbf{H}$ (2005): Four $\mathrm{Na}^{+} / \mathrm{H}^{+}$ Exchanger Isoforms Are Distributed to Golgi and Post-Golgi Compartments and Are Involved in Organelle pH Regulation' J Biol Chem 280, 1561-1572

Niederer SA, Swietach P, Wilson DA, Smith NP, Vaughan-Jones RD (2008): Measuring and modeling chloride-hydroxyl exchange in the guinea-pig ventricular myocyte. Biophys J 94(6), 2385-403

Numata M, Orlowski J (2001): Molecular cloning and characterization of a novel $\mathrm{Na}^{+} / \mathrm{H}^{+}$ exchanger localized to the trans-Golgi network. J Biol Chem 276, 17387-17394

Orchard CH, Kentish JC (1990): Effects of changes of $\mathrm{pH}$ on the contractile function of cardiac muscle. Am J Physiol 258(6 Pt 1), C967-81

Orlowski J (1993): Heterologous expression and functional properties of the amiloride high affinity (NHE-1) and low affinity (NHE-3) isoforms of the rat $\mathrm{Na}^{+} / \mathrm{H}^{+}$exchanger. $\mathrm{J}$ Biol Chem 268, 16369-16377

Orlowski, J, Kandasamy, RA (1996): Delineation of transmembrane domains of the $\mathrm{Na}^{+} / \mathrm{H}^{+}$ exchanger that confer sensitivity to pharmacological antagonists. J. Biol.chem. 271(33), 19922-19927 
Orlowski J, Grinstein S (1997): $\mathrm{Na}^{+} / \mathrm{H}^{+}$exchangers of mammalian cells. J Bio Chem 272 , 22373-22376

Orlowski J, Grinstein S (2004): Diversity of the mammalian sodium/proton exchanger SLC9 gene family. Pflugers Arch 447(5), 549-65

Orlowski J, Kandasamy RA, Shull GE (1992): Molecular cloning of putative members of the $\mathrm{Na} / \mathrm{H}$ exchanger gene family. cDNA cloning, deduced amino acid sequence, and mRNA tissue expression of the rat $\mathrm{Na}^{+} / \mathrm{H}^{+}$exchanger NHE-1 and two structurally related proteins. $\mathrm{J}$ Biol Chem 267(13), 9331-9

Petrecca K, Atanasiu R, Grinstein S, Orlowski J, Shrier A (1999): Subcelllular Localization of the sheep cardiac purkinje fibers. J Mol Cell Cardiol 29, 1131-1140

Phan VN, Kusuhara M, Lucchesi PA, Berk BC (1997): A 90-kD Na $/ \mathrm{H}^{+}$exchanger kinase has increased activity in spontaneously hypertensive rat vascular smooth muscle cells. Hypertension 29, 1265-1272

Pierce GN, Meng H (1992): The role of sodium-proton exchenge in ischemic-reperfusion injury in the heart. Am J Cardio Vasc Pathol $\underline{4}, 91-102$

Pucéat M, Vassort G (1995): Neurohumoral modulation of intracellular $\mathrm{pH}$ in the heart. Caudiovasc Res 29, 178-183

Pucéat M, Clément-Chomienne O, Terzic A, Vassort G (1993): $\alpha 1$-adrenoceptor and pruinoceptor agonists modulate $\mathrm{Na}-\mathrm{H}$ antoport in single cardiac cells. Am J Physiol 264 , H310-H319

Raley-Susman KM, Cragoe EJ Jr, Sapolsky RM, Kopito RR (1991): Regulation of intracellular $\mathrm{pH}$ in cultured hippocampal neurons by an amiloride-insensitive $\mathrm{Na}^{+} / \mathrm{H}^{+}$ exchanger. J Biol Chem 266(5), 2739-45

Richards SM, Jaconi ME, Vassort G, Puceat M (1999): A spliced variant of AE1 gene encodes a truncated form of Band 3 in heart: the predominant anion exchanger in ventricular myocytes. J Cell Sci 112(Pt 10), 1519-28

Romero MF, Fulton CM, Boron WF (2004): The SLC4 family of HCO3 - transporters. Pflugers Arch 447(5), 495-509

Roos A, Boron W (1981): Intracellular pH. Physiol Rev 61, 296-434

Sabri A, Byron KL, Samarel Am, Bell Lucchesi PA (1998): Hydrogen peroxide activates mitogen-activated protein kinases and $\mathrm{Na}^{+} / \mathrm{H}^{+}$exchange in neonatal rat cardial myocytes. Circ Res $\underline{82}, 1053-1062$

Sabri A, Muske G, Zhang H, Pak E, Darrow A, Andrade-Gordon P, Steinberg SF (2000): Signaling properties and functions of two distinct cardiomyocyte protease-acitvated receptors. Circ Res $\underline{86}, 1054-1061$ 
Saffitz JE, Kanter HL, Green KG, Tolley TK, Beyer EC (1994): Tissue-specific determinants of anisotropic conduction velocity in canine atrial and ventricular myocardium. Circ Res 74(6), 1065-70

Sandmann S, Yu M, Kaschina E, Blume A, Bouzinova E, Aalkjaer C, Unger T (2001): Differential effects of angiotensin $\mathrm{AT}_{1}$ and $\mathrm{AT}_{2}$ receptors on the expression. translation and function of the $\mathrm{Na}^{+} / \mathrm{H}^{+}$exchanger and $\mathrm{Na}^{+}-\mathrm{HCO}^{-}$symporter in the rat heart myocardial infarction. J Am Coll Cardiol 37, 2154-2165

Sardet C, Franchi A, Poryssegur J (1989): Molecular cloning, primary structure, and expression of the human growth factor-activatable $\mathrm{Na}^{+} / \mathrm{H}^{+}$antiporter. Cell $\underline{56}, 271-280$

Sardet C, Counillon L, Franchi A, Pouyssegur J (1990): Growth factors induce phosphorylation of the $\mathrm{Na}^{+} / \mathrm{H}^{+}$antitransporter, glycoprotein of $110 \mathrm{kD}$. Science $\underline{247}, 723-6$

Satoh H, Delbridge LM, Blatter LA, Bers DM (1996): Surface:volume relationship in cardiac myocytes studied with confocal microscopy and membrane capacitance measurements: species-dependence and developmental effects. Biophys J $\underline{70(3)}$, 1494-504

Schlüter KD, Schäfer M, Balser C, Taimor G, Piper HM (1998): Influence of pHi and creatine phosphate on alpha-adrenocepteor-mediated cardiac hypertrophy. J Mol Cell Cardiol $\underline{30}, 763-771$

Scholz W, Albus U (1995): Potential of selective sodium-hydrogen exchange inhibitors in cardiovascular therapy. Cardiovasc Res $\underline{29}$, 184-188

Scholz W, Albus U, Counillon L, Gögelein H, Lang HJ, Linz W, Wichert A, Schölkens BA (1995): protective effects of HOE642, a selective sodium- hydrogen exchange subtype 1 inhibitor, on cardiac ischemia and reperfusion. Cardiovasc Res 29, 260-268

Scholz W, Albus U, Lang HJ, Linz W, Martorana PA, Englert HC, Schölkens BA (1993): Hoe 694, a new $\mathrm{Na}^{+} / \mathrm{H}^{+}$exchange inhibitor and is effects in cardiac ischemia. $\mathrm{Br} \mathrm{J}$ Pharmacol $\underline{109}$, 526-528

Schomig A, Richardt G (1990): Cardiac sympathetic activity in myocardial ischemia: release and effects of noradrenaline. Basic Res Cardiol 도, 9-10

Shcheynikov N, Wang Y, Park M, Ko SB, Dorwart M, Naruse S, Thomas PJ, Muallem S (2006): Coupling modes and stoichiometry of $\mathrm{Cl}^{-} / \mathrm{HCO}_{3}{ }^{-}$exchange by slc26a3 and slc26a6. $\mathrm{J}$ Gen Physiol 127(5), 511-24

Shimada Y, Hearse DJ, Avkiran M (1996): Impact of extracellular buffer composition on cardioprotective efficacy of $\mathrm{Na}^{+} / \mathrm{H}^{+}$exchange inhibitors. Am J Physiol 270, H692-H700

Shrode LD, Gan BS, D'Souza SJ, Orlowski J, Grinstein S (1998): Topological analysis of NHE1, the ubiquitous $\mathrm{Na}^{+} / \mathrm{H}^{+}$exchanger using chymotryptic cleavage. Am J Physiol $275(2 \mathrm{Pt}$ 1) C431-9

Snabaitis Ak, Yokoyama H, Avkiran M (2000): Roles of mitogen-activated protein kinases and protein kinase $\mathrm{C}$ in a1A-adrenoceptor-mediated stimulation of the sarcolemmal $\mathrm{Na}^{+} / \mathrm{H}^{+}$ exchanger. Circ Res $\underline{86}, 214-220$ 
Snabaitis Ak, D'Mello R, Dashnyam S, Avkiran M (2006): A Novel Role for Protein Phosphatase 2A in Receptor-mediated Regulation of the Cardiac Sarcolemmal $\mathrm{Na}^{+} / \mathrm{H}^{+}$ exchanger NHE1. J Biol Chem 281(29), 20252-20262

Soeller C, Cannell MB (1999): Examination of the transverse tubular system in living cardiac rat myocytes by 2 -photon microscopy and digital image-processing techniques. Circ Res $\underline{84}$ 266-275, pmid:10024300

Soleimani M, Singh G, Dominguez JH, Howard R (1995): Long-term high osmolality activates $\mathrm{Na}^{+}-\mathrm{H}^{+}$exchanger and protein kinase $\mathrm{C}$ in aortic smooth muscle cells. Circ Res 76(4), 530-5

Spitznagel H, Chung O, Xia Q, Rossius B, Illner S, Jahnichen G, Sandmann S, Reinecke A, Daemen MJ, Unger T (2000): Cardioprotective effects of the $\mathrm{Na}^{+} / \mathrm{H}^{+}$exchange inhibitor cariporide in infarctinduced heart failure. Cardiovasc Res $\underline{46}, 102-110$

Stokes GG (1852): On the composition and resolution of streams of polarized light from different sources. Trans Cambridge Phil Soc $\underline{9}$, 399-416

Strömer H, de Groot MC, Horn M, Faul C, Leupold A, Morgan JP, Scholz W, Neubauer S (2000): $\mathrm{Na}^{+} / \mathrm{H}^{+}$-Exchange inhibition with HOE642 improves postechemic recovery due to attenuation of $\mathrm{Ca}^{2+}$ overload and prolonged acidosis on reperfusion. Circulation 101(23), $2749-2755$

Swietach P, Vanghan-Jones RD (2005): Spatial regulation of intracellular $\mathrm{pH}$ in the ventricular myocyte. Ann N Y Acad Sci 1047, 271-82

Swietach P, Rossini A, Spitzer KW, Vaughan-Jones RD (2007a): $\mathrm{H}^{+}$-ion activation and inactivation of the ventricular gap junction: a basis for spatial regulation of intracellular $\mathrm{pH}$. Circ Res 100(7), 1045-54

Swietach P, Spitzer KW, Vaughan-Jones RD (2007b): pH-Dependence of extrinsic and intrinsic $\mathrm{H}^{+}$-ion mobility in the rat ventricular myocyte, investigated using flash photolysis of a caged- $\mathrm{H}^{+}$compound. Biophys $\mathrm{J}$ 92(2), 641-53

Szabó EZ, Numata M, Lukashova V, Iannuzzi P, Orlowski J (2005): $\beta$-Arrestins bind and decrease cell-surface abundance of the $\mathrm{Na}^{+} / \mathrm{H}^{+}$exchanger NHE5 isoform. Proc Natl Acad Sci USA $102(8), 2790-2795$

Takahashi E, Abe J, Gallis B, Aebersold R, Spring DJ, Krebs EG, Berk BC (1999): p90RSK is a serum-stimulated $\mathrm{Na}^{+} / \mathrm{H}^{+}$exchanger isoform- 1 kinase: regulatory phophorylation of serine 703 of $\mathrm{Na}^{+} / \mathrm{H}^{+}$exchanger isoform-1. J Biol Chem 274, 31349-31356

Takewaki S, Kuro M, Hiroi Y, Yamazaki T, Noguchi T, Miyagishi A, Nakahara K (1995): Activation of $\mathrm{Na}^{+}-\mathrm{H}^{+}$antiporter (NHE-1) gene expression during growth, hypertrophy and proliferation of the rabbit cardiovascular system. J Mol Cell Cardiol 27, 729-42

Tani M, Neely JR (1989): Role of intracellular $\mathrm{Na}^{+}$in $\mathrm{Ca}^{2+}$ overload and depressed recovery of ventricular function of reperfused ischemic rat hearts. Possible involvement of $\mathrm{Na}^{+}-\mathrm{H}^{+}$and $\mathrm{Na}^{+}-\mathrm{Ca}^{2+}$ exchange. Circ Res $\underline{65}, 1045-1056$ 
Théroux P, Chaitman BR, Danchin N, Erhardt L, Meinertz T, Schroeder JS, Tognoni G, White HD, Willerson JT, Jessel A, for the GUARD During Ischemia Against Necrosis (GUARDLAN) Investigators (2000): Inhibition of the sodium-hydrogen exchange with cariporide to prevent myocardial infarction in high-risk ischemic situations. Main results of the Guardian trial. Circulation 102(25), 3032-3038

Thomas JA, Buchsbaum RN, Zimniak A, Racker E (1979): Intracellular pH measurements in Ehrlich ascites tumor cells utilizing spectroscopic probes generated in situ. Biochemistry $\underline{81}, 2210-2218$

Tonnessen TI, Sandvig K, Olsnes $\mathbf{S}$ (1990): Role of $\mathrm{Na}^{+}-\mathrm{H}^{+}$and $\mathrm{Cl}^{-}-\mathrm{HCO}_{3}{ }^{-}$antiports in the regulation of cystolic pH near neutrality. Am J Physiol 258, C1117-1126

Touret N, Tanneur V, Godart H, Seidler R, Taki N, Bürger E, Dämmgen J, Counillon L (2003): Characterization of sabiporide, a new specific NHE-1 inhibitor exhibiting slow dissociation kinetics and cardioprotective effects. Eur J Pharmacol 459(2-3), 151-8

Towbin H, Staehelin T, Gordon J (1979): Electrophoretic transfer of proteins from polyacrylamide gels to nitrocellulose sheets: procedure and some applications. Proc Natl Acad Sci USA 76(9), 4350-4

Tracey WR, Allen MC, Frazier DE, Fossa AA, Johnson CG, Marala RB, Knight DR, Guzman-Perez A (2003): Zoniporide: A Potent and Selective Inhibitor of the Human Sodium-Hydrogen Exchanger Isoform 1 (NHE-1). Cardiovasc Drug Rev 21(1), 17-32

Tse CM, Levine SA, Yun CH, Brant SR, Pouyssegur J, Montrose MH, Donowitz M (1993): Functional characteristics of a cloned epithelial $\mathrm{Na}^{+} / \mathrm{H}^{+}$exchanger (NHE3): resistance to amiloride and inhibition by protein kinase C. Proc Natl Acad Sci USA 90(19), 9110-4

Tytgat J (1994): How to isolate cardiac myocytes. Cardiovasc Res $\underline{28}, 280-283$

Vaughan-Jones RD, Peercy BE, Keener JP, Spitzer KW (2002): Intrinsic $\mathrm{H}^{+}$-ion mobility in the rabbit ventricular myocyte. J Physiol 541(Pt 1), 139-58

Vaughan-Jones RD, Spitzer KW, Swietach P (2006): Spatial aspects of intracellular pH regulation in heart muscle. Prog Biophys Mol Biol 90(1-3), 207-24

Vaughan-Jones RD, Spitzer KW, Swietach P (2009): Intracellular pH regulation in heart. J Mol Cell Cardiol 46, 318-331

Virkki LV, Wilson DA, Vaughan-Jones RD, Boron WF (2002): Functional characterization of human $\mathrm{NBC} 4$ as an electrogenic $\mathrm{Na}^{+}-\mathrm{HCO}_{3}{ }^{-}$cotransporter (NBCe2). Am J Physiol, Cell Physiol 282(6), C1278-1289

Vu TKH, Hung DT, Wheaton VI, Coughlin SR (1991): Molecular cloning of a functional thrombin receptor reveals a noval proteolytic mechanism of receptor activation. Cell $\underline{64}$, 1051-1068

Wakabayashi S, Ikeda T, Iwamoto T, Pouysségur J, Shigekawa M (1997): Calmodulinbinding autoinhibitory domain controls $\mathrm{pH}$-sensing in the $\mathrm{Na}^{+} / \mathrm{H}^{+}$exchanger NHE-1 through sequence specific interaction. Biochemistry $\underline{36}, 12854-12861$ 
Wakabayashi S, Pang T, Su Y, Shigekawa M (2000): A novel topology model of the human $\mathrm{Na}^{+} / \mathrm{H}^{+}$exchanger isoform 1. J Biol Chem 275, 7942-7949

Wang D, Balkovetz DF, Warnock DG (1995): Mutotional analysis of transmembrane histidines in the amiloride-sensitive $\mathrm{Na}^{+} / \mathrm{H}^{+}$exchanger. Am J Physiol 269, C392-C402

Wang H, Sakurai K, Endoh M (2000): Pharmacological analysis by HOE642 and KBR9032 of the role of $\mathrm{Na}^{+} / \mathrm{H}^{+}$exchange in the endothelin-1-induced $\mathrm{Ca}^{2+}$ signalling in rabbit ventricular myocytes. Br J Pharmacol 131(3), 638-644

Wang H, Silva NL, Lucchesi PA, Haworth R, Wang K, Michalak M, Pelech S, Flegel L (1997): Phosphrylation and regulation of the $\mathrm{Na}^{+} / \mathrm{H}^{+}$exchanger through mitogen-activated protein kinase. Biochemistry 29 , 9151-9158

Whitaker JE, Haugland RP, Prendergast FG (1991): Spectral and photophysical studies of benzo[c]xanthene dyes: Dual emission pH sensors. Anal Biochem 194, 330-334

Wu ML, Tseng YZ (1993): The modulatory effects of endothelin-1, carbachol and isoprenaline upon $\mathrm{Na}^{+} / \mathrm{H}^{+}$exchange in dog cardiac Purkinje fibres. J Physiol 471, 583-597

Xu H, Chen R, Ghishan FK (2005): Subcloning, localication, and expression of the rat intestinal sodium-hydrogen exchanger isoform8. Am J Physiol Gastrointest Liver Physiol $\underline{289(1)}, \mathrm{G} 36-41$

Yamaji Y, Hayashi M, Iyori M, Katajima W, Saruta T (1992): Chronic DOC treatment enhances $\mathrm{Na}^{+} / \mathrm{H}^{+}$exchanger activity of beta-intercalated cells in rabbit CCD. Am J Physiol $\underline{265}$, F712-717

Yamamoto T, Shirayama T, Sakatani T, Takahashi T, Tanaka H, Takamatsu T, Spitzer KW, Matsubara $\mathbf{H}$ (2007): Enhanced activity of ventricular $\mathrm{Na}^{+}-\mathrm{HCO}_{3}{ }^{-}$cotransport in pressure overload hypertrophy. Am J Physiol, Heart Circ Physiol 293(2), H1254-1264

Yamamoto T, Swietach P, Rossini A, Loh SH, Vaughan-Jones RD, Spitzer KW (2005): Functional diversity of electrogenic $\mathrm{Na}^{+}-\mathrm{HCO}_{3}{ }^{-}$cotransport in vertricular myocytes from rat, rabbit and guines-pig. J Physiol 562, 455-475

Yang W, Dyck J, Wang H, Fliegel L (1996): Regulation of NHE-1 Promoter in mammilian myocardium. Am J Physiol 270, H259-266

Yasutake M, Ibuki C, Hearse DJ, Avkiran M (1994): $\mathrm{Na}^{+} / \mathrm{H}^{+}$exchange and reperfusion arrhythmias: protection by intracoronary infusion of a novel inhibitor. Am J Physiol 267, H 2430-H 2440

Yasutake M, Haworth RS, King A, Avkiran M (1996): Thrombin activates the sarcolemmal $\mathrm{Na}^{+} / \mathrm{H}^{+}$exchanger. Evidence for a receptor-mediated mechanism involving protein kinase C. Circ Res 79(4), 705-15

Yeager M (1998): Structure of cardiac gap junction intercellular channels. J Struct Biol 121(2), 231-45 
Yokoyama H, Avkiran M (1997): Protein kinase C-mediated stimulation of the sarcolemmal $\mathrm{Na}^{+} / \mathrm{H}^{+}$exchanger contributes to the arrhythnogenic action of thrombin. Circulation 96 , I58

Yokoyame H, Yasutake M, Avikran M (1998): $\alpha$-Adrenergic stimula-tion of sarcolemmal $\mathrm{Na}^{+} / \mathrm{H}^{+}$exchanger activity in rat ventric-ular myocytes: evidence for selective mediation by the $\alpha 1$-adrenoceptor subtype. Circ Res $\underline{82}$, 1078-1085

Yokoyama H, Gunasegaram S, Harding SE, Avikran M (2000): Sarcolemmal $\mathrm{Na}^{+} / \mathrm{H}^{+}$ Exchanger Activity and Expression in Human Ventricular Myocardium. J Am Coll Cardiol $\underline{36(2)}, 534-540$

Yoshida H, Karmazyn M (2000): $\mathrm{Na}^{+} / \mathrm{H}^{+}$exchange inhibition attenuates hypertrophy and heart failure in 1-wk postinfarction rat myocardium. Am J Physiol, Heart Circ Physiol 278(1), H300-4

Yu FH, Shull GE, Orlowski J (1993): Functional properties of the rat $\mathrm{Na}^{+} / \mathrm{H}^{+}$exchanger NHE-2 isoform expressed in $\mathrm{Na}^{+} / \mathrm{H}^{+}$exchanger -deficient Chinese hamster overy cells. J Biol Chem 268, 25536-25541

Yun CHC, Tse CM, Nath S, Levine SL, Donowitz M (1995): Structrue/ function studies of mammalian $\mathrm{Na}^{+} / \mathrm{H}^{+}$exchangers: an update. J Physiol Lond $\underline{482}, 1-6$

Yusufi AN, Szczepanska-Konkel M, Dousa TP (1988): Role of N-linked oligosaccharides in the transport activity of the $\mathrm{Na}^{+} / \mathrm{H}^{+}$antiporter in rat renal brush-border membrane. $\mathrm{J}$ Biol Chem 263(27), 13683-91

Zaniboni M, Rossini A, Swietach P, Banger N, Spitzer KW, Vaughan-Jones RD (2003a): Proton permeation through the myocardial gap junction. Circ Res 93(8), 726-35

Zaniboni M, Swietach P, Rossini A, Yamamoto T, Spitzer KW, Vaughan-Jones RD (2003b): Intracellular proton mobility and buffering power in cardiac ventricularmyocytes from rat, rabbit, and guinea pig. Am J Physiol, Heart Circ Physiol 285(3), H1236-1246

Zhao XS, Gallardo ID, Lin L, Schageman JJ, Shohet R (2002): Transcriptional mapping and genomic analysis of the cardiac atria and ventricles. Physiol Genomics $\underline{12}, 53-60$ 


\section{Erklärungen}

Hiermit erkläre ich, Hui Yan, an Eides Statt, die vorliegende Dissertation mit dem Titel

Die $\mathrm{Na}^{+} / \mathrm{H}^{+}$-Austauscher-abhängige $\mathrm{pH}$-Regulation in Vorhof- und Ventrikelmyozyten selbstständig und ohne unerlaubte Hilfe angefertigt zu haben.

Frechen, den

Hui Yan

Hiermit erkläre ich, Hui Yan, dass ich mich an keiner anderen Universität um den Doktorgrad beworben habe.

Frechen, den

Hui Yan 


\section{Danksagung}

An erster Stelle danke ich Herrn Professor Dr. J. Kockskämper, Institut für Pharmakologie und Klinische Pharmazie der Universität Marburg, ganz herzlich für seine außerordentliche und intensive gute Betreuung. Für die Anregung zum Forschungsthema möchte ich mich bei Herrn Professor Dr. B. Pieske, Leiter der kardiologischen Abteilung der Universität Graz, Österreich, bedanken. 


\section{Lebenslauf}

Ich wurde am 18. 10. 1973 in einer Lehrerfamilie in Yunnan, China, geboren. Im September 1979 wurde ich mit 6 Jahren eingeschult. Es folgten fünf Jahre Grundschule, drei Jahre Mittelschule und drei Jahre Gymnasium in der Stadt Shuicheng, Provinz Guizhou, China. Im August 1990 wurde ich vom Nanjing Railway Medical College (heute die Medizinische Fakultät der Southeast University) im Fach Humanmedizin aufgenommen. Nach dem Studienabschluss im Juli 1995 arbeitete ich als Assistenzärztin in einem Lehrkrankenhaus der Universität Nanjing in der Stadt Nanjing, Jiangsu, in China. Sechs Jahre später, nach der erfolgreichen Facharztprüfung im Bereich Infektionserkrankungen, kam ich nach Deutschland. Nach anderthalbjährigem Deutsch-Sprachkurs nahm ich im April 2003 das Studium der Humanmedizin an der Georg-August-Universität in Göttingen auf. Im Juni 2008 schloss ich mein Studium mit dem zweiten Abschnitt der ärztlichen Prüfung ab. Seit Januar 2009 bin ich in der Abteilung für Neurologie im St.-Katharinen-Hospital in Frechen bei Köln als Assistenzärztin tätig. 